\title{
Thermal degradation and fire behavior of high performance polymers
}

\author{
A. Ramgobin, G. Fontaine et S. Bourbigot* \\ Univ. Lille, ENSCL, UMR 8207, UMET, Unité Matériaux et Transformation, \\ F59652 Lille, France
}

\section{Introduction}

Over the past few decades there has been significant effort put into the elaboration and design of stronger, more resistant and capable polymers. Numerous new families of polymers with novel properties have been reported with potential applications in challenging areas such as aerospace, defense, energy, electronics, or automotive. Such polymers exhibit enhanced servicetemperatures and outstanding resistance to environmental stress[1]. With the coming into market of polymers that have such significantly enhanced properties as compared to common ones, the terms "high performance" or "advanced engineering" have been employed to describe them[2].

High performance polymers have existed for more than half a century. Considerable effort was attributed to high performance polymers in the 1960s where most thermally stable heterocyclic rings were incorporated within polymers. At the time, the goal was to achieve as high a thermal stability as possible. DuPont's well-known Kapton', a polyimide film, emerged during this decade. Other high performance polymers as $\mathrm{Vespel}^{\oplus}$ and polysulfones also appeared in the market during this period.

However, the proper definition for a high performance polymer is yet to be established. Indeed, numerous attempts at defining high performance polymers have been made. This high number is mostly because the term "high performance" is a constantly evolving one. Indeed, high performance polymers may be defined in many ways, depending on the end-use and the organization developing or using the material. A general definition for high performance polymers would be polymers that meet even higher requirements than standard engineering plastics[3]. This leads to "high performance" polymers being a broad term that can be used to describe many polymeric materials. However, in the context of this investigation, the definition of "high performance" polymer will be closely related to what was reported by Hergenrother et al. - a high performance polymer is one, which retains usable properties at temperatures $>177$ ${ }^{\circ} \mathrm{C}[4]$.

In the 1970s, routes to developing polyetheretherketones, (PEEK, ICI), polyetherketones (PEK, ICI) and Polyetherimide (Ultem ${ }^{\mathrm{TM}}$, General Electric, GE) were found. These products were launched in the 1980s. High performance polymeric fibers were also made during this period. A high modulus, rigid rod polymer, Polybenzoxazole (PBO), first made by the Air Force Wright Patterson Laboratories, and subsequently developed by Dow Chemical and commercialized in the 1990 os by Toyobo joins the family of high performance fibers. Another high performance rigid rod polymer that shows excellent thermal and mechanical properties is polypyridobisimidazole (PIPD) first developed by Sikkema in 1997 [5]. 
Polymers may be classified into two major classes: thermoplastic and thermosetting. These two categories may be subdivided further depending on their crystallinity. Indeed, amorphous polymers are those which have a near-zero degree of crystallinity (such as polyetherimide). This implies that they have high levels of irregularities in their structure. This may come from different reasons ranging from high levels of branching or the presence of bulky side groups in the polymer. On the other hand, polymers that possess highly ordered structures dispersed in an amorphous phase are called semi-crystalline (for example, polyether ether ketone). Another type of polymer that will be discussed in this work are rigid rod polymers. These types of polymers exhibit outstanding thermal and mechanical properties and considerable interest has been paid to them. Some examples of rigid rod polymers are polybenzoxazole, or polybenzimidazole.

The thermal stability of a polymer may be studied by different methods. One of the most extensively used method is thermogravimetric analysis (TGA). This method provides data on the evolution of the mass of a material with respect to the temperature in different atmospheres. Isothermal or varying temperatures may be used for such analyses. Indeed, by studying the evolution of the weight of a material with respect to a heating rate, the degradation temperature and the behavior at specific temperatures may be deduced. However, this method does not give any information about the thermal decomposition products that are released. For this reason, TGA is often coupled with other analytical techniques such as mass spectrometry (MS) or Fourier-transform infrared spectrometry (FTIR).

However, with MS and FTIR coupled with TGA, it is not possible to separate decomposition products. Very often, spectra with all the different degradation products are obtained. Therefore, another instrument that is often chosen to identify degradation products is the pyrolysis-gaschromatography/mass spectrometry (Py-GC/MS). Py-GC/MS at different pyrolysis temperatures can be used to separate and identify the different decomposition products at those temperatures.

The kinetic parameters of the thermal decomposition of a polymer is also an important factor in elucidating the degradation mechanism of a polymeric material. There are various methods for such thermal analysis and two of them are the most popular. The first method is based on the isoconversion procedure developed by Ozawa Flynn and Wall (OFW)[6] [7]. The second method was developed by Friedman[8]. It uses the derivatives of mass loss and it can be applied for $n$ order reactions. This may be done using various methods based of TGA results of a given material.

The evaluation of fire performances of high performance polymers was also reviewed. The most common tests for the evaluation of the fire performance of a material are the limiting oxygen index test and the Underwriters Laboratories 94 (UL-94) test. Other tests such as the pyrolysis combustion flow calorimetry (PCFC) or microscale combustion calorimetry (MCC) and cone calorimeter are also used to measure the heat release rates during the combustion or degradation of a material. This provides insight on the susceptibility of a material to feed or extinguish a fire.

PCFC (or MCC) provides heat release rates on small samples (usually milligrams) by measuring oxygen consumption. It is a non flaming, 1 dimensional test that does not take into account surface properties of the material. It provides insight on the heat of combustion and specific heat release rate (in $\mathrm{W} / \mathrm{g}$ ).

Cone calorimeter compares to PCFC in the sense that the heat release rate may also be measured by oxygen consumption. However, in the case of cone calorimetry, the heat release rate are actually heat flux (in $\mathrm{kW} / \mathrm{m}^{2}$ ). Indeed, for cone calorimetry, test samples are larger (about $10 \mathrm{x}$ 
$10 \mathrm{x} 0.3) \mathrm{mm}^{3}$. The test comprises of irradiating a sample with an incident heat flux. The material reacts and may (or may not) flame up. The oxygen consumption due to the burning sample is measured and this leads to the heat release rate of the burning sample.

When it comes to reviewing the thermal properties of high performance and high temperature polymers, a number of works already exist. Indeed, in 1979, Arnold et al regrouped a large number of high performance polymers that were available at the time in order to study their thermal behavior. Since then, quite a number of reviews that have been written regarding the thermal properties of high performance polymers[4,9-11]. However, few works encompass the thermal stability and the fire behavior of high performance polymers. Indeed, Mittal et al have made an overview of some high performance polymers in 2011[12]. However, thermal decomposition data are scarce in the review. Polymer specific reviews have also been made, regrouping the thermal properties of a specific type of high performance polymer[12,13]. Among the few papers that have both an in-depth review on the thermal stability and the fire performances of polymeric materials, Bourbigot et al have regrouped high performance fibers. Their work also consisted in furthering the fire behavior with fire tests for materials that were not yet tested in flame tests[14].

In this work, a different approach will be adopted. A series of halogen-free polymeric materials exhibiting high performance and thermal stability will be reviewed (Table 1). The focus of this work lies on the study of their thermal stabilities and their behavior at elevated temperatures. Possible decomposition mechanisms will be elucidated where possible and a relationship with the thermal stability of the polymers will be attempted. A relationship between the fire behavior and the thermal decomposition will also be attempted. This work is limited to polymers that are widely available on the market these days. New high performance polymers are still being researched but so far, there has been little or no success in developing new classes of them. 


\begin{tabular}{|c|c|c|c|}
\hline $\begin{array}{l}\text { Chemical name or } \\
\text { designation }\end{array}$ & $\begin{array}{l}\text { Generic } \\
\text { name }\end{array}$ & Chemical structure & $\begin{array}{l}\text { Trade } \\
\text { name }\end{array}$ \\
\hline Polyetherimide & PEI & & Ultem $^{\circledast}$ \\
\hline $\begin{array}{l}\text { Polyether ether } \\
\text { ketone }\end{array}$ & PEEK & & PEEK $^{\circledast}$ \\
\hline $\begin{array}{l}\text { Poly(phenylene } \\
\text { sulfone) }\end{array}$ & PPSU & & Radel $^{\circledast} \mathrm{R}$ \\
\hline Polyimide & PI & & Kapton $^{\circledast}$ \\
\hline Polyamide-imide & PAI & & Torlon $^{\circledR}$ \\
\hline $\begin{array}{l}\text { Poly-p-phenylene-2- } \\
\text { 6-benzobis-oxazole }\end{array}$ & $\mathrm{PBO}$ & & Zylon $^{\circledast}$ \\
\hline $\begin{array}{l}\text { Poly(2,2'-(m- } \\
\text { phenylene)-5,5'- } \\
\text { bisbenzimi-dazole) }\end{array}$ & PBI & & PBI \\
\hline $\begin{array}{l}\text { Poly(2,6- } \\
\text { diimidazo(4,5-b:4,5'- } \\
\text { e)pyridi-nylene-1,4 } \\
\text { (2,5-dihydroxy)- } \\
\text { phenylene) }\end{array}$ & PIPD & & $\mathrm{M}_{5}{ }^{\circledast}$ \\
\hline $\begin{array}{l}\text { Poly(p-phenylene } \\
\text { terephtal-amide) }\end{array}$ & PPTA & & Kevlar $^{\circledast}$ \\
\hline
\end{tabular}




\section{Polyetherimides}

Polyetherimides (PEI, Figure 1) are amorphous, high performance thermoplastics; its color is from amber to transparent. They have outstanding mechanical, thermal and chemical properties. Because of these properties, they are often chosen for highly demanding applications whereby high temperature and harsh environments are encountered. Some applications include lighting reflectors[15], electrical industry[16], automotive[16], and wire coating[16].

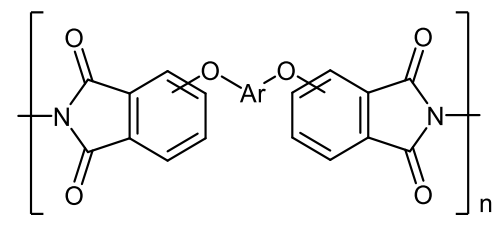

Figure 1. General structure of polyetherimide

Polyetherimides are polyimides, which consist of ether linkages in the aromatic polymer backbone. The presence of these ether linkages provides flexibility to the polymer, allowing for a good melt processability while the aromatic-rich backbone keeps the thermal and mechanical properties of the polymer excellent.

The most widespread polyetherimide is commercialized under the trademark ULTEM resin (Figure 2). It was made available commercially in 1982 by the General Electric's Plastics Business group. Presently, it is commercialized by Sabic.<smiles>Cc1cccc(N2C(=O)c3ccc(Oc4ccc(C(C)(C)c5ccc(Oc6ccc7c(c6)C(=O)N(C)C7=O)cc5)cc4)cc3C2=O)c1</smiles>

Figure 2. Structure of Ultem (General Electric)

\section{Synthesis}

There are two main synthetic routes of PEI (Ultem). Both comprise of the melt polymerization of bisphenol A dianhydride with a diamine, most often, m-phenylenediamine as shown in Scheme 1. The dianhydride is synthesized by the reaction of two moles of a phtalic anhydride derivative with one mole of bisphenol $\mathrm{A}$. The condensation of the dianhydride and the diamine forms a polyamic acid. A heat or catalytic treatment of this acid leads to the polyetherimde, Ultem. Another pathway comprises of making the imide in the first step, followed by a nucleophilic substitution process to yield the polymer. The first route is the most widely used pathway in industry, since it gives better yields due to the stability of tetracarboxylic dianhydrides. 

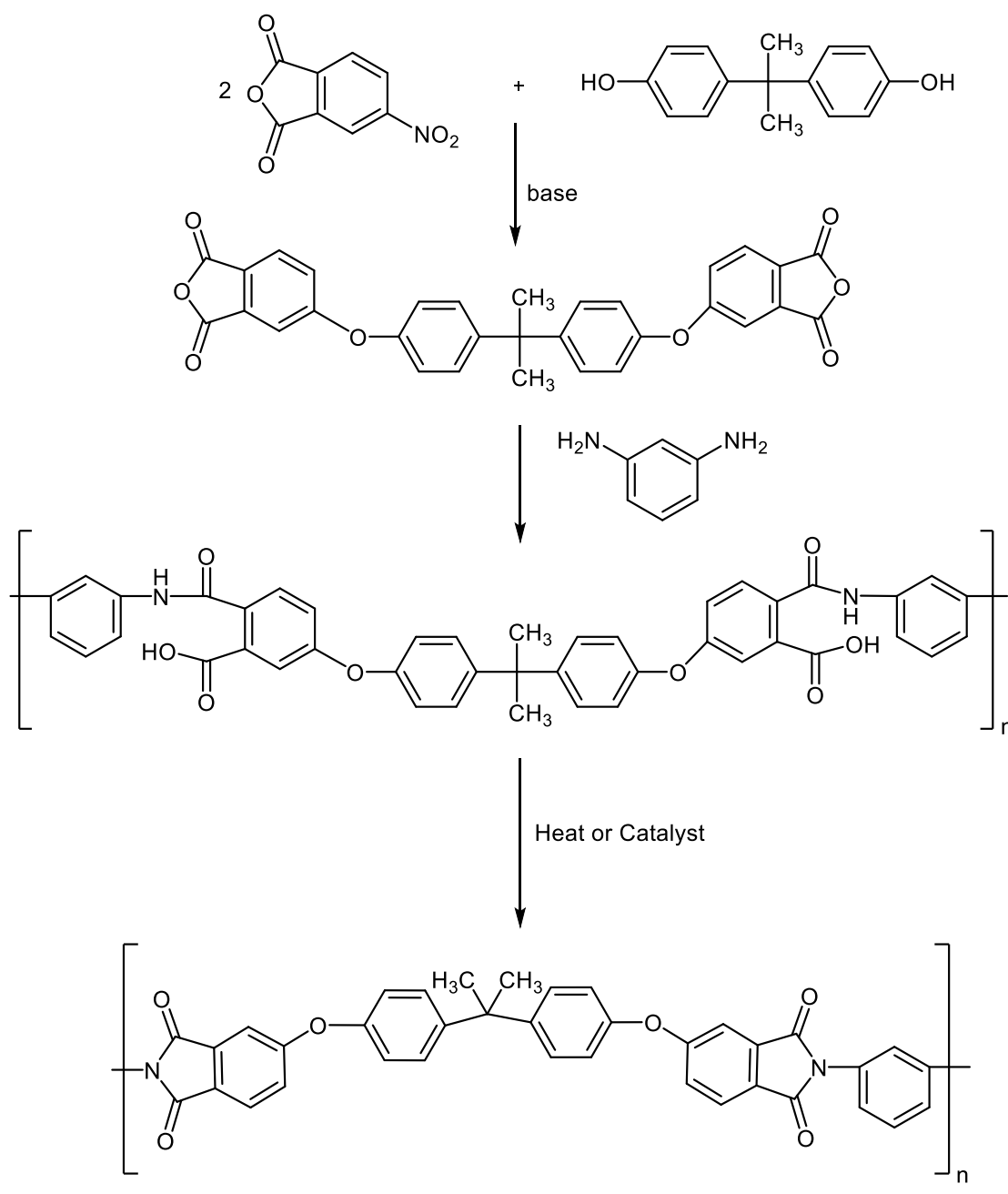

Scheme 1. Synthetic route for the production of Ultem

\section{Thermal Properties}

Polyetherimides have a glass transition temperature of $217^{\circ} \mathrm{C}[15]$. They can be subjected to conventional melt-processing techniques at temperatures of $350-425{ }^{\circ} \mathrm{C}[16]$. It is thermally stable up to $500{ }^{\circ} \mathrm{C}$. Commercial grades of PEI include additives (such as glass fiber reinforced $\mathrm{PEI}$ ) because they tend to increase further the temperature resistance of the material.

Thermogravimetric analyses at different heating rates have been performed on polyetherimides in order to study their thermal stability $[17,18]$. Foreman et al. studied the service lives of PEI under different criteria. The 6o-minute half-life temperature (temperature at which half the material degrades within 60 minutes under pyrolytic conditions) of PEI was found to be $477^{\circ} \mathrm{C}$ in nitrogen. The service life curves correspond to the time required for $5 \%$ of the material to degrade at a specific temperature in nitrogen. In the case of PEI, the TGA service life temperature for 1 year was found to be $318{ }^{\circ} \mathrm{C}$ and that for 10 years was $292{ }^{\circ} \mathrm{C}$. This corresponds to the temperature at which a $5 \mathrm{w} \%$ mass loss is observed for this period. This temperature was higher than for regular engineering polymers (for example, polyphenylene sulfide has a TGA service lifetime for 1-year lifetime at $230^{\circ} \mathrm{C}$ ).

Thermogravimetric analyses (TGA) of PEI at different heating rates, in air and in inert atmospheres were also reported [19-23]

Figure 3 shows the TGA plot of Ultem with a heating rate of $10{ }^{\circ} \mathrm{C} / \mathrm{min}$. It was reported that the onset of the degradation occurs at around $450^{\circ} \mathrm{C}$ under nitrogen[23,24]. The maximum rate of decomposition temperature is about $510^{\circ} \mathrm{C}$ (DTG curve). The DTG curve shows a second, less 
significant decomposition stage that occurs in the range $600-650{ }^{\circ} \mathrm{C}$ under nitrogen. The weight loss at $800{ }^{\circ} \mathrm{C}$ under nitrogen is around $40 \%$.
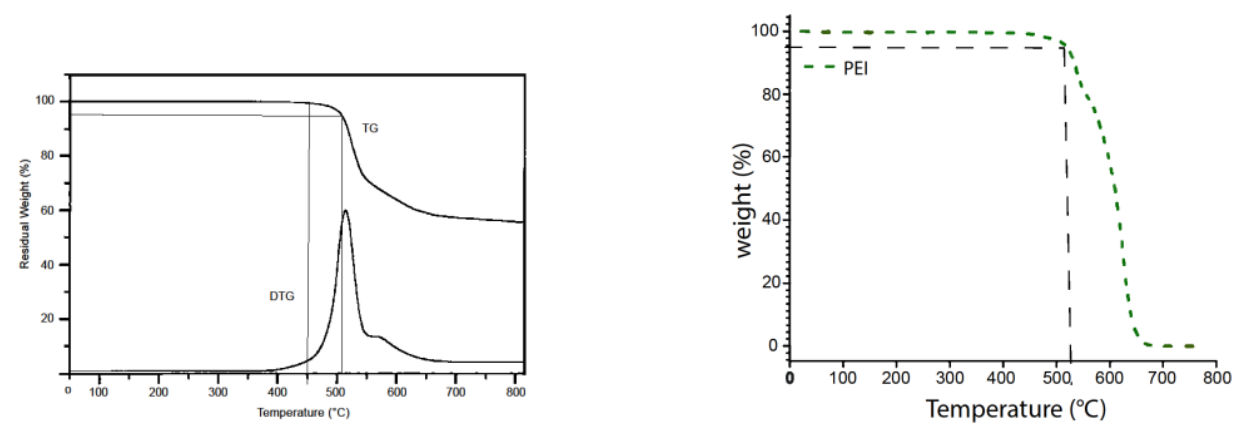

Figure 3. Thermogravimetric analysis of and DTG curve of PEI under nitrogen (left) [25] and TGA plot under air[21] (right) at a heating rate of $10^{\circ} \mathrm{C} / \mathrm{min}[26]$

In this case, the degradation temperature is given as the temperature at which the polymer starts to degrade (weight $<100 \mathrm{wt} \%$ ). However, a more generally accepted definition for this criterion is the temperature at which $5 \mathrm{wt} \%$ of a material is degraded $\left(\mathrm{T}_{\text {onset }}\right)$. With this definition, the degradation temperature (in nitrogen) of PEI is in fact closer to $500{ }^{\circ} \mathrm{C}$ than $450^{\circ} \mathrm{C}$.

When it comes to TGA, it is suggested that the degradation temperature of a material can be different depending on the atmosphere. The TGA plot of PEI in air with a heating rate of 10 ${ }^{\circ} \mathrm{C} / \mathrm{min}$ was reported by Halawani et al. in 2017 (Figure 3) [21]. It can be observed from the TG plots under the air and nitrogen that the nature of the atmosphere does not have a significant impact on the onset of the thermal degradation of PEI. However, when subjected to high heat in an oxidative environment, PEI degrades in two fast steps. Contrarily to its behavior in nitrogen, the second decomposition step observed in the TGA plot of PEI in air leads to the nearcomplete decomposition of the polymer. The residual mass in air at $800^{\circ} \mathrm{C}$ is o wt $\%$ as compared to $50 \mathrm{wt} \%$ in nitrogen.

The TG plot shows two apparent weight loss stages, which are clearly observed on the DTG curve (Figure 3), of the TGA of PEI in nitrogen. The two temperatures at which the weight loss rates are maximum are $540{ }^{\circ} \mathrm{C}$ (first stage) and $585{ }^{\circ} \mathrm{C}$ (stage two). It can also be observed, from the TGA plot that the residual weight above $700^{\circ} \mathrm{C}$ does not show significant decrease. This suggests that carbonization plays a vital role in the solid-phase mechanism.

In addition to making the determination of the different decomposition temperatures possible, TGA also provides a way to determine the kinetic parameters for the thermal decomposition of a material. The kinetic parameters of the thermal degradation of PEI has been thoroughly studied in the past[20,24,27]. One of the first works concerning the kinetics of the thermal decomposition of PEI consisted in using thermogravimetry at different heating rates under nitrogen [20]. However, the kinetics studied were limited to the first stage of the degradation when it is in fact a two-stage decomposition. The bivariate fitting method was used and a comparison to other model-free kinetics (MFK) fitting methods was reported. A summary of these results are shown in Table 2. These methods assume an Arrhenius dependence of the reaction rate on the temperature and have been applied in a wide range of kinetic studies. 
Table 2. The kinetic parameters of the thermal decomposition of PEI using different methods.

\begin{tabular}{llll}
\hline Method & $\begin{array}{l}\text { Apparent activation } \\
\text { energy }(\mathrm{kJ} / \mathrm{mol})\end{array}$ & Apparent order & $\begin{array}{l}\text { Pre-exponential } \\
\text { factor }\left(\mathrm{min}^{-1}\right)\end{array}$ \\
\hline Bivariate fitting[20] & 192 & 5.33 & $1.45 \times 10^{12}$ \\
Ozawa's [26] & 184 & & \\
Friedman's [24] & 192 & 6.09 & $1.45 \times 10^{12}$ \\
Kissinger's [24] & 178 & & \\
\hline
\end{tabular}

In a more recent study, the kinetic parameters of the two stages of the thermal decomposition of PEI was performed using the ThermaKin[21] model. It was possible to separate the two decomposition stages of PEI. The results are summarized in the table below.

Table 3. Kinetic parameters of the thermal decomposition of PEI using generalized functions [28].

\begin{tabular}{ll}
\hline Property & Value \\
\hline First Apparent activation energy $(\mathrm{kJ} / \mathrm{mol})$ & 465 \\
First Pre-exponential factor $\left(\mathrm{min}^{-1}\right)$ & $1.06 \times 10^{27}$ \\
Second apparent activation energy & 36 \\
Second pre-exponential factor $\left(\mathrm{s}^{-1}\right)$ & $6.5 \times 10^{2}$ \\
\hline
\end{tabular}

In this study, the two steps of the decomposition are taken into account and the kinetic parameters of each degradation steps are calculated. The first activation energy, which corresponds to the first decomposition step was determined to be $465 \mathrm{~kJ} / \mathrm{mol}$ and had a corresponding pre-exponential factor of $1.06 \times 10^{27} \mathrm{~min}^{-1}$. As for the second step, the activation energy was determined to be $36 \mathrm{~kJ} / \mathrm{mol}$ with a corresponding pre-exponential factor of $6.5 \times 10^{2}$ $\mathrm{s}^{-1}$. These results are not consistent with the initial kinetic parameters determined in the previous paper. This might be because the two-step decomposition of PEI not taken into account in earlier papers. Therefore, this work seems to provide a more accurate simulation of the kinetic parameters of the thermal degradation of PEI.

Even if TG plots gives valuable information regarding the temperature and the energy required for thermal degradation to within the material, they do not cater for the identification.

Moreover, the decomposition products of a material may play a crucial role in the context of fire behavior. Therefore, it is of interest to investigate the mechanism adopted when a polymeric material thermally decomposes. Works at elucidating the thermal decomposition mechanism of PEI has been carried out using various methods such as pyrolysis/gas chromatography/mass spectrometry (Py-GC/MS)[26], stepwise Py-GC/MS[29], thermogravimetry/mass spectrometry/Fourier Transform Infrared spectrometer (TG/MS/FTIR) [23], direct pyrolysis/mass spectrometry (DPMS) [30] as well as thermogravimetry/mass spectrometry (TG/MS)[23].

These methods allows for the identification of decomposition products that are released when a material is subjected to thermal stress. Py-GC/MS allows the identification of decomposition products when a material is subjected to a specific temperature for a given duration. Evolved decomposition products are separated using gas chromatography and identified using massspectrometry. However, using this method, the different phases of decomposition cannot be discerned from each other. This is why some researchers have adopted stepwise Py-GC/MS, whereby the material is subjected to different pyrolysis temperatures. These temperatures may be determined prior to the analyses by using TGA. TG/MS/FTIR provides real time data on the 
remaining weight of a material simultaneously with the mass spectra of all the decomposition products along with the FTIR of the gases that are evolved. This method combines three analytical techniques, each providing information of different nature on the degradation products. Indeed, by coupling FTIR and MS, the nature of the bonds involved in the decomposition gases are identified by FTIR. This makes the identification of the possible decomposition using MS easier. Finally, direct pyrolysis mass spectrometry (also known as evolved gas analysis - mass spectrometry) provides the possibility of identifying different pyrolysis products at specific temperatures.

Py-GC/MS has the advantage of collecting all the decomposition products in a trap before separating the degradation products with respect to their boiling points and polarity. This provides the possibility of identifying individual species. However, by allowing the degradation products to stagnate all in the same place before separating them, there is the risk that individual decomposition products recombine in the trap.

However, unlike Py-GC/MS, the other methods mentioned do not separate the different degradation products. This makes the identification of specific products using mass spectrometry more challenging as the mass spectrum data of all the degradation products at a specific temperature are observed on the same spectrum.

Table 4 shows the volatile decomposition products of PEI, determined by flash pyrolysis at different temperatures up to $850^{\circ} \mathrm{C}[29]$. Most of the high temperature decomposition products are identified and can be used to devise a tentative decomposition mechanism for PEI.

The main products of PEI decomposition have been identified as $\mathrm{CO}, \mathrm{CO}_{2}$, phenol, benzonitrile and aniline [30]. It was first suggested that PEI decomposes following two main mechanisms: ether bond breaking mechanism and carboxyl induced chain breaking mechanism[2o]. Further works allowed to conclude that the decomposition was a two stage mechanism. The first-stage reaction is assigned to the main-chain random scission of hydrolysed imide groups induced by water existing in the sample as the primary mechanism. The second stage of the pyrolysis involves the scission of ether and isopropylene groups with the evolution of water that was consumed during hydrolysis of other imide groups [29]. 


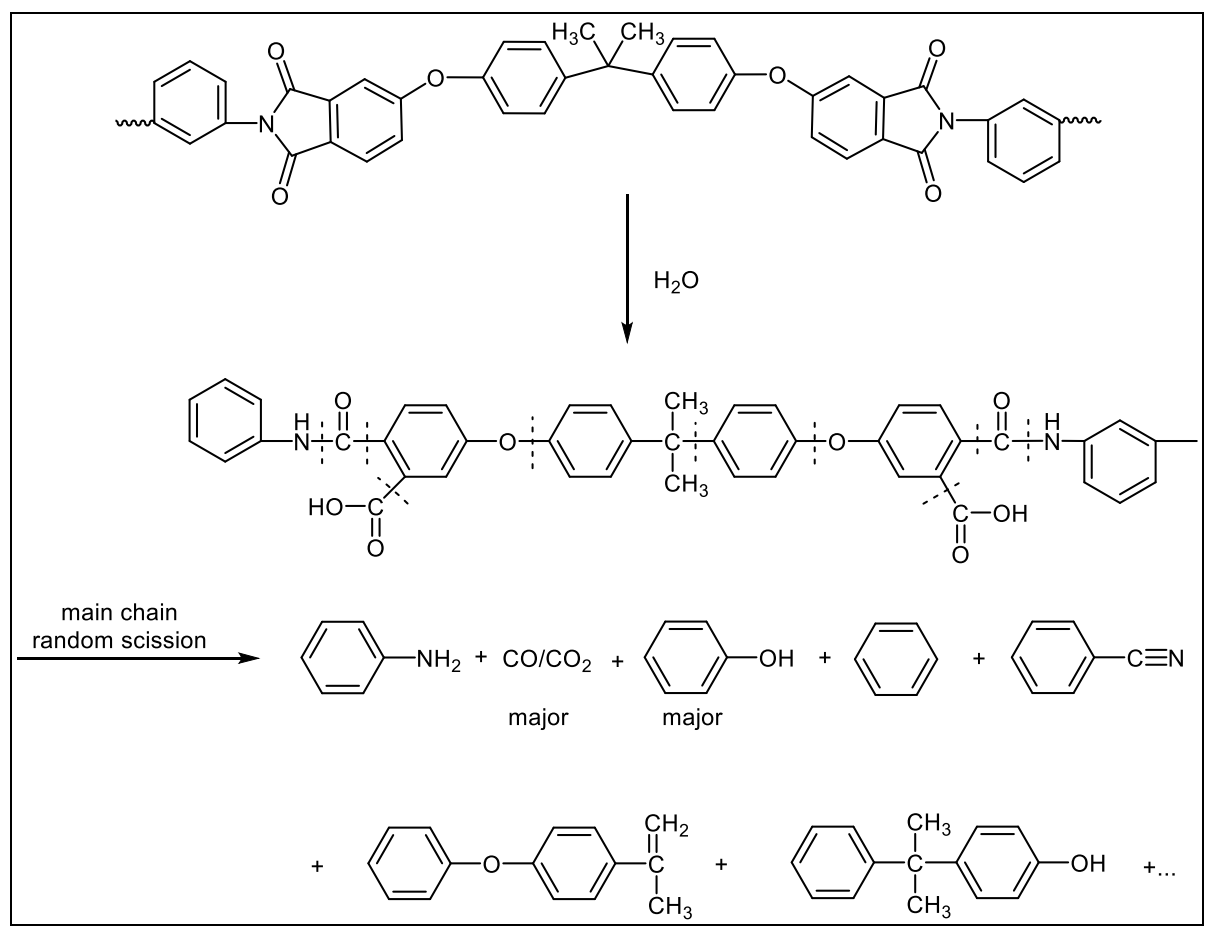

Scheme 2. Postulated hydrolysis of imide groups followed by random chain scission[29]

Table 4. Identification of the products in Flash Py-GC/MS of PEI up to $850^{\circ} \mathrm{C}$ in helium [26]

\begin{tabular}{|c|c|c|c|}
\hline Compound & Name & Compound & Name \\
\hline $\mathrm{CO}$ & & & 4-Ethylphenol \\
\hline & Benzene & & p-Vinylphenol \\
\hline & Methyl-benzene & & Naphthalene \\
\hline & Ethylbenzene & & 4-(p-Isopropenyl)phenol \\
\hline & p-Xylene & & 2-Vinylnaphthalene \\
\hline & Styrene & & Diphenylether \\
\hline & Isocyanatobenzene & & Diphenylmethane \\
\hline & Aniline & & $\begin{array}{l}\text { 1-Methyl-4- } \\
\text { phenoxybenzene }\end{array}$ \\
\hline & Phenol + benzonitrile & & Dibenzofuran \\
\hline & 2-Methylphenol & & Fluorene \\
\hline & 4-Methylphenol & & $\begin{array}{l}\text { 4-(1-Methyl-1- } \\
\text { phenylethyl)phenol }\end{array}$ \\
\hline
\end{tabular}


In another study, the analysis of the thermal decomposition of PEI was performed by direct pyrolysis mass spectrometry (DPMS)[30].

By using DPMS, the mass spectra acquired allowed the identification of low temperature degradation products that are evolved during the decomposition of PEI. At $400{ }^{\circ} \mathrm{C}$, the mass spectrum was assigned to an open chain compound containing part of the repeat unit of PEI (Figure 4).

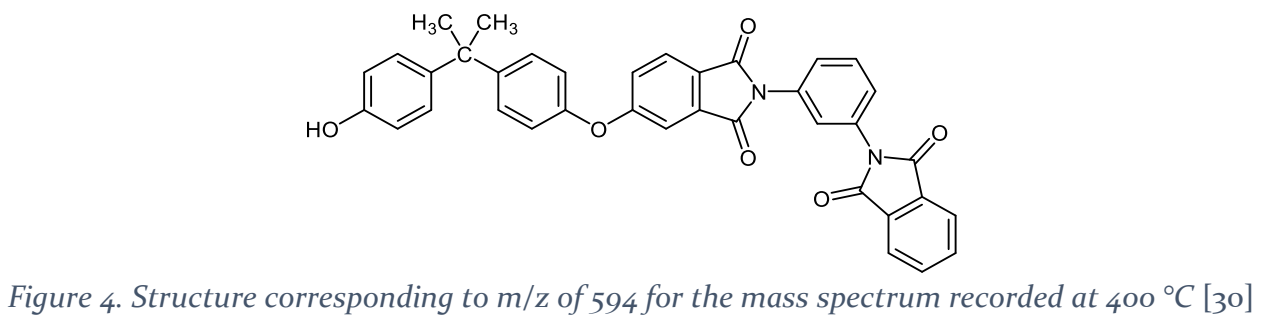

However, $400{ }^{\circ} \mathrm{C}$ corresponds to merely the onset of the degradation of PEI. Therefore, in order to get better insight on the degradation products, it is important to look at the products evolved at higher temperatures. The mass spectra of the pyrolysis products evolved at $520^{\circ} \mathrm{C}$ and $620^{\circ} \mathrm{C}$ have been reported[30].

The mass spectrum at $520{ }^{\circ} \mathrm{C}$ evidenced that the main products evolved are phenol, isopropylidenephenols, isopropylidenediphenyl ether. phtalimide ring substituted with other groups such as aromatic ethers and $\mathrm{OH}$. These phtalimide rings may have been generated by the disproportionation of the isopropylidene bridge of the bisphenol A units of PEI, followed by hydrogen transfer reactions (Scheme 3).

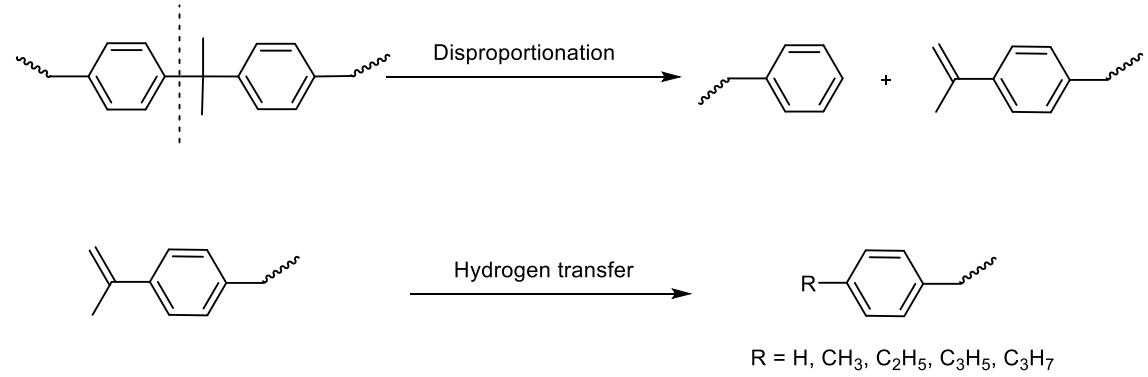

Scheme 3. Postulated disproportionation and C-H transfer mechanism occurring at lower temperature [30]

The formation of phtalimide based structures containing phenyl rings substituted with hydroxyl group or bisphenol A or both can be explained by the scission of ether bridges (Scheme 4a and $4 \mathrm{~b})$. The presence of nitrogen containing end groups may be explained by the scission of phenylphtalmide bonds (Scheme 4c). Extensive associated hydrogen transfer reactions may explain the high char residue in the pyrolysis of PEI. 


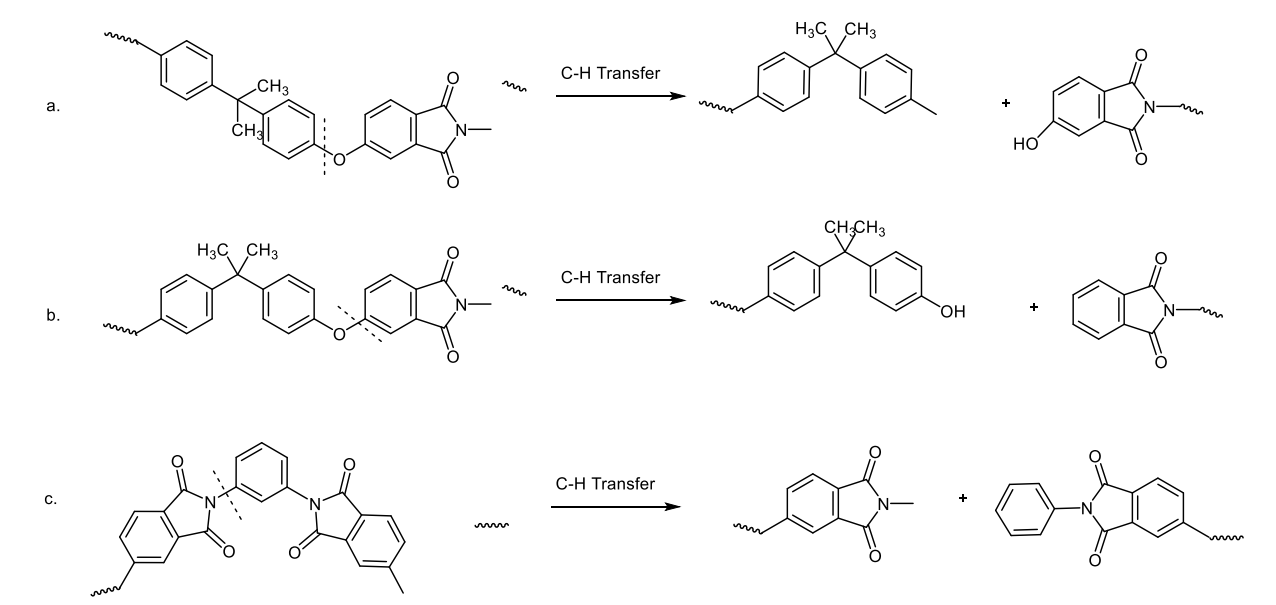

Scheme 4. Postulated hydrogen transfer mechanism leading to different phtalimide derivatives[30]

At $620^{\circ} \mathrm{C}$, the mass spectrum recorded shows the presence of lower molecular weight molecules. The peaks are assigned to $\mathrm{CO}_{2}$, benzene, toluene, aniline, benzonitrile, and amine-substituted benzene derivatives. Some phtalamide derivatives are also observed, albeit with lower intensity. This may be due high temperature pyrolysis of $\mathrm{N}-\mathrm{H}$ phtalimide end-groups, involving the formation of thermally unstable isocyanate intermediate that decomposes to form nitriles and carbon dioxide[30] (Scheme 5).

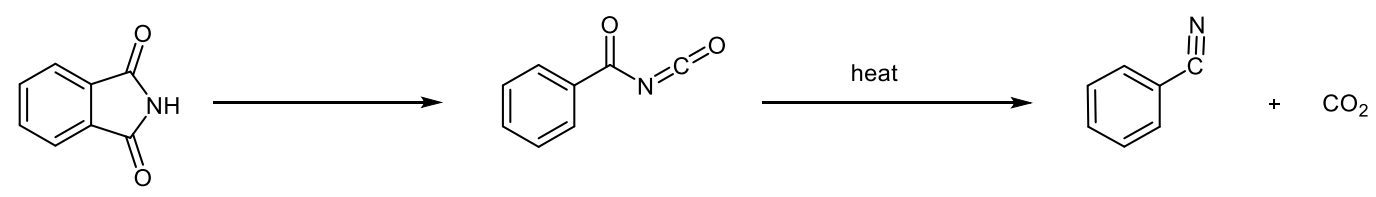

Scheme 5. Hydrogen transfer and decomposition in NH phtalimide end-groups [30]

The high char residue coming from the pyrolysis of PEI may be explained by the formation of polyamic acid that undergo decarboxylation at $\mathrm{T}>600{ }^{\circ} \mathrm{C}$. This leads to the formation of aromatic imides. The tautomeric equilibrim of imides is shifted towards iminolization when the temperature is high. The iminols undergo dehydration and form cross-linked structure, contributing to the char residue and nitrile formation [31,32] (Scheme 6).

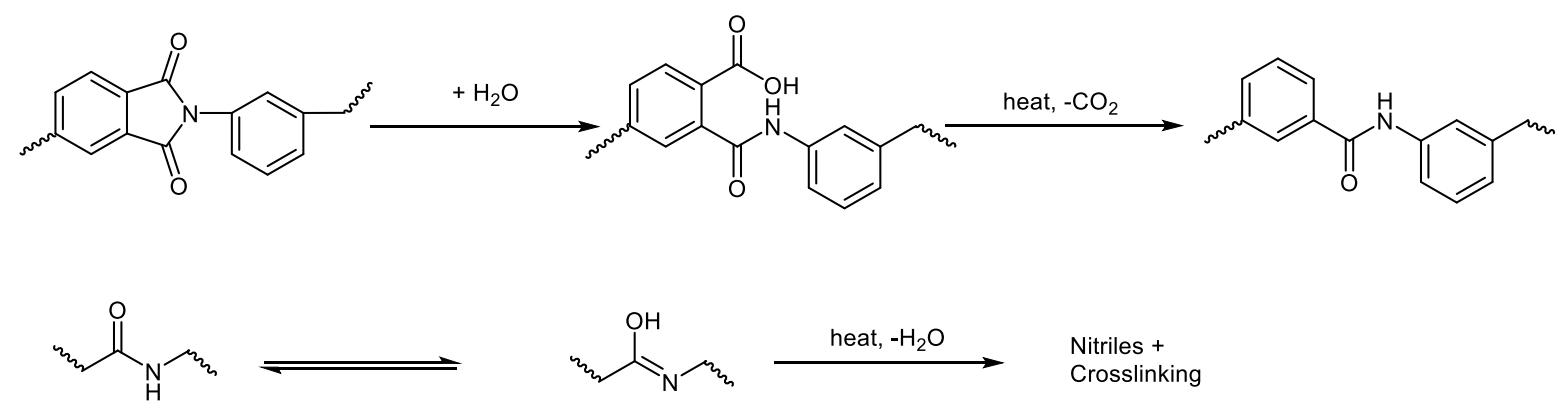

Scheme 6. Poly(amic acid) formation and tautomerisation equilibrium of phtalimide rings[30]

DPMS analysis allowed the deduction that the main preliminary degradation products of PEI are phtalimide derivatives. These derivatives offer a plethora of decomposition pathways that lead to the formation of nitrile derivatives, carbon dioxide and water (Scheme 5 and Scheme 6). 


\section{Fire behavior}

One of the notable properties of PEI is its inherent flame retardancy. Indeed, PEI has a limiting oxygen index of 45.2 [33], which is an extremely high value considering that it is neither a halogen containing polymer, nor is it flame retarded chemically. It can achieve Vo rating in the UL-94 test[34].

Cone calorimetry at $50 \mathrm{~kW} / \mathrm{m}^{2}$ have been performed on samples of PEI in evaluate its reaction to fire. The results of these tests are summarized in Table 5. PEI has a relatively low ignition time when subjected to $50 \mathrm{~kW} / \mathrm{m}^{2}(67 \mathrm{~s})$. It has two peaks of heat release rate, which are relatively low $\left(74 \mathrm{kw} / \mathrm{m}^{2}\right.$ and $\left.65 \mathrm{~kW} / \mathrm{m}^{2}\right)$ as compared to a regular polyester $\left(131 \mathrm{~kW} / \mathrm{m}^{2}\right)$ when tested in similar conditions. The total heat released during a five-minute cone calorimeter test at 50 $\mathrm{kW} / \mathrm{m}^{2}$ sums up to $58 \mathrm{~kJ}$, which is among the lowest values for an amorphous thermoplastic. The effective heat of combustion of PEI is reported as $18 \mathrm{MJ} / \mathrm{kg}$. Moreover, PEI has an average smoke specific extinction area of $270 \mathrm{~m}^{2} / \mathrm{kg}$ and a carbon monoxide yield of $0.13 \mathrm{~kg} / \mathrm{kg}$ [35] .

Table 5. Summary of cone calorimeter results at $50 \mathrm{~kW} / \mathrm{m}^{2}$ of PEI[35]

\begin{tabular}{ll}
\hline PEI & Value \\
\hline Time to sustained ignition $(\mathrm{s})$ & 67 \\
Peak heat release rate $\left(\mathrm{kW} / \mathrm{m}^{2}\right)$ & 74 \\
Time to peak heat release rate $(\mathrm{s})$ & 167 \\
Total heat released $(\mathrm{MJ})$ & 58 \\
Effective heat of combustion $(18 \mathrm{MJ} / \mathrm{kg})$ & 18 \\
Mass loss $(\%)$ & $13 \%$ \\
\hline
\end{tabular}

\section{Concluding remarks}

PEI is the only amorphous thermoplastic polymer that is stable at such a high temperature. Its high glass transition temperature allows it to retain a high percentage of its mechanical strength at high temperatures.

The relatively high degradation temperature of PEI may be attributed to the highly aromatic imide backbone. This also accounts for the high char residue that is yielded when the polymer is subjected to high temperatures.

The decomposition products suggest that when under thermal stress, the first degradation corresponds to a depolymerization reaction. During this reaction, it is reported that amidoiminol tautomerization occurs, favoring crosslinking and the formation of nitriles. This causes an increased char formation. These two characteristic decomposition behaviors may explain the inherent flame retardancy of PEI. Indeed, the high char residue may create a protective layer upon exposure to outside heat flux. This can limit the liberation of combustibles during the combustion of the polymer, thus decreasing the total heat released. 


\section{Polyetheretherkeetone (PEEK)}

Polyether ether ketone (PEEK) is a subfamily of polyarylketones (PAEK). PAEKs are semicrystalline engineering thermoplastic polymers that show high thermal, mechanical, chemical, and electrical properties. They have a plethora of applications in various industries including automotive, aerospace, chemical, and oil industries. It has a continuous use of $260{ }^{\circ} \mathrm{C}$ and a melting point of $343^{\circ} \mathrm{C}$.

PEEK was the first PAEK to be fully commercialized[36]. This was possible thanks to Rose et al.[37], from Imperial Chemical Industries (ICI)[2], who identified diphenyl sulfone as a suitable solvent for making PEEK with similar toughness and crystallinity.

\section{Synthesis}

The first syntheses of polyaryletherketones (PAEK) were reported in the early 196os[38]. They were based on electrophilic substitution reactions, more precisely, Friedel-Crafts Acylation. However, because of the low solubility of the crystalline polymers, strongly acidic media were required. Polyphosphoric acid[39] and $\mathrm{HF} / \mathrm{BF}_{3}[40$ ] were later used to dissolve the polymers by protonating their carbonyl groups.

PEEK is one of the most commercially prepared PAEK on the market [36]. It is prepared by reacting 1,4-benzenediol (hydroquinone) with 4,4'-difluoobenzophenone in diphenyl sulfone in the presence of alkali-metal carbonates under an inert atmosphere at temperatures close to the melting point of the polymer[40] (Scheme 7).

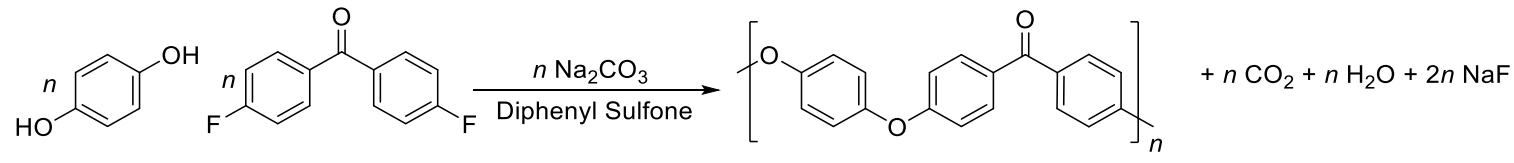

Scheme 7. Synthetic pathway for PEEK.

However, since PEEK was first synthesized, many routes have been developed for its production. An in-depth review on the synthesis and modification of PEEK in 2012 reported 5 main routes, as follows[41]:

- Electrophilic substitution route or Friedel-Crafts acylation[42]

- Nucleophilic substitution route or displacement reaction[43]

- Nickel-catalyzed coupling polymerization[44]

- Synthesis by removing bulky substituent from soluble amorphous pre-polymer[45,46]

- $\quad$ Ring opening polymerization of cyclic PEEK oligomers[47]

The synthetic routes of PEEK production may have different effects on the physicochemical properties of the polymer. Indeed, the retrosynthetic history of a polymer may allow it to have higher molecular weight or inherent viscosity as well branching [41]. Purity of the polymers may also depend on the synthetic route. Depending on the volatility of the reactants used and byproducts formed, the end product may be more or less pure at the end of the reaction [41].

It was also reported that it is possible to bring post-polymerization modifications to PEEK. However, because PEEK is insoluble in most organic solvents, usual application of many organic methods are impossible to functionalize PEEK. 


\section{Thermal Properties}

PEEK has a relatively high temperature resistance, with a reported continuous use at $260^{\circ} \mathrm{C}$ and a melting point of $343{ }^{\circ} \mathrm{C}[48]$. Thermal degradation starts between $575{ }^{\circ} \mathrm{C}$ and $580{ }^{\circ} \mathrm{C}$. PEEK being an organic polymer, this decomposition temperature is relatively high[49]. In order to better understand the thermal behavior of PEEK, it was subjected to thermogravimetric analyses.

Figure 5 shows how the residual weight of PEEK evolves with temperature under inert (nitrogen) and thermo-oxidative (air) atmospheres under different heating rates.

Under nitrogen, the TG plot of PEEK shows two distinct mass loss steps. A sharp weight loss occurs at around $580{ }^{\circ} \mathrm{C}$, causing a decrease of around $45 \%$ of the initial mass. This first mass loss is assigned to the random chain scission of ether and ketone bonds[50]. The remaining mass was assigned to carbonaceous char[49], which has a slower rate of decomposition. This first mass loss was previously reported and was assigned to the loss of phenol derivatives as degradation products[51]. Moreover, $\mathrm{CO}$ and $\mathrm{CO}_{2}$ were also identified over this temperature range [51,52]. $\mathrm{CO}$ and $\mathrm{CO}_{2}$ may be attributed to being by-products of the decomposition of PEEK to phenols derivatives.
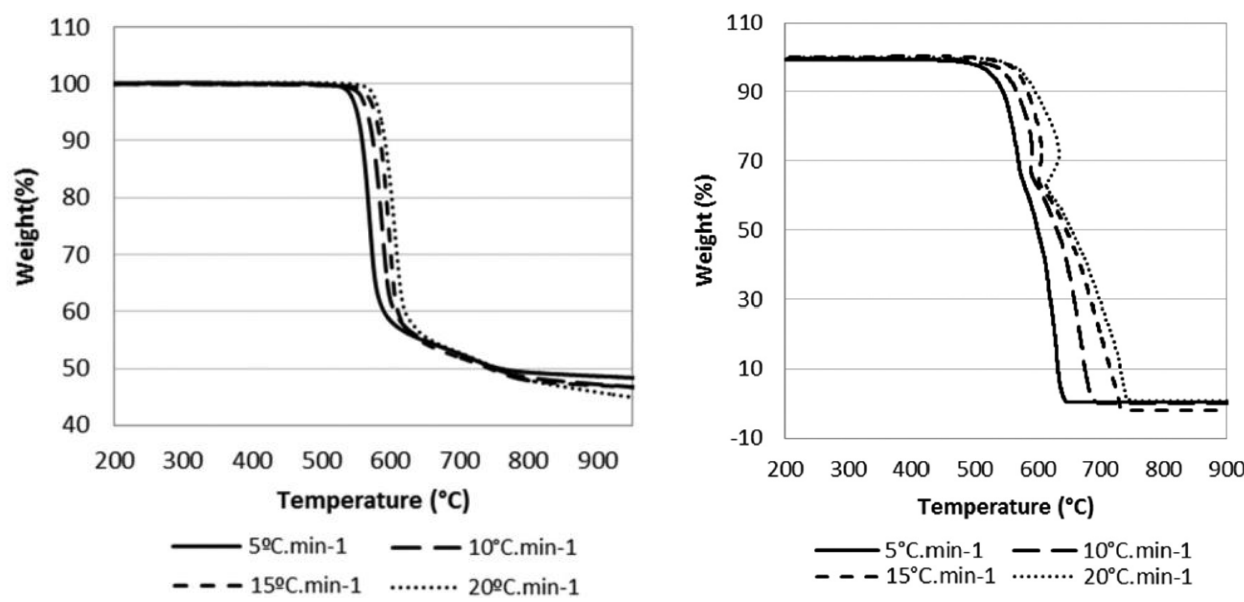

Figure 5. Thermal decomposition of PEEK nitrogen (left) and in air (right) @ heating rates: 5 ${ }^{\circ} \mathrm{C} / \mathrm{min}, 10^{\circ} \mathrm{C} / \mathrm{min}, 15^{\circ} \mathrm{C} / \mathrm{min}$, and $20{ }^{\circ} \mathrm{C} / \min [53]$.

From the TG plot in air, it can be clearly observed that the decomposition occurs in two-steps, similarly to the thermal decomposition under nitrogen. The first step occurs at slightly lower temperatures than when the analysis is performed under nitrogen (data summarized in Table 6). It may be attributed to random chain scission and of ether and ketone bonds [54]. The second step is attributed to the oxidation of the carbonaceous char formed as a result of the first decomposition step[52]. The onset of the thermal decomposition occurs at $507{ }^{\circ} \mathrm{C}$. PEEK decomposes at a lower temperature in air than under nitrogen $\left(-19^{\circ} \mathrm{C}\right)$. The amount of residue generated is also significantly higher when the thermal analysis is performed under nitrogen (about $45 \mathrm{wt} \%)$ than in air (<1 wt\%).

Table 6 shows the decomposition onset temperature ( $\left.\mathrm{T}_{\text {onset }}\right)$, the maximum mass loss rate $\left(\mathrm{T}_{\max }\right)$ and the percentage residue after the TGA of PEEK under nitrogen and in air. At low heating rates, the degradation temperature is lower than at higher heating rates. A sharp mass loss is observed just below $600{ }^{\circ} \mathrm{C}$ both in air and under nitrogen. This causes a decrease in mass of around $45 \%$. 
Table 6. Thermal characteristics of PEEK at different heating rates under pyrolytic and thermooxidative conditions

Nitrogen

\begin{tabular}{lcccc|cccc}
\hline $\begin{array}{l}\text { Heating rate } \\
\left({ }^{\circ} \mathbf{C} / \mathbf{m i n}\right)\end{array}$ & $\mathbf{5}$ & $\mathbf{1 0}$ & $\mathbf{1 5}$ & $\mathbf{2 0}$ & $\mathbf{5}$ & $\mathbf{1 0}$ & $\mathbf{1 5}$ & $\mathbf{2 0}$ \\
$\mathbf{T}_{\text {onset }}\left({ }^{\circ} \mathbf{C}\right)$ & 526 & 537 & 562 & 572 & 507 & 531 & 542 & 546 \\
$\mathbf{T}_{\max }\left({ }^{\circ} \mathbf{C}\right)$ & 567 & 588 & 599 & 605 & 600 & 587 & 602 & 630 \\
Residue (wt\%) & 48 & 46 & 46 & 44 & 0.4 & 0.1 & 0 & 0 \\
\hline
\end{tabular}

Vasconcelos et al. made TGA of PEEK at different heating rates both in air and under nitrogen in order to determine the kinetic parameters of its decomposition[55]

Under nitrogen, the activation energy for a conversion rate of $5 \%$ was found to be $238 \mathrm{~kJ} / \mathrm{mol}$ [55]. The lifetime of the material at $350^{\circ} \mathrm{C}$ was found to be 216 years for this decomposition under nitrogen.

Patel et al. found and activation energy of around $220 \mathrm{~kJ} / \mathrm{mol}$ with an Arrhenius pre-exponential factor corresponding to $1 \times 10^{23} \mathrm{~s}^{-1}$ using the Kissinger method[5o]. The parameters were also extracted using the iso-conversion method. It was concluded that the up to $70 \%$ conversion, the average activation energy for the thermal decomposition of PEEK was constant at around 250 $\mathrm{kJ} / \mathrm{mol}$.

In synthetic air atmosphere, the activation energy for a conversion rate of $5 \%$ was about 135 $\mathrm{kJ} / \mathrm{mol}$. The time required for the material to decompose by $5 \%$ in air at $350{ }^{\circ} \mathrm{C}$ is reduced to 1.05 years [55].

\section{Mechanism of the Thermal Decomposition of PEEK}

Pyrolysis products of PEEK were determined by stepwise pyrolysis/gas-chromatography/massspectrometry (Py-GC/MS), flash pyrolysis and stepwise pyrolysis[56]. Table 7 shows the degradation products of PEEK under flash pyrolysis conditions at different temperatures[50].

Hull et al. have performed an in depth review on the decomposition studies of PEEK in 2010[50]. From the degradation products that were detected by Py-GC/MS, an attempt to elucidate the degradation pathway of PEEK was made. The results are summarized in Table 7.

In the initial stage of the decomposition (at $450^{\circ} \mathrm{C}$ ), the identified decomposition products are reported to be 4-phenoxyphenol and 1,4-diphenoxybenzene. This suggests that the decomposition of PEEK is initiated in two possible mechanism: cleavage of the main chain followed by cleavage at chain ends/branches or solely by the cleavage of chain ends and branches[50].

At higher temperatures, lower molecular weight compounds are identified. This may be because the main chain scission is less targeted to solely the low energy bonds. This leads to other volatile products such as $\mathrm{CO}, \mathrm{CO}_{2}$ or diphenyl ether, which are identified at $650^{\circ} \mathrm{C}$. At $750^{\circ} \mathrm{C}$ and higher, dibenzofuran, biphenyl and naphthalene are identified.

Phenol has been identified as the main decomposition product at temperatures above 650 ${ }^{\circ} \mathrm{C}[56]$. Another major decomposition product is reported to be dibenzofuran. This can be associated to a ring closure reaction occurring between diradicals at the ether groups of PEEK 
monomer units. Dibenzofuran is also found at $750^{\circ} \mathrm{C}$. This high temperature environment favors the recombination of adjacent radicals[56] (Scheme 8).<smiles>Cc1ccc(Oc2ccc(Oc3ccc(C(=O)c4ccc(Oc5ccc(Oc6ccc(C(=O)c7ccc(Oc8ccc(C)cc8)cc7)cc6)cc5)cc4)cc3)cc2)cc1</smiles><smiles>Cc1ccc(Oc2ccc(Oc3ccc(C=O)cc3)cc2)cc1</smiles><smiles>CC(C)CCCc1ccc(Oc2ccc(Oc3ccc(O)cc3)cc2)cc1</smiles>

Scheme 8. Decomposition mechanism leading to phenoxyphenol at $450^{\circ} \mathrm{C}[56]$

At temperatures higher than $900{ }^{\circ} \mathrm{C}$, significant amount of phenylphenol has been identified[51]. This may be attributed to the pyrolysis of ether containing species in the partially carbonized solid residue. 
Table 7. Decomposition of PEEK by temperature analyzed by flash Py-GC/MS[50,56].

\begin{tabular}{|c|c|c|}
\hline Temperature $\left({ }^{\circ} \mathrm{C}\right)$ & Structure & Decomposition Product \\
\hline \multirow[t]{2}{*}{450} & & 4-phenoxyphenol \\
\hline & & 1,4-diphenoxybenzene \\
\hline \multirow[t]{2}{*}{650} & $\partial_{2}$ & $\mathrm{CO}+\mathrm{CO}_{2}$ \\
\hline & & Diphenyl Ether \\
\hline \multirow[t]{10}{*}{750} & & Phenol \\
\hline & & Benzene \\
\hline & & Dibenzofurane \\
\hline & & Hydroquinone \\
\hline & & 4-Dibenzofuranol \\
\hline & & 4-Hydroxybenzophenone \\
\hline & & p-Benzoquinone \\
\hline & & Biphenyl \\
\hline & & Naphthalene \\
\hline & & Fluorene \\
\hline \multirow[t]{3}{*}{1100} & & 4-Hydroxybenzophenone \\
\hline & & 1,4-Diphenoxybenzene \\
\hline & & 4-Phenylphenol \\
\hline
\end{tabular}

Tentative pathways to the decomposition products at different temperatures have been proposed in order to explain the thermal decomposition mechanism of PEEK.

The low temperature degradation (at around $450^{\circ} \mathrm{C}$ ) is associated with the random scission of the lowest energy bond. This corresponds to the carbonyl-aromatic bond. This scission would form two resonance-stabilized groups. 
At $650^{\circ} \mathrm{C}$, phenol and diphenyl ether are identified. Their formation requires higher energy because the radical intermediates formed are not stabilized by resonance with the presence of an aryl ketone or phenol ring. The formation of $\mathrm{CO}$ at this temperature may be explained by the decarbonylation of aldehydes and $\mathrm{CO}_{2}$ may be formed by the decarboxylation of carboxylic acids formed during the initial decomposition [50].

At $750{ }^{\circ} \mathrm{C}$, phenol is still formed and the formation of benzene is detected. In addition, the formation of hydroquinone and benzoquinone are observed. This high temperature allows for the formation of less energetically favored radicals. A diradical pathway may lead to the formation of benzoquinone. However, to explain the formation of hydroquinone, a stepwise process is suggested. Ring closure reactions followed by random chain scission could lead to further formation of benzofuran and dibenzofuranol[5o].

The high char yield suggests that aforementioned random chain scission reactions are coupled with carbonization processes. The pyrolysis gas chromatography-mass spectrometry data suggest that the dominant pyrolysis route at temperatures above $800{ }^{\circ} \mathrm{C}$ correspond to carbonization[56].

These tentative mechanistic pathways give a good idea of the possible modes of decomposition that may be adopted when PEEK is subjected to high temperatures. However, they are not conclusive and further work is required to ascertain the actual thermal decomposition mechanism of PEEK. However, the nature of the decomposition products account for its apparently low flammability (see Fire behavior below). Indeed, despite the release of small molecules that could eventualy act as a fuel in a fire scenario, it is noteworthy that a large fraction of the material is carbonized during its thermal decomposition. This means that in the event of a fire, only a small fraction of the material would actually decompose into possible fuel to feeding a flame.

\section{Fire behavior}

There are several types of fire tests that may be performed on a material, each giving different properties of the material. An in-depth study of the different fire properties of PEEK has been previously carried out[53]. It has a Limiting Oxygen Index of $35 \%$ v/v and an UL 94 rating Vo[57].

A non-flaming test, PCFC, was used to examine PEEK sampled with different molecular weight. The results are summarized in the table below. The samples 9oG, $150 \mathrm{G}$ and $450 \mathrm{G}$ correspond to three different viscosities of the polymers with $90 \mathrm{G}$ being the least viscous and $450 \mathrm{o}$ the most viscous. The onset temperature is slightly lower in low viscosity PEEK. The same may be observed regarding the peak temperature. However, the peak of heat release rate is higher in $450 \mathrm{O}$ as compared to $150 \mathrm{OG}(+24 \mathrm{~W} / \mathrm{g})$ and $90 \mathrm{O}(+69 \mathrm{~W} / \mathrm{g})$. In addition, the char yield and the total heat released are similar for the three samples [53].

Table 8. PCFC experiments for different types of PEEK [53] (heating rate: $1{ }^{\circ} \mathrm{C} / \mathrm{s}$ )

\begin{tabular}{lccccc}
\hline & $\begin{array}{c}\text { Onset } \\
\text { Temperature } \\
\left({ }^{\circ} \mathrm{C}\right)\end{array}$ & $\begin{array}{c}\text { Peak } \\
\text { Temperature } \\
\left({ }^{\circ} \mathrm{C}\right)\end{array}$ & $\begin{array}{c}\text { PHRR } \\
(\mathrm{W} / \mathrm{g})\end{array}$ & Char (\%) & THR (kJ/g) \\
\hline 90G [53] & 571 & 615 & 287 & 52 & 11 \\
150G [53] & 575 & 616 & 332 & 48 & 11 \\
$\mathbf{4 5 0 G ~ [ 5 3 ]}$ & 580 & 617 & 356 & 50 & 11 \\
\hline
\end{tabular}


Another study dealing with the pyrolysis combustion flow calorimetry of PEEK has been previously reported [53]. The average heat release capacities of PEEK were determined via PCFC at a heating rate of $258{ }^{\circ} \mathrm{C} / \mathrm{min}$. The heat release capacity was $180 \mathrm{~J} \mathrm{~g}^{-1} \mathrm{~K}^{-1}[58]$, the total heat released was $12.4 \mathrm{~kJ} / \mathrm{g}$ and the char yield was $47 \%$.

A flaming test was also used to determine the fire properties of PEEK [59]. The Cone Calorimeter test, from Fire Testing Technology (FTT) was used to study the burning behavior of PEEK. An irradiance of $50 \mathrm{~kW} / \mathrm{m}^{2}$ was used. The results are shown in Figure 6 and average values summarized in Table 9.

The time to ignition was $110 \mathrm{~s}$. The heat release rate increased to a shoulder around $200 \mathrm{~kW} / \mathrm{m}^{2}$ in about $140 \mathrm{~s}$, and then continued to burn reaching a peak of heat release rate of $415 \mathrm{~kW} / \mathrm{m}^{2}$. The total heat released was reported to be around $36 \mathrm{MJ} / \mathrm{m}^{2}$. The char yielded was around $51 \%$.

Table 9. PEEK at 5okW/m². Summary: time to ignition, Peak Heat Release Rate (PHRR); Time to Peak Heat Release Rate (tPHRR), Char Yield, Total Heat Released [53].

\begin{tabular}{cccccc}
\hline & $\begin{array}{c}\text { Time to } \\
\text { ignition }(\mathrm{s})\end{array}$ & $\begin{array}{c}\text { PHRR } \\
\left(\mathbf{k W} / \mathbf{m}^{2}\right)\end{array}$ & $\begin{array}{c}\text { tPHRR } \\
(\mathbf{s})\end{array}$ & $\begin{array}{c}\text { Char yield } \\
(\%)\end{array}$ & $\begin{array}{c}\text { THR } \\
\left(\mathbf{M J} / \mathbf{m}^{2}\right)\end{array}$ \\
\hline PEEK & 110 & 415 & 182 & 51 & 36 \\
\hline
\end{tabular}

Moreover, after flaming out, it was reported that the heat release rate does not return to zero. This phenomenon was attributed to a non-flaming oxidation of the char (Figure 6).

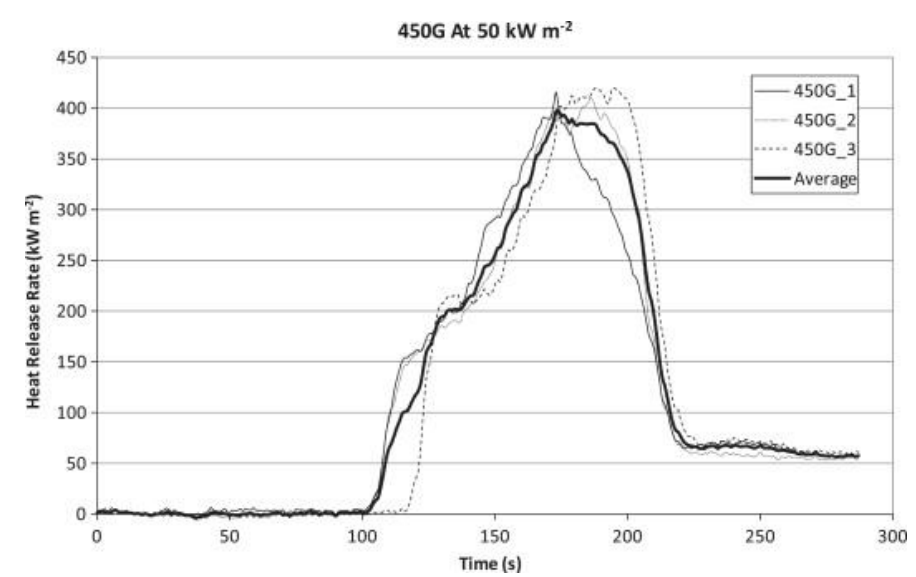

Figure 6. Cone colorimeter data for HRR of PEEK $450 G$ and the average [53]. 


\section{Concluding remarks}

The high aromatic proportion in PEEK, like in PEI accounts for its high thermal stability. The semi-crystalline nature of PEEK allows it to keep its dimensional stability until its glass transition temperature.

A thorough review was carried out concerning the decomposition mechanism of PEEK but the actual decomposition pathway was not conclusively reached. However, decomposition mechanism proposed has shown that there is a major fraction of the polymer that crosslinks when it is subjected to thermal stress. This means that the decomposition releases a lower amount of combustibles when is decomposes as opposed to if it were to completely decompose. Since it is the release of combustibles that fuels a fire, the enhanced thermal stability of PEEK evidences its low flammability.

Moreover, the cross-linking nature of PEEK also protects the polymer when it is exposed to a heat flux. This is observed in the cone calorimeter test results. Firstly, the incident heat flux required for the material to ignite is itself relatively high $\left(50 \mathrm{~kW} / \mathrm{m}^{2}\right)$. This may be explained by its enhanced thermal stability. However, when is it ignited, the peak of heat release rate is relatively low. Indeed, when compared to polystyrene under similar conditions, the heat release rate of PEEK is about 3 times lower ( $1294 \mathrm{~kW} / \mathrm{m}^{2}$ for polystyrene [53] as compared to $400 \mathrm{~kW} / \mathrm{m}^{2}$ for PEEK). 


\section{Poly(phenylene sulfone)}

Poly(phenylene sulfone) (PPSU or PPSF) is a high performance polymer which exhibits outstanding mechanical and thermal stability. It is an amorphous thermoplastic polymer with sulfone and ether linkages in the backbone (Figure 7). These properties make it a potential candidate for materials in electronic circuit boards or in the aeronautics industry [6o]. One of the highest performing polyphenylene sulfone on the market is known under the trademark Radel ${ }^{\circledR} \mathrm{R}$ and is commercialized by Solvay. The structure of Radel ${ }^{\circledast}$ consists of a highly aromatic backbone with sulfone bonds contributing to it resonant structure.

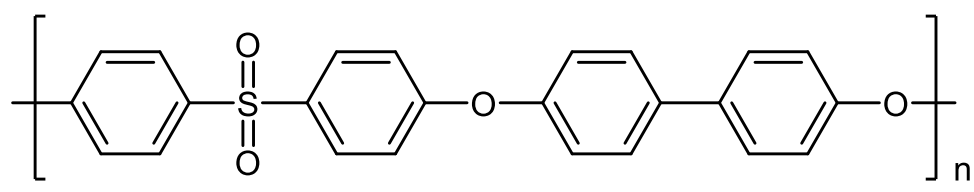

Figure 7. Structure of Radel $^{\circledR} R$

\section{Synthesis}

There are many different ways that may be adopted to prepare PPSU. One of the first methods was the condensation reaction between the sodium salt of bisphenol A with 4,4'dichlorodiphenyl sulfone in dimethylsulfoxide [9].

Another method of preparing PPSU involves the nickel-catalyzed coupling of an aromatic dihalides. It is a two-step process whereby the first reaction consists of forming aromatic dichloride intermediates possessing the desired structure in the polymer to be synthesized [61]. This aromatic dichloride then self-reacts in the presence of $\mathrm{Ni}^{\circ}$, triphenylphosphine and zinc to form the polymer [62].

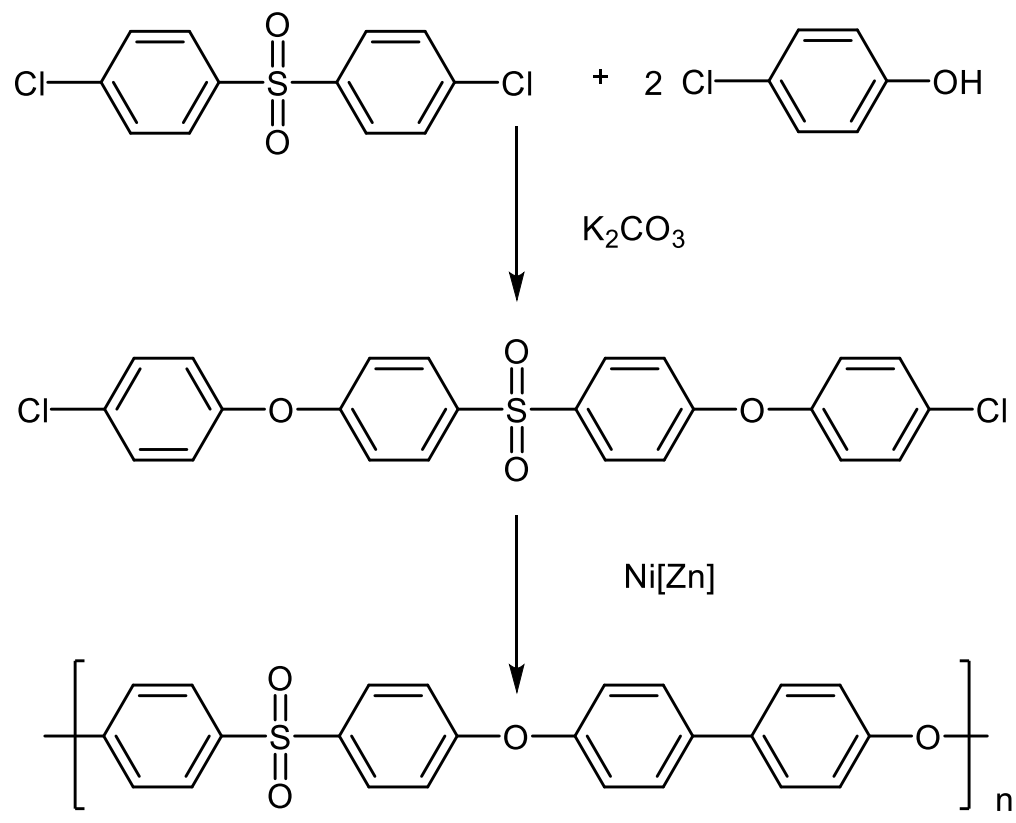

Scheme 9. Preparation of PPSU using nickel based catalyst [62]

\section{Thermal Properties}

PPSU is one of the highest performing sulfone polymers. It has a glass transition temperature of around $220{ }^{\circ} \mathrm{C}$ and a continuous use temperature of $180{ }^{\circ} \mathrm{C}$. An unannealed sample of Radel ${ }^{\circledast}$ 5000 has a deflection temperature of $207^{\circ} \mathrm{C}$ when it is subjected to a $1.8 \mathrm{MPa}$ stress [63]. 
The thermal stability of PPSU has been studied by TGA in pyrolytic and thermo-oxidative atmospheres at different heating rates[64-66]. When subjected to an identical heating rate, PPSU starts to decompose at a higher temperature in an inert atmosphere as compared to an oxidative one.
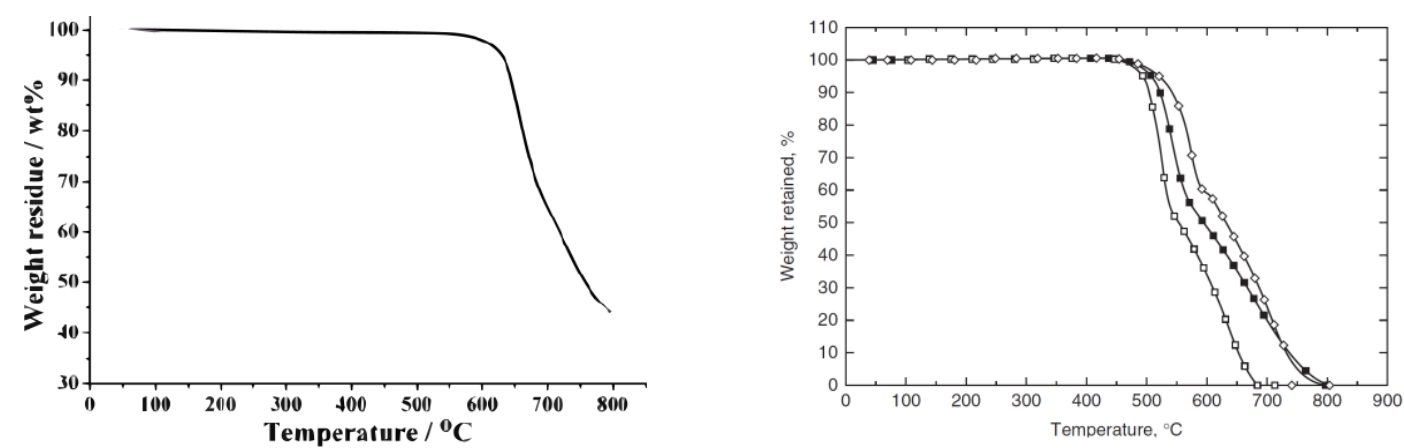

Figure 8. TGA plots of PPSU under nitrogen (left) and TGA plots of polysulfone ( $\square$ ), polyethersulfone ( $\square$ ) and PPSU ( $(\nabla)$ (right) at a heating rate of $10^{\circ} \mathrm{C} / \mathrm{min}[60,66]$

The thermal stability of PPSU under nitrogen is illustrated by the TGA plot on Erreur ! Source du renvoi introuvable. (left). It suggests that at this heating rate, the decomposition of PPSU occurs in one step. The onset of the degradation is around $600{ }^{\circ} \mathrm{C}$. This high thermal stability may be due to the high aromatic backbone on the polymer. Moreover, the residual mass at 800 ${ }^{\circ} \mathrm{C}$ is significant (> $40 \mathrm{wt} \%$ ).

However, the thermal stability of PPSU is different in air. The TGA plots performed in air of three sulfur containing polymers polysulfone (PSU), polyethersulfone (PES), and PPSU are shown on Figure 8. It can be observed that the onset of thermal degradation occurs at similar temperatures for all three polymers. However, PPSU appears to degrade at a lower temperature (around $500{ }^{\circ} \mathrm{C}$ ) in air than under nitrogen $\left(600^{\circ} \mathrm{C}\right)$. The first step of the thermal decomposition may be dependent on oxygen. Moreover, the decomposition of PPSU appears to consist of 2 steps when it is heated in air.

A study concerning the kinetics of the thermal degradation of PPSU has been reported by Youjie et al [64]. It consisted of applying the Ozawa-Flynn-Wall method on a commercial unfilled PPSU from BASF. TGA analysis at different heating rates were performed under nitrogen and in air .
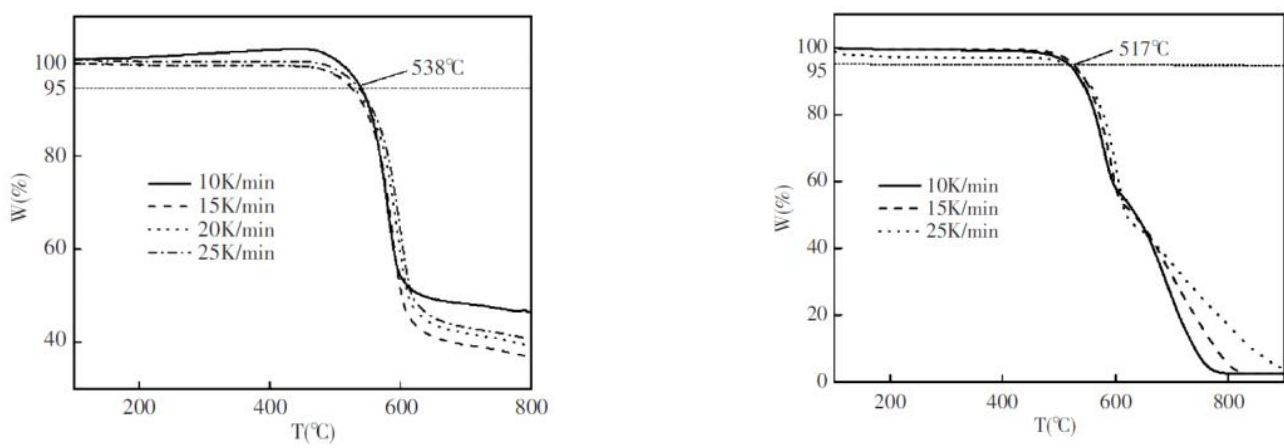

Figure 9. TGA plots of PPSU under nitrogen (left) and in air (right) at 10, 1520 (only for measurement under nitrogen) and $25^{\circ} \mathrm{C} / \mathrm{min}$

The average activation energy for the degradation of PPSU in nitrogen was calculated to be 299 $\mathrm{kJ} / \mathrm{mol}$ (average value) under nitrogen. Under thermo-oxidative atmosphere, two decomposition steps were observed. Therefore, two activation energies were extracted. For the first 
decomposition, the activation energy was calculated to be $211 \mathrm{~kJ} / \mathrm{mol}$ and the second decomposition step was reported to be $111 \mathrm{~kJ} / \mathrm{mol}$.

To further understand its thermal decomposition pattern, Py-GC/MS analyses were performed on PPSU [67]. The analyses were performed at $850{ }^{\circ} \mathrm{C}$ and $950{ }^{\circ} \mathrm{C}$ in order to properly pyrolyze the sample. Table 10 shows the different pyrolyzates that were analyzed when PPSU was subjected to aforementioned temperatures under helium.

Table 10. Structural assignments for pyrolysis products obtained via Py-GCMS analyses at $850{ }^{\circ} \mathrm{C}$ and $950{ }^{\circ} \mathrm{C}[67]$

\begin{tabular}{|c|c|c|c|c|}
\hline \multirow{2}{*}{ Structure } & \multirow{2}{*}{$\mathrm{Mw}(\mathrm{g} / \mathrm{mol})$} & \multirow{2}{*}{ Name of compound } & \multicolumn{2}{|c|}{ Peak intensity (\%) } \\
\hline & & & $850^{\circ} \mathrm{C}$ & $950^{\circ} \mathrm{C}$ \\
\hline $\mathrm{SO}_{2}$ & 64 & Sulfur dioxide & 85 & 80 \\
\hline & 78 & Benzene & 26 & 39 \\
\hline & 92 & Toluene & 4 & 5 \\
\hline & 104 & Styrene & $<1$ & 2 \\
\hline & 110 & Benzenethiol & 1 & 1 \\
\hline & 94 & Phenol & 100 & 100 \\
\hline & 128 & Naphtalene & $<1$ & 5 \\
\hline & 154 & Biphenyl & 21 & 27 \\
\hline & 170 & Diphenyl ether & 42 & 36 \\
\hline & 168 & Dibenzofuran & 17 & 21 \\
\hline & 186 & Diphenyl sulfide & 3 & 3 \\
\hline & 170 & p-hydroxyl diphenyl & 3 & 3 \\
\hline & 184 & Dibenzothiophene & 1 & 3 \\
\hline & 218 & Diphenyl disulfide & 2 & 1 \\
\hline & 246 & p-diphenyl phenylether & 8 & 4 \\
\hline
\end{tabular}

On top of Py-GCMS, MALDI-TOF experiments were also carried out. This allowed the identification of low energy fragmentations of the polymer. The study of the decomposition products coupled with MALDI-TOF analysis have made it possible to attempt at elucidating the thermal decomposition pathway for PPSU [67].

The first step of the thermal decomposition involves the cleavage of phenyl-sulfone $\left(\mathrm{Ph}-\mathrm{SO}_{2}\right)$ linkages. Depending on the amount of energy single or multiple $\mathrm{Ph}-\mathrm{SO}_{2}$ bonds releasing sulfur dioxide (Scheme 10). 


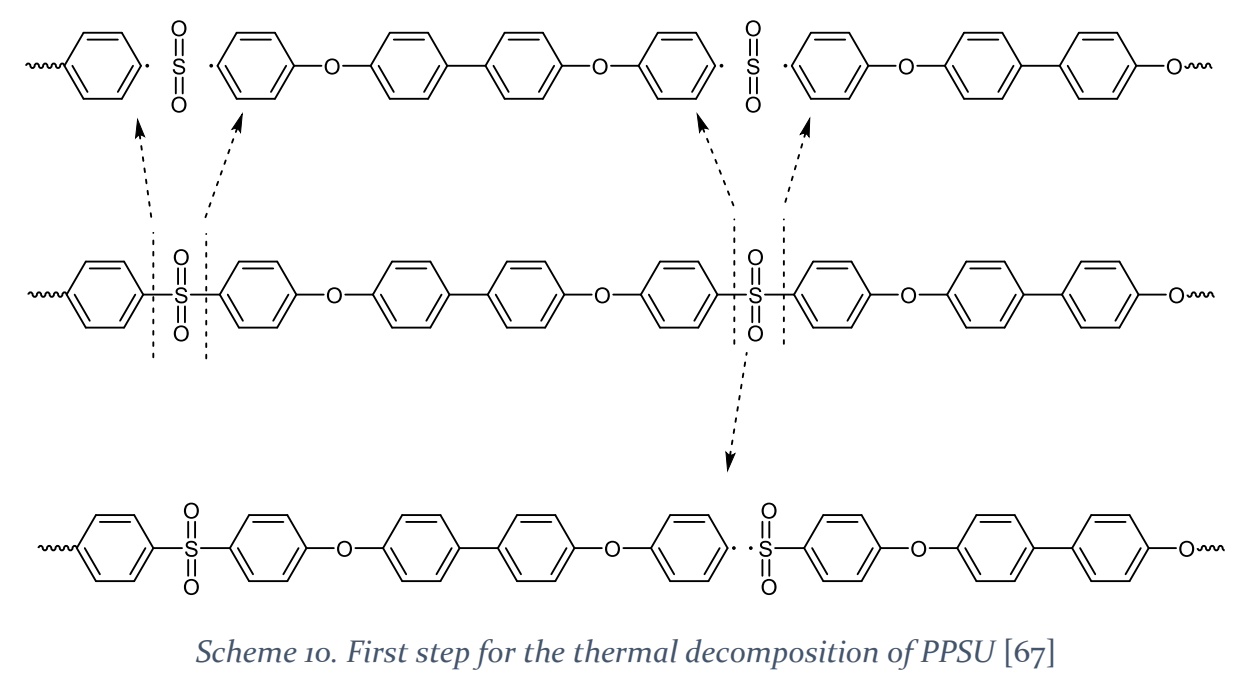

The second thermal decomposition step may involve the cleavage of Phenyl-Oxygen or PhenylPhenyl bonds. The cleavage of phenyl-oxygen bonds would lead to the formation of phenol, $p$ diphenyl phenylether, or biphenyl radicals. On the other hand, the cleavage of phenyl-phenyl linkage would lead to the formation of diphenyl ether radicals. The third step of the decomposition would involve the cleavage of the same bonds as in the second step, albeit from smaller molecules[67].

Ellison et al. have performed an in-depth analysis of the Py-GCMS of PPSU in an attempt to elucidate its thermal degradation mechanism. The first step of the suggested mechanism is reported in this review but readers are invited to consult the original article for a more integral version of the decomposition mechanism [67].

\section{Fire Behavior}

The high char yield in the TGA plot of PPSU suggests that it exhibits some sort of fire retardancy. However, in order to confirm this assumption, fire tests need to be carried out. Indeed, the fire properties of PPSU has been studied by different methods. Cone calorimetry has been used to investigate time to ignition and heat released by burning PPSU upon exposure to an external heat flux [68]. Milligram scale combustion calorimetry tests was also performed on PPSU[68].

Standard tests such as UL-94, LOI, and smoke density tests are reported for PPSU. Table 11 summarizes the results of these tests.

Table 11. Summary of some fire properties of PPSU

\begin{tabular}{lll}
\hline Property & Test Method & Result \\
\hline Flammability rating & UL-94 & V-o at o.8 mm \\
Limiting oxygen index (LOI) & ASTM D-286 & 38.0 \\
$\begin{array}{l}\text { Smoke density } \\
\begin{array}{l}\text { Specific optical density } \\
\text { flaming condition) }\end{array}\end{array}$ & ASTM E662 & 30 at $6.2 \mathrm{~mm}$ (thickness) \\
\hline
\end{tabular}

The V-o rating from the UL-94 and the high LOI (38\%) show that the PPSU possesses great flame resistance.

Microscale combustion calorimeter (MCC) and cone calorimetry were performed on PPSU. MCC provided another method for the onset of the decomposition based on heat release parameters [68]. Moreover, the critical heat flux for ignition was also extracted from the same 
measurements. The parameters calculated from MCC measurements (which is a milligramsample based instrument) were compared to those of the cone calorimeter. The ignition parameters for PPSU are summarized in table

Table 12. Ignition parameters for PPSU from cone calorimeter and microscale combustion calorimeter [63].

\begin{tabular}{lll}
\hline PPSU & & Value \\
\hline MCC Based Measurements & $\begin{array}{l}\text { Onset temperature }\left({ }^{\circ} \mathrm{C}\right) \\
\text { Critical heat flux for sustained } \\
\text { pyrolysis }\left(\mathrm{kW} / \mathrm{m}^{2}\right)\end{array}$ & 274 \\
\hline $\begin{array}{l}\text { Cone Calorimeter based } \\
\text { measurements }\end{array}$ & $\begin{array}{l}\text { Temperature at ignition }(\mathrm{s}) \\
\text { Critical heat flux for piloted }\end{array}$ & 203 \\
\hline
\end{tabular}

The onset of the degradation is coherent with TGA. Indeed, the MCC has a heating rate of 60 ${ }^{\circ} \mathrm{C} / \mathrm{min}$. This is lower than in usual TGA. Therefore, the degradation onset is expected to be higher. Moreover, the temperature at ignition is lower than the degradation onset. This may be due to the experimental conditions which had to sacrifice some precision on the measurement of surface temperature. The critical heat flux for sustained pyrolysis $\left(27 \mathrm{~kW} / \mathrm{m}^{2}\right)$ was slightly higher than the critical heat flux for piloted ignition $\left(23 \mathrm{~kW} / \mathrm{m}^{2}\right)$.

The study of the heat release rate of PPSU was performed on PPSU which had sustained hygroscopic conditioning prior to the measurements. Only dry PPSU is of interest.
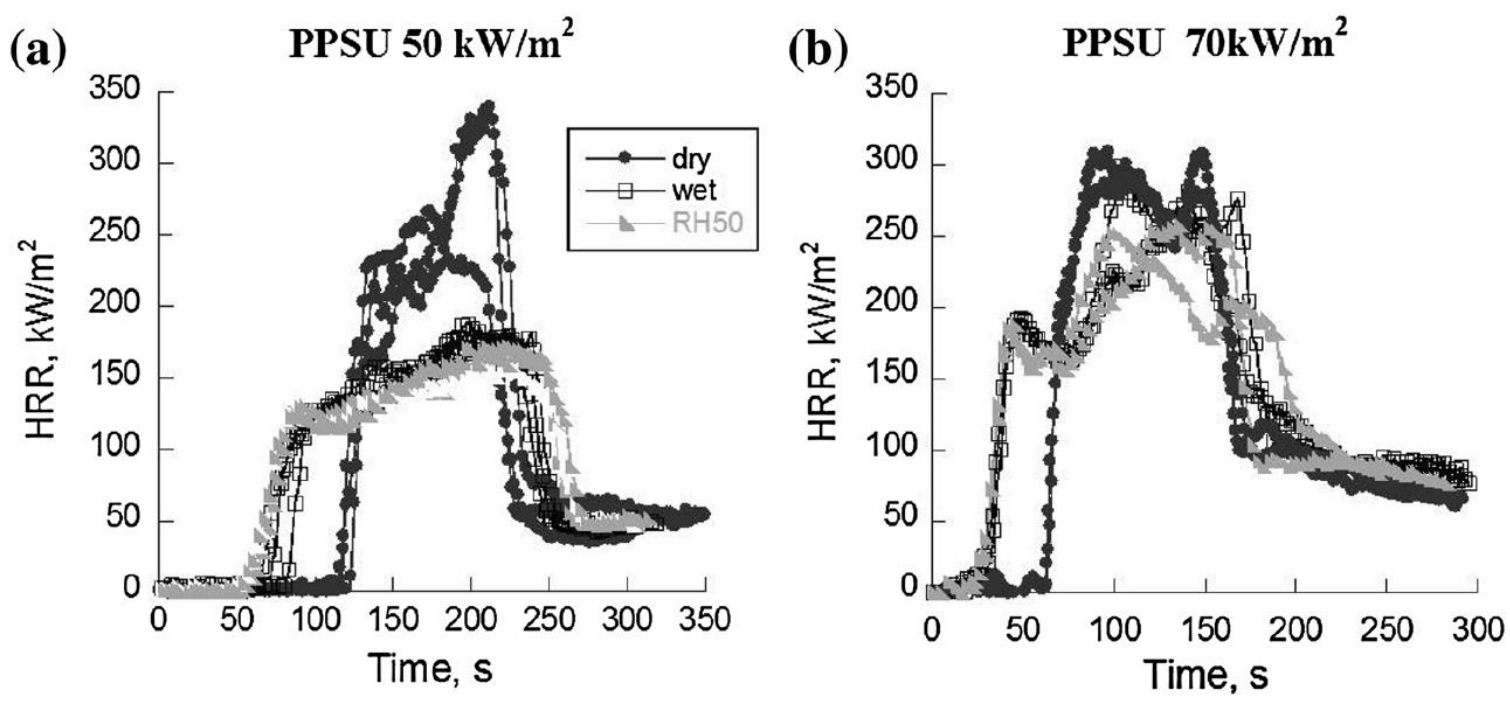

Figure 10. Cone calorimetry results for tests on PPSU at $50 \mathrm{~kW} / \mathrm{m}^{2}$ (left) and $70 \mathrm{~kW} / \mathrm{m}^{2}$ (right)

At $50 \mathrm{~kW} / \mathrm{m}^{2}$ incident heat flux, PPSU has a time to ignition at around $200 \mathrm{~s}$. The average peak of heat release rate was around $250-350 \mathrm{~kW} / \mathrm{m}^{2}$. This is lower than other engineering polymers such as PA66 (pHRR at around $\left.500 \mathrm{~kW} / \mathrm{m}^{2}\right)$ [68].

Moreover, at $70 \mathrm{~kW} / \mathrm{m}^{2}$, the peak of heat release rate is almost lower than at $50 \mathrm{~kW} / \mathrm{m}^{2}$. The time to ignition is lower, as expected. There seems to be a residual heat flux that is maintained in the last $100 \mathrm{~s}$ of the measurement.

The authors also made some visual observation when performing the cone calorimeter test and it was reported that there was not foam or bubbling. 


\section{Concluding Remarks}

The study of the thermal stability of PPSU using TGA provided some interesting insight on the decomposition behavior of the material. The high char residue at high temperatures may imply that there is some form of cross-linking that occurs during the pyrolysis process. This crosslinked structure is thermo-oxidized when the TGA is performed in air. However, the formation of a carbonaceous char is promising in the field of fire retardancy as it can act as a heat and mass transfer barrier in a fire scenario.

Moreover, the degradation temperature of PPSU is quite high for a non-loaded polymeric material. This high thermal stability may be attributed to the high aromatic content in the polymer backbone. Moreover, thanks to its high glass transition temperature, it can keep its dimensional stability at relatively high temperatures, making it suitable for some high temperature use.

An in-depth study concerning the mechanism of thermal decomposition of PPSU has been performed. The first step of the thermal decomposition was quite properly described as the breaking of sulfone-carbon bonds. However, despite some highly interesting insights on possible degradation pathways of PPSU, there lacks supporting evidence other than the Py-GCMS and MALDI-TOF to properly understand the pathway of the degradation. Indeed, there are possible recombination reactions that may occur within a Py-GCMS. This may lead to the identification of products that may not occur other than in the instrument conditions.

The peak of heat release rate of PPSU is relatively low and is consistent with that of highperformance polymers (about $300 \mathrm{~kW} / \mathrm{m}^{2}$ at an incident heat flux of $50 \mathrm{~kW} / \mathrm{m}^{2}$ ). This is around 3 times lower than that of polystyrene $\left(1294 \mathrm{~kW} / \mathrm{m}^{2}\right.$ at the same heat flux) [53]. However, it still lies within the range of engineering polymers. Moreover, the cone calorimeter results show that there is a relatively high residual heat flux during the last $150 \mathrm{~s}$ of the experiments. This is assigned to smoldering leading to further thermo-oxidative decomposition of the material.

\section{Polyimide}

Polyimides are among the most popular high temperature/high performance polymers on the market. They are a generation of polymers with inherently rigid chains and possess high thermal and electrical properties. They are used in many fields such as microelectronics, high temperature matrices, as well as adhesives for gas separation membranes. Polyimides are used in various forms such as high temperature structural adhesives, coatings, films, or laminating resins. Their excellent thermal stability is attributed to the inert imide ring and high interchain interactions[58].

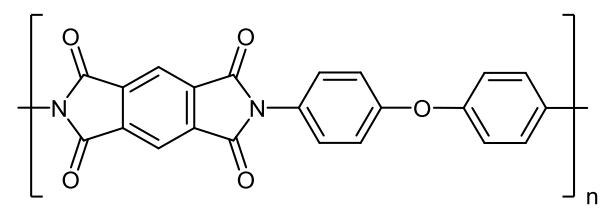

Figure 11. Typical structure of a polyimide $\left(\right.$ Kapton $\left.^{\oplus}\right)$

In fact, aromatic polyimides make up most of the polyimide market today. They have been considered, more than once, as a replacement for metals and glass in many high performance applications such as electronics, aerospace and automotive industries[69]. 


\section{Synthesis}

The first synthesis of a polyimide was carried out by Bogert and Renshaw in 1908[69]. However, it was not until 1959 that a patented high-molecular weight polyimide was synthesized by Dupont. The result of this synthesis gave rise to the widely known Kapton, which was commercialized in the early 1960 [70].

Depending on monomers used, a very large variety of polyimides can be made. They can be roughly classified as aromatic, semi-aromatic and aliphatic polyimides. Since this review concerns high temperature polymers, this chapter will be limited to aromatic polyimides, which possess the highest thermal properties.

Many reaction pathways to form polyimides have been devised by different specialists in the field. Typically, aromatic polyimides are prepared via a two-step procedure: a ring opening polyadition of aromatic diamines to aromatic tetracarboxylic diangydrides in $\mathrm{N}$-methyl pyrrolyidone (NMP) solution to give polyamic acid. The latter thus formed is imidized into polyimides by thermal cyclodehydration. This is illustrated in Scheme 11.<smiles>Nc1ccc(Oc2ccc(N)cc2)cc1</smiles>

4,4'-oxydianiline<smiles>O=c1oc(=O)c2cc3c(=O)oc(=O)c3cc12</smiles>

pyromellitic dianhydride $\mathrm{n}$<smiles>CN(C)C(=O)c1cc(C(=O)O)c(C(=O)Nc2ccc(Oc3ccc(N(C)C)cc3)cc2)cc1C(=O)O</smiles><smiles>CN(C)c1ccc(Oc2ccc(-n3c(=O)c4cc5c(=O)n(C)c(=O)c5cc4c3=O)cc2)cc1</smiles>

Scheme 11. Typical synthetic pathway to polyimide[71]

\section{Thermal properties}

Polyimides are known to have high thermal stability. This is mostly due to their rigid heterocyclic imide and aromatic rings on the polymer backbone. It is reported that polyimides have a continuous service temperature in air that is as high as $260{ }^{\circ} \mathrm{C}$ and short-term use temperature of up to $482{ }^{\circ} \mathrm{C}[70]$.

Thermogravimetric analysis has been performed on PI at different heating rates in air in order to investigate their thermal stability (Figure 12). The temperature of the onset of the degradation increases with increasing heating rate. By using increased heating rates, the authors observed that the degradation of PI occurs in more than one step. This was further observed on the DTG curves (Figure 12) whereby the maxima can be easily distinguished[72]. 

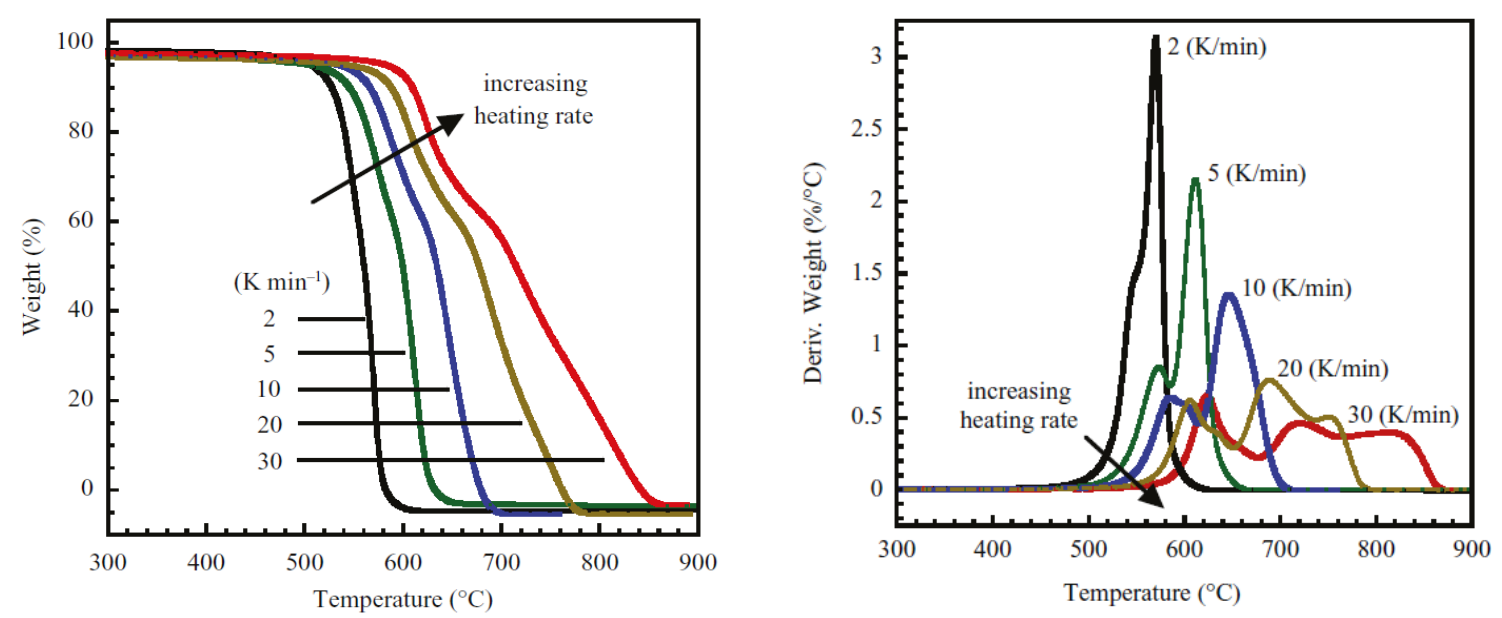

Figure 12. (Left): TGA curves of Kapton in air at different heating rates and (right) and the corresponding DTG curves

Other TGA performed on similar kinds of polyimides have shown that aromatic PI remain stable up to over $500{ }^{\circ} \mathrm{C}$ in inert atmospheres (heating rate $3{ }^{\circ} \mathrm{C} / \mathrm{min}$, helium atmosphere). After this temperature, there is significant weight lost until about $65 \mathrm{wt} \%$ of the original sample. This weight is maintained until $100{ }^{\circ} \mathrm{C}[73]$.

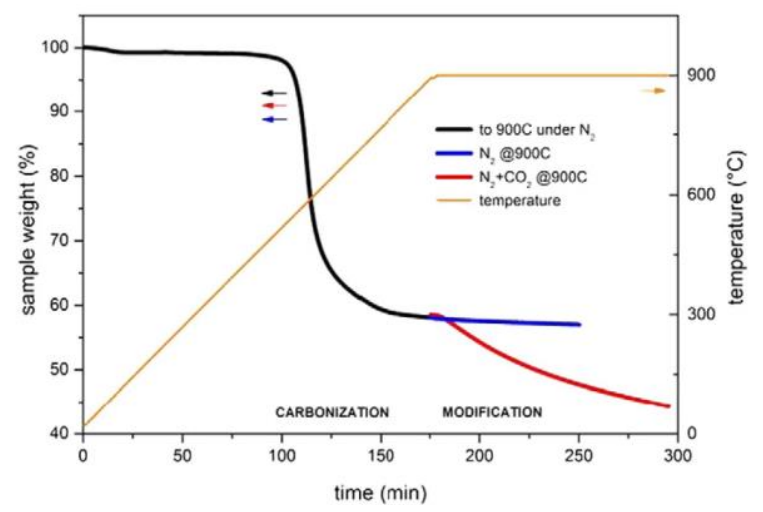

Figure 13. TGA curve of polyimide at heating rate of $5^{\circ} \mathrm{C} /$ min under nitrogen (black) [73]

The TGA of PI under nitrogen shows that the temperature of the onset of the degradation is higher than in air (approximately $550^{\circ} \mathrm{C}$ ).

Isothermal thermogravimetry performed on PI suggest that at low temperatures (below $520^{\circ} \mathrm{C}$ ), the thermal decomposition of PI occurs in a single step. At higher temperatures, the degradation is a two-step process [74].

The thermo-oxidative degradation of PI was carried out in order to explore the kinetics of the decomposition [72]. Isoconversional kinetic methods were used in order to determine the activation energy as a function of conversion. The method made use of thermogravimetric techniques at different heating rates and calculations using Friedman analysis.

A multi-step ( 5 steps) decomposition mechanism was chosen for the study. The parameters used for the kinetic model is given in Table 13 . 


\begin{tabular}{lcccc}
\hline & $\begin{array}{c}\text { Activation energy } \\
\left(\mathrm{kJ} \mathrm{mol}^{-1}\right)\end{array}$ & $\begin{array}{c}\text { Log } \\
\left(\mathrm{A}_{\mathrm{I}} / \mathrm{s}^{-1}\right)\end{array}$ & $\begin{array}{c}\text { Reaction } \\
\text { order }\end{array}$ & $\begin{array}{c}\text { Log } \\
\left(K_{\text {cat }}\right)\end{array}$ \\
\hline Step 1 & 189.62 & 8.40 & 0.77 & 0.94 \\
Step 2 & 189.48 & 8.38 & 0.75 & 0.93 \\
Step 3 & 168.73 & 7.73 & 0.89 & 0.09 \\
Step 4 & 0.10 & -3.43 & 3.17 & 1.65 \\
Step 5 & 9.79 & -3.17 & 0.40 & 1.38 \\
\hline
\end{tabular}

These parameters were used to develop an isothermal model, which had a maximum error or 16 $\%$ with experimental results[72,74]. Isothermal kinetic parameters were calculated using various methods[75]. The activation energy calculated were in the range $346-370 \mathrm{~kJ} / \mathrm{mol}$ and $\ln \mathrm{A}$ ranging from $43.4-50.1 \mathrm{~min}^{-1}$.

The thermal decomposition products under pyrolytic and thermo-oxidative atmospheres have been studied using different methods [72,75,76].

The early stage of the thermal decomposition of was studied using thermogravimetry coupled with GC/MS and solid-state nuclear magnetic resonance[77]. Pyrolysis GC/MS at $600{ }^{\circ} \mathrm{C}$ and 700 ${ }^{\circ} \mathrm{C}$, Evolved gas analysis were also performed on PI[76]. Another study using NMR suggested a mechanism for its decomposition [77].

The results of the pyrolysis gas chromatography mass spectrometry at $600{ }^{\circ} \mathrm{C}$ and $700{ }^{\circ} \mathrm{C}$ of PI are presented in Table 14. The peak areas of the different identified products were also reported. This provides and insight on how temperature may affect the amount of a certain decomposition product that evolved when a material is subjected to thermal stress.

The main decomposition products at $600{ }^{\circ} \mathrm{C}$ include aniline, phenol. At $700{ }^{\circ} \mathrm{C}$, the major pyrolysis product identified was carbon dioxide. Benzene and benzonitrile were also identified. These products were not identified at $600{ }^{\circ} \mathrm{C}$. This suggests that the main pyrolysis product under $700{ }^{\circ} \mathrm{C}$ is carbon dioxide. From these decomposition products, two probable pathways are have been reported by Zhang et al for the thermal decomposition of PI [78] (Scheme 12).

The first suggested pathway involves the cleavage of the imide ring. This cleavage would generate intermediates that can further react to form aniline and N-phenylphtalamide by hydrolysis and the evolution of carbon monoxide (Scheme $12 \mathrm{a}$ ).
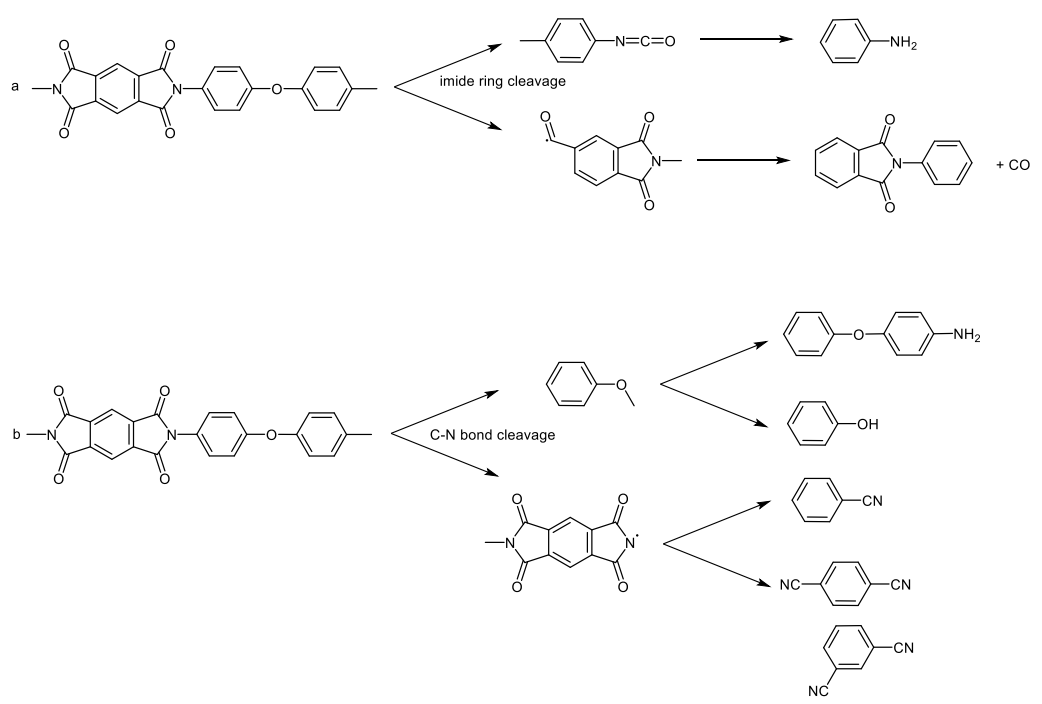
From the relative intensities of the products evolved (Table 14) it can be observed that there is a greater proportion of phenol as compared to aniline when the pyrolysis is performed at $600{ }^{\circ} \mathrm{C}$. This suggests that the $\mathrm{C}-\mathrm{N}$ bond is easier to break than the imide ring. A decomposition pathway starting with the cleavage of $\mathrm{C}-\mathrm{N}$ bonds is also suggested (Scheme $12 \mathrm{~b}$ ).

Table 14. Decomposition products of PI when subjected to pyrolysis at $600{ }^{\circ} \mathrm{C}$ and $700{ }^{\circ} \mathrm{C}$, and identified by GC/MS [79].

\begin{tabular}{|c|c|c|c|c|}
\hline \multirow{2}{*}{ Structure } & \multirow{2}{*}{$\begin{array}{l}\mathrm{Mw} \\
(\mathrm{g} / \mathrm{mol})\end{array}$} & \multirow{2}{*}{ Name of compound } & \multicolumn{2}{|c|}{ Peak area (\%) } \\
\hline & & & $600^{\circ} \mathrm{C}$ & $700^{\circ} \mathrm{C}$ \\
\hline $\mathrm{CO}_{2}$ & 44 & Carbon dioxide & 4.93 & 37.5 \\
\hline & 78 & Benzene & / & 2.2 \\
\hline & 103 & Benzonitrile & / & 7.1 \\
\hline & 93 & Aniline & 13.7 & 7.8 \\
\hline & 94 & Phenol & 44.6 & 16.1 \\
\hline & 128 & & 8.2 & $7 \cdot 4$ \\
\hline & & $\begin{array}{l}\text { Benzenedicarbonitrile } \\
+\end{array}$ & & \\
\hline & & $\begin{array}{l}1,3^{-} \\
\text {benzenedicarbonitrile }\end{array}$ & & \\
\hline & 170 & Diphenyl ether & 0.95 & 1.6 \\
\hline & 168 & Dibenzofuran & 8.4 & 6.7 \\
\hline & 185 & 4-aminophenylether & 10.1 & 1.6 \\
\hline & 223 & N-phenylphtalamide & 2.4 & 2.2 \\
\hline & 109 & 4-aminophenol & $5 \cdot 9$ & \\
\hline
\end{tabular}

The presence of flammable products such as phenol, aniline and benzonitrile among the decomposition products and indicate that PI may potentially release combustibles during its thermal degradation. This implies that if sufficient heat is given to the material, it could feed a flame. However, TG plots have evidenced the high char residue that PI leaved when it is heated. This may also play a role in the fire behavior of PI.

\section{Fire behavior}

Pyrolysis combustion flow calorimetry performed on different PI revealed that they have a heat release capacities of ranging from 13 to $38 \mathrm{~J} / \mathrm{g}-\mathrm{K}[79]$. The peak of heat release rate is reported to be $84 \mathrm{~W} / \mathrm{g}$, occurring at $602{ }^{\circ} \mathrm{C}$ (heating rate: $1{ }^{\circ} \mathrm{C} / \mathrm{s}$ ) [57]. The heat of combustion of degradation of PI is reported to be $6.6 \mathrm{~kJ} / \mathrm{g}$. It leaves around $51 \%$ char after combustion.

Cone calorimeter was performed using an incident heat flux of 35,50 and $75 \mathrm{~kW} / \mathrm{m}^{2}$ for $300 \mathrm{~s}$ on knitted PI fibers (Figure 14). Ignition was only observed at an incident heat flux of $75 \mathrm{~kW} / \mathrm{m}^{2}$. 
The time to ignition recorded was $33 \mathrm{~s}$. The peak of heat release rate was $53 \mathrm{~kW} / \mathrm{m}^{2}$ and the total heat released summed up to $72 \mathrm{MJ} / \mathrm{m}^{2}[79]$.

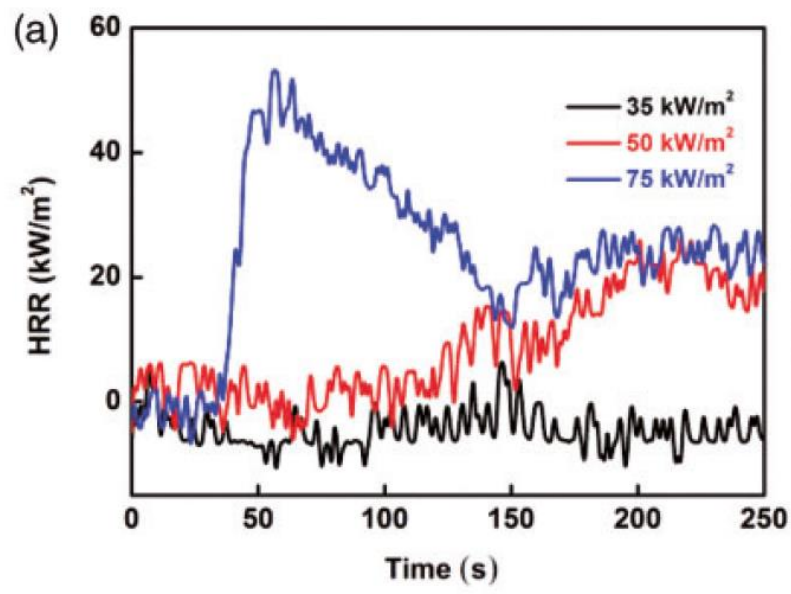

Figure 14. Heat Release Rate vs time for PI fibers under different heat flux [79].

Low-density PI (LDPI) foam was also studied under similar conditions. By varying the incident heat flux on the material, it was found that the minimum heat flux to ignite LDPI was $54 \mathrm{~kW} / \mathrm{m}^{2}$. Such a high heat flux may be attributed to the fact that PI is highly thermally stable. This means that it does not decompose until enough heat is supplied for it to release combustibles, leading to ignition [8o].

PI (Kapton ${ }^{\circledR}$ ) has a documented LOI of $37 \%$ [8o]. Vertical burning test performed on both woven and knitted PI showed the absence of ignition when approached with a flame.

\section{Bismaleimide Resins (BMI)}

Bismaleimide resins are a subclass of thermosetting polyimides. They are a relatively recent class of addition curable polyimides which have become prominent in the field of high performance thermosetting polymers due to their unique qualities. They depict excellent mechanical and electrical properties in hot-wet environment, are relatively cheap, exhibit high thermal stability and processability, and are relatively cheap[81]. BMI resin is commercialized under the trade name Kerimid ${ }^{\circledR}$ by Huntsman.

One of the most widely used BMI building block is 4,4'-bismaleimidodiphenylmethane (MDABMA) combined with diallylbisphenol $\mathrm{A}[82]$. This is partly due to its high availability and low cost. However, most aromatic diamines can be converted to their corresponding bismaleimide. This suggests that there is a plethora of possible polymeric materials that can arise from BMI building blocks.

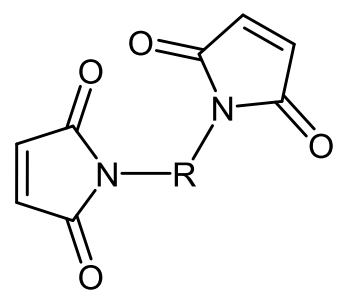

Figure 15. General structure of a bismaleimide monomer. $R=$ alkyl or aryl

The high thermal stability of BMI based materials comes from their highly crosslinked structures[83]. BMIs also present a few drawbacks such as brittleness due to its high crosslink 
density after curing, poor processability due to poor solubility in common solvents, high melting point, and a narrow temperature window for processing [81]. However, owing to the development of new monomers, new types of BMIs with improved properties have been synthesized [84]. An in-depth review discussing the different properties of a large variety of BMI based polymers has been carried out by Iredale et. al. recently [84].

\section{Concluding remarks}

Polyimides comprise of a rather wide range of thermally stable polymers. Their enhanced thermal stability is mostly due to their rigid and well-ordered heterocyclic aromatic backbones.

In terms of fire performances, PI only ignites when the incident heat flux is at $75 \mathrm{~kW} / \mathrm{m}^{2}$. This implies that the surface temperature of the polymer is as high as $890^{\circ} \mathrm{C}$. This is extremely high and enough to overcome the bond energy within the polymer backbone and release sufficient combustibles to ignite. Despite this high a heat flux, the peak of heat release rate is relatively low $\left(53 \mathrm{~kW} / \mathrm{m}^{2}\right)$.

Indeed, when looking at the reported decomposition behavior of PI, there is evidence of the formation of combustibles. However, the highly charring nature of PI means that relatively large portion of the polymer does not release combustibles. This could explain the relatively low burning rate of PI and its flame retardancy. 


\section{Polyamide-imide}

Polyamide-imides (PAI) are a class of amorphous high performance polymer, which can be either thermosetting or thermoplastic. The most widespread PAI is known under the tradename Torlon $^{\circledR}$, commercialized by Solvay Specialty Polymers. PAI exhibits exceptional thermal resistance and mechanical properties. It has the highest strength and stiffness of any thermoplastics up to $275{ }^{\circ} \mathrm{C}$ [85]. The general structure of a polyamideimide is shown on Figure 16.<smiles>CNC(=O)c1ccc2c(c1)C(=O)N([Te]C)C2=O</smiles>

Figure 16. Repeat unit of a typical PAI

\section{Synthesis}

There are two major routes reported for the synthesis of PAI: amide-imide forming reactions and reactions involving amide or imide-containing monomers.

Amide-imide forming reactions were the original pathways towards PAIs. This route makes use of trimellitic anhydride (TMA) or trimellitic anhydride chloride (TMAc) with a diamine [85] or with diisocyanate $[86,87]$. A reaction scheme using the diisocyanate and TMA is illustrated in Scheme 13.

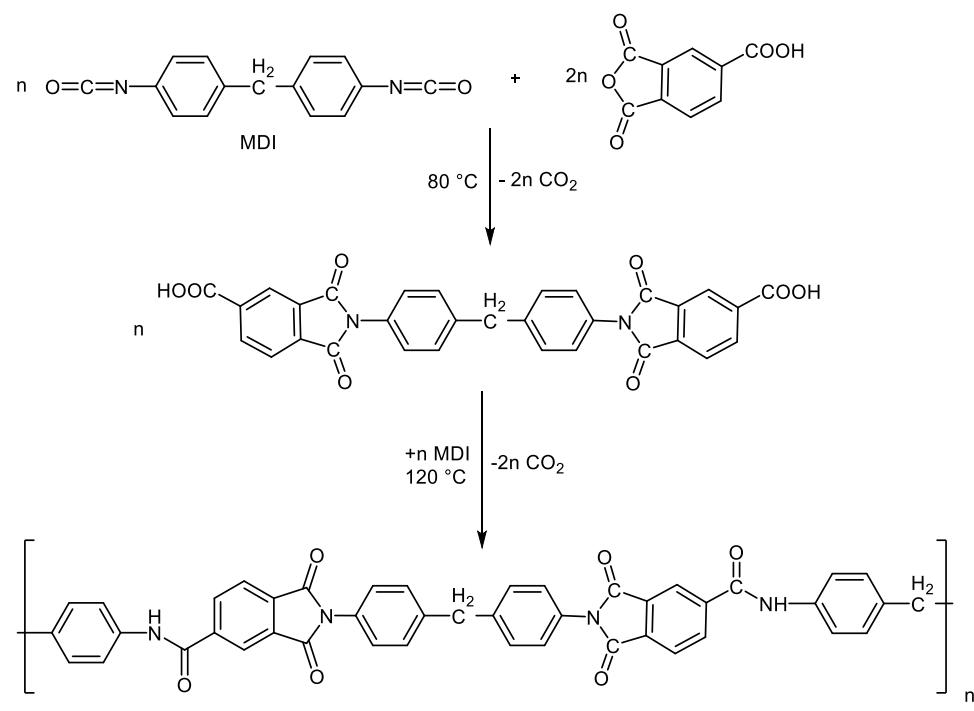

Scheme 13. Reaction scheme synthesis of PAI via diisocyanate pathway [88]

\section{Thermal properties}

Polyamide imides possess great thermal stability. The decomposition onset is at $450{ }^{\circ} \mathrm{C}$. It has a weight loss of $10 \mathrm{wt} \%$ at $540{ }^{\circ} \mathrm{C}\left(10{ }^{\circ} \mathrm{C} / \mathrm{min}\right.$ heating rate $)$ in air. Long term aging tests on the polymer performed at $250^{\circ} \mathrm{C}$ showed that only $10-20 \%$ drop in tensile strength over 10 ooo $\mathrm{h}$.

Thermogravimetric analysis on a commercial version of PAI (Torlon ${ }^{\circledR}$ ) was performed by Abbasi et al [89]. The thermal behavior of PAI was compared to PEI (polyetherimide). The TGA curve of neat PAI shows that the onset of the degradation occurs around $450{ }^{\circ} \mathrm{C}$. Under these 
conditions, the onset of the degradation of PAI occurs at a lower temperature than that of PEI. However, the rate of degradation is also slower.

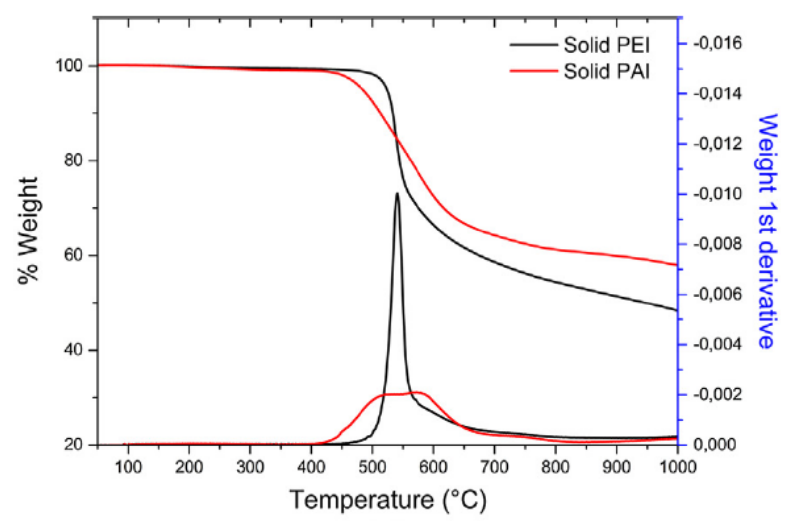

Figure 17. TGA plot of Torlon ${ }^{\circledR} \mathrm{PAI}$ and polyetherimide under nitrogen at a heating rate of $10{ }^{\circ} \mathrm{C} / \mathrm{min}[89]$

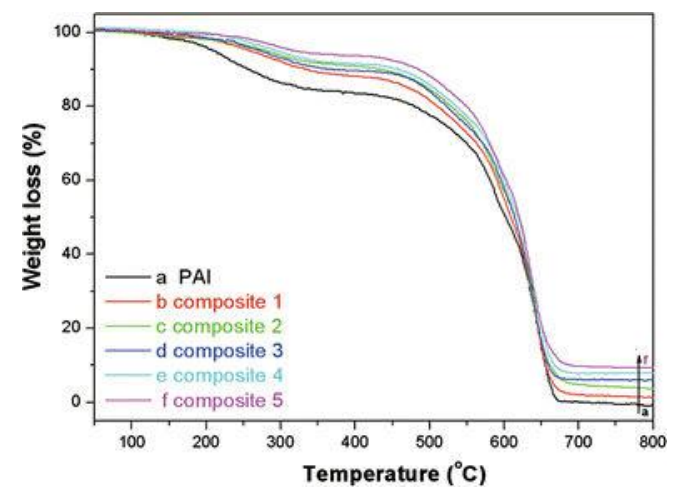

Figure 18. TGA of PAI and silica-based PAI nanocomposite films in air at a heating rate of $10{ }^{\circ} \mathrm{C} / \mathrm{min}$ [90]

The TGA of PAI in air (Figure 18) shows that there is a first degradation at around $200{ }^{\circ} \mathrm{C}$ and another major degradation step at $550{ }^{\circ} \mathrm{C}$. It is noteworthy that first degradation is not visible under nitrogen.

Pyrolysis gas-chromatography/mass-spectrometry performed on PAI at $800{ }^{\circ} \mathrm{C}$ and $1000{ }^{\circ} \mathrm{C}$ revealed that the major peaks were those of carbon dioxide, benzene and aniline, phenol, methylaniline, $1 \mathrm{H}$-isoindole-1,3 $(2 \mathrm{H})$-dione, 4-phenoxyaniline, 2-phenyl-1H-isoindole-1,3(2H)dione and 3,5-diphenyl-1,3,4-oxadiazol-2(3H)-one. This suggests that the degradation of PAI begins with the release of small molecules followed by condensation reactions that produce larger compounds.

Evolved gas analysis was also performed on PAI with a heating rate of $20{ }^{\circ} \mathrm{C} / \mathrm{min}$ under helium. It revealed that most of the decomposition products are evolved between 450 and $700{ }^{\circ} \mathrm{C}$.

Py-GC/MS at $600{ }^{\circ} \mathrm{C}$ revealed that there are some other pyrolyzates that are released at lower temperatures. These mostly correspond to isocyanates, cyanobenzene and phtalamide derivatives. The repeat unit of PAI was also identified among the decomposition products of PAI.[9o].

PAI is reported to thermally decompose via intramolecular scission. The activation energy for the pyrolysis is approximately $275 \mathrm{~kJ} / \mathrm{mol}$ [58].

\section{Fire behavior}

The heat of combustion of PAI is reported to be $19.3 \mathrm{~kJ} / \mathrm{g}$. The heat release rate of PAI when is ignites is $48 \mathrm{~kW} / \mathrm{m}^{2}[58]$. The ignition temperature of PAI is $526^{\circ} \mathrm{C}$ [58]. 
PAI has an LOI of $45 \% \mathrm{v} / \mathrm{v}$ and a V-o UL 94 rating. This implies that PAI does not readily burn in air nor does it sustain combustion when there it is approached by a flame. These two tests bring forward the inherent fire retardant nature of PAI. Moreover, the smoke extinction area of PAI is $120 \mathrm{~m}^{2} / \mathrm{kg}$, which is relatively low, as compared to polyethylene $\left(325 \mathrm{~m}^{2} / \mathrm{kg}\right)$ [58]. This means that in a fire scenario, PAI would release less than half the amount of smoke per unit mass of the polymer than would PE.

The critical heat flux for PAI is reported to lie between $40-50 \mathrm{kw} / \mathrm{m}^{2}$. This means that the polymer would not sustain ignition if it were exposed to a lower heat flux. This confirms the high fire resistance of PAI. Indeed, when compared to PA6, the critical heat flux is much lower (15$17 \mathrm{~kW} / \mathrm{m}^{2}$ ). This suggests that PA6 will readily sustain a flame if it is exposed to a heat flux above $\left.17 \mathrm{~kW} / \mathrm{m}^{2}\right)[76]$.

\section{Concluding remarks}

PAIs encompass a relatively wide variety of polymers. In this review, we have seen that PAI is thermally stable in nitrogen at temperatures above $450^{\circ} \mathrm{C}$. However, the decomposition it very different in air. It occurs in more than two steps, contrarily to the decomposition in nitrogen, which occurs one fast degradation step closely followed by another slow step. The early degradation of PAI in air may be attributed to the loss of water, which was absorbed in the polymer.

The Py-GC/MS of PAI has allowed the identification of its decomposition products at different temperatures. However, work still has to be done in order to elucidate a thermal decomposition mechanism in air or under inert atmosphere.

Evolved gas analysis confirms that under inert atmosphere, most of the volatile decomposition products evolve at temperatures superior to $450{ }^{\circ} \mathrm{C}$. More work has to be done in order to investigate the nature of the residual char that is left after the burning process of the material.

Few works study the fire performances of PAI. Using a micro scale calorimeter, non-flaming fire tests were performed on PAI and some combustion parameters were retrieved. Furthermore, the LOI test and the UL-94 rating suggest that PAI has great potential as a fire resistant polymer. 


\section{Polybenzoxazole fibers}

Poly(p-phenylene-2,6-benzobisoxazole) (PBO), known by its trademark Zylon ${ }^{\circledR}$, is a rigid rod isotropic liquid crystal polymer. It consists of a polybenzoxazole backbone containing an aromatic heterocyclic ring (Figure 19). It exhibits excellent flame resistance and thermal stability[91], solvent resistance, and remarkable tensile strength[92] and modulus[93].

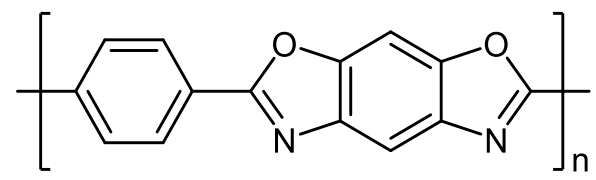

Figure 19. Structure of $P B O$

\section{Synthesis}

$\mathrm{PBO}$ is a rigid rod polymer made from lyotropic liquid crystal polymer solutions[93]. It is prepared using 2,6-diamino-1,3-benzenediol (DABDO) and terephtalic acid in polyphosphoric acid (PPA) as shown in the reaction scheme below.<smiles>CC(C)(C)c1ccc(-c2nc3cc4nc(C(C)(C)C)oc4cc3o2)cc1</smiles>

Scheme 14. Synthesis of PBO

This original reaction pathway was reported as being expensive in terms of preparation and purification[94]. Other reaction pathways for the synthesis of PBO have been devised since its first synthesis[92,95-97]. Due to the high viscosity and low solubility of PBO, a dry-jet, wet spinning technique is adopted for its production[98]. It was commercialized by Dow Chemical Company, using the patent license from Stanford Research institute (William, 1989 and 1990) and by Toyobo Co. Ltd.

\section{Thermal properties}

The thermal stability of PBO has been extensively studied in different atmospheres[99-101]. The glass transition temperature or melting temperature for PBO are unknown because PBO degrades before that. Therefore, these values are predicted to be above their degradation temperature (above $680^{\circ} \mathrm{C}$ ) [92].

A recent study on the thermal stability of $\mathrm{PBO}$ emphasized the difference of its thermal stability in air as compared to inert atmospheres. Indeed the onset of the degradation of PBO in air (610 $\left.{ }^{\circ} \mathrm{C}\right)$ is lower than in nitrogen $\left(634{ }^{\circ} \mathrm{C}\right)$. This is evidenced by the thermogravimetric analyses performed under the aforementioned atmospheres (Figure 20). In air, the peak rate of decomposition occurs at $646{ }^{\circ} \mathrm{C}$ whereas in nitrogen it is at $704{ }^{\circ} \mathrm{C}$. The residue at $900{ }^{\circ} \mathrm{C}$ is 3 $\mathrm{wt} \%$ and $16 \mathrm{wt} \%$ in air and nitrogen respectively. This indicates that oxygen has a significant impact upon the decomposition behavior of $\mathrm{PBO}[102]$. The data for the TGA of PBO are summarized in Table 15. 

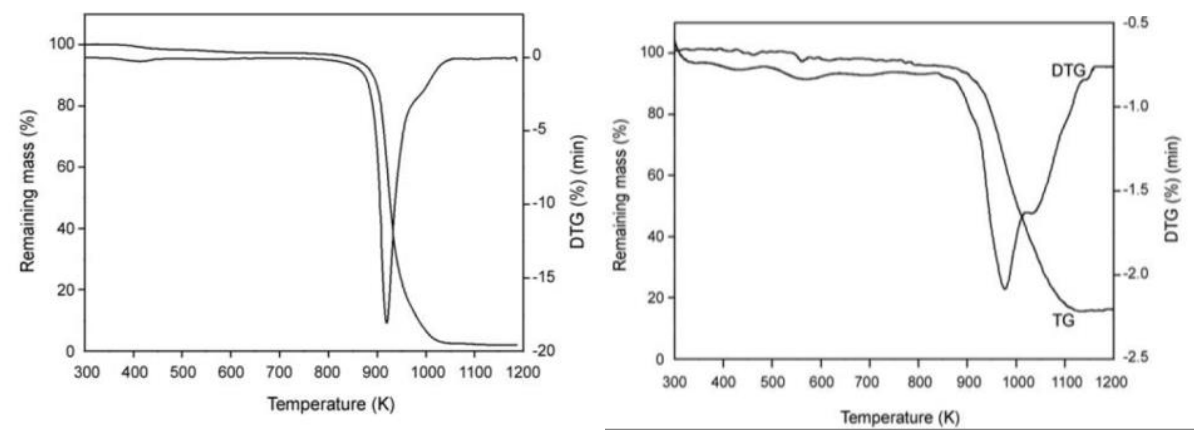

Figure 20. Thermogravimetric analysis of PBO under (left) nitrogen and (right) air with a heating rate at 10 ${ }^{\circ} \mathrm{C} / \min [102]$

Table 15. Thermal decomposition data for the degradation of PBO in air and nitrogen

\begin{tabular}{|c|c|c|}
\hline Decomposition data & Air & Nitrogen \\
\hline $\begin{array}{l}\text { Temperature at Peak } \\
\text { decomposition rate }\left({ }^{\circ} \mathrm{C}\right)\end{array}$ & $646[102], 610[103]$ & $704[102], 648[103]$ \\
\hline Residue at $900{ }^{\circ} \mathrm{C}(\mathrm{wt} \%)$ & $3[102]$ & $16[102]$ \\
\hline $\begin{array}{l}\text { Temperature at onset of } \\
\text { degradation }\left({ }^{\circ} \mathrm{C}\right)\end{array}$ & $610[102], 515$ [103] & $634[102], 557$ [103] \\
\hline $\begin{array}{l}\text { Temperature of half } \\
\text { decomposition }\left({ }^{\circ} \mathrm{C}\right)\end{array}$ & 683 [102], 615 [103] & $670[103]$ \\
\hline
\end{tabular}

Another paper aiming at understanding the thermal degradation of PBO utilized TGA simultaneously with differential scanning calorimetry. The DSC analysis showed that the decomposition of $\mathrm{PBO}$ in air is exothermic while that in nitrogen is endothermic. This brought even more light upon the influence of oxygen on the thermal degradation of PBO [91]. Oxidative degradation is suggested to be the weight loss process of PBO in air[104].
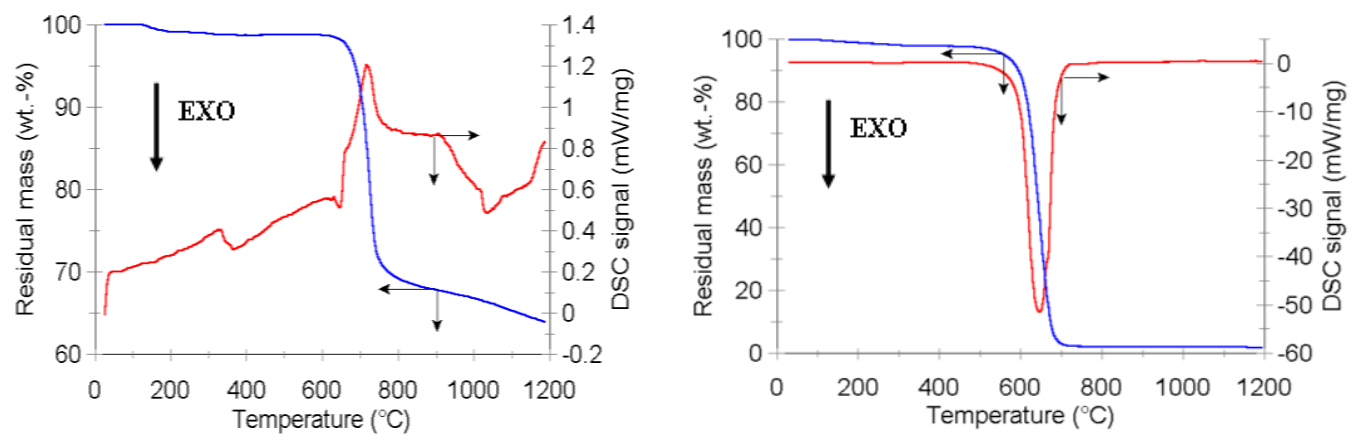

Figure 21. Simultaneous TG/DSC curves of PBO fibers under (left) nitrogen and (right) air with a heating rate at $10^{\circ} \mathrm{C} / \min [91]$

Isothermal aging study in air was also performed on PBO fibers[10o]. At $343{ }^{\circ} \mathrm{C}, 10 \%$ weight reduction was observed after 200 hours at this temperature. At $371{ }^{\circ} \mathrm{C}$, PBO retained $78 \%$ of its weight and at $316^{\circ} \mathrm{C}$, no weight reduction was observed, displaying its excellent thermal stability.

Moreover, the DSC curve of PBO under nitrogen shows a weak exothermal effect just before its degradation. This has been assigned to an increase in crystallinity of the fiber[104].

TGA data also allowed for the determination of the kinetic parameters of the thermal decomposition of PBO [100,105]. 
One of the former attempts at evaluating the Arrhenius parameters for $\mathrm{PBO}$ was carried out by Nielsen et al. in 1993 [10o]. Isothermal weight loss curves at different temperatures were plotted for $\mathrm{PBO}$. It was observed that the mass loss rate was close to zero at $500{ }^{\circ} \mathrm{C}$ but increased rapidly at $600{ }^{\circ} \mathrm{C}$. Arrhenius plots allowed for the comparisons of the weight loss rates of $\mathrm{PBO}$ with other polymers (Figure 22). The activation energy and pre-exponential factor for the thermal degradation of PBO, obtained by least squares analysis of data are reported in Table 16 [10o].

Table 16. Kinetic parameters calculated using Arrhenius plot at maximum weight loss rates at different temperatures [100].

\begin{tabular}{llll}
\hline Polymer & Atmosphere & $\begin{array}{l}\text { Activation energy } \\
(\mathrm{kJ} / \mathrm{mol})\end{array}$ & $\begin{array}{l}\text { Pre-exponential } \\
\text { factor }\left(\mathrm{s}^{-1}\right)\end{array}$ \\
\hline PBO & Nitrogen & 289 & $1.0 \times 10^{16}$ \\
PBO & Air & 163 & $6.5 \times 10^{10}$ \\
\hline
\end{tabular}
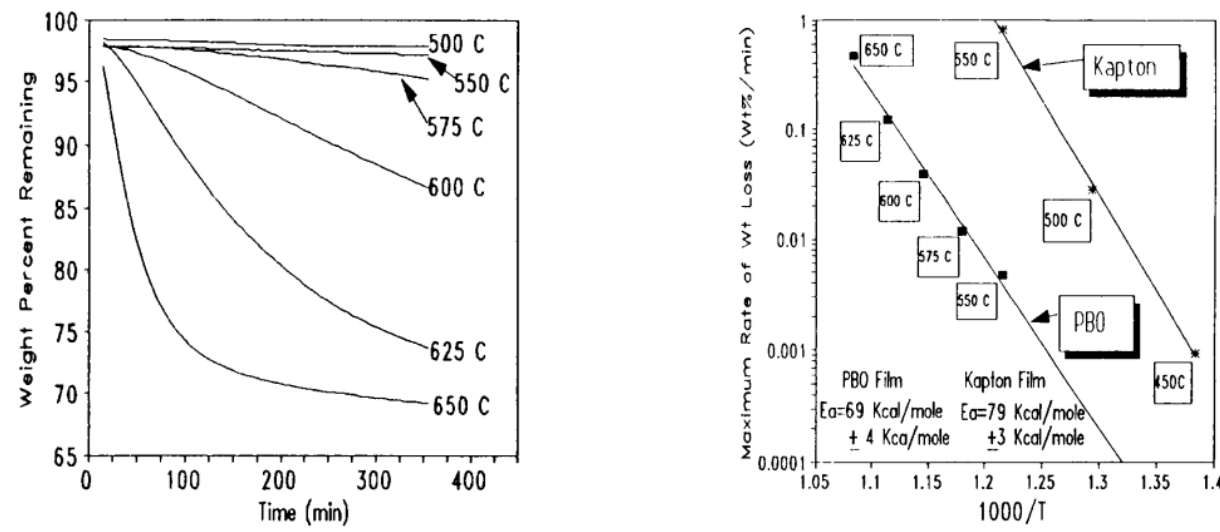

Figure 22. (left) Isothermal weight loss curve of PBO at different temperatures and (right) Arrhenius plots of maximum weight loss rate plotted against $1 / T\left(K^{-1}\right)[100]$

From the kinetic analysis, it was reported that $\mathrm{PBO}$ has a thermal degradation in air that seems to correspond to a Prout-Tompkins autocatalytic model process. However, further information regarding this assumption was not provided. This study allowed, to some extent, predictions of remaining $\mathrm{PBO}$ weight percent when subjected to an isothermal stress [100].

In a more recent study, Bourbigot et al thoroughly investigated the thermal behavior of PBO where TG analyses were performed at different heating rates in air and nitrogen. The invariant kinetic parameters (IKP) method was used to compute the invariant kinetic parameters of the thermal degradation of PBO [91]. As opposed to the kinetic analysis carried out by Nielsen et al, this method used a dynamic system whereby the temperature was not constant.

In the IKP method, a constantly changing temperature is used to derive the kinetic parameters. This is not the case for the first method, whereby the isothermal mass loss is observed. Both methods agree on the fact that more energy is required for the decomposition of PBO in nitrogen rather than in air. Moreover, the values obtained by both methods are in the same order of magnitude.

Table 17. Invariant kinetic parameters of PBO [91]

\begin{tabular}{llll}
\hline Atmosphere & $\begin{array}{l}\text { Invariant Activation } \\
\text { energy }(\mathrm{kJ} / \mathrm{mol})\end{array}$ & $\begin{array}{l}\text { Invariant Pre- } \\
\text { exponential factor }\left(\mathrm{s}^{-1}\right)\end{array}$ & $\begin{array}{l}\text { Temperature } \\
\text { range }\left({ }^{\circ} \mathrm{C}\right)\end{array}$ \\
\hline Nitrogen & 327 & $2.6 \times 10^{14}$ & $500-800$
\end{tabular}


In attempts at elucidating a decomposition mechanism of $\mathrm{PBO}$, the thermal decomposition products PBO needed to be analyzed. This has been studied via TG/FTIR[14], pyrolysis gaschromatography/mass-spectrometry (Py-GC/MS) [106], TG/MS [107], and Raman spectroscopy [102].

TG-FTIR, in air, was performed on PBO (Figure 23). The TG plot of PBO in air evidenced that the main mass loss occurs in the temperature range $550^{\circ} \mathrm{C}$ to $750^{\circ} \mathrm{C}$. Infrared spectra of evolved gases were recorded at different temperatures. From these, the main decomposition gases observed were $\mathrm{HCN}, \mathrm{NO}_{2}, \mathrm{CO}, \mathrm{CO}_{2}$, and water. The peaks of water and $\mathrm{CO}_{2}$ start to appear at $550^{\circ} \mathrm{C}$ whereas those of $\mathrm{HCN}, \mathrm{NO}_{2}$, and $\mathrm{CO}$ became more apparent as from $650^{\circ} \mathrm{C}$. It is suggested that complex chemical reactions occur at temperatures above $650{ }^{\circ} \mathrm{C}$. The infrared spectrum at $800{ }^{\circ} \mathrm{C}$ shows that there is a decrease in the peak intensity corresponding to water, $\mathrm{NO}_{2}$, and an increase in $\mathrm{CO}_{2}$ peak intensity. This increase of $\mathrm{CO}_{2}$ is attributed to the oxidation of heterocycles present in the polymer[106].

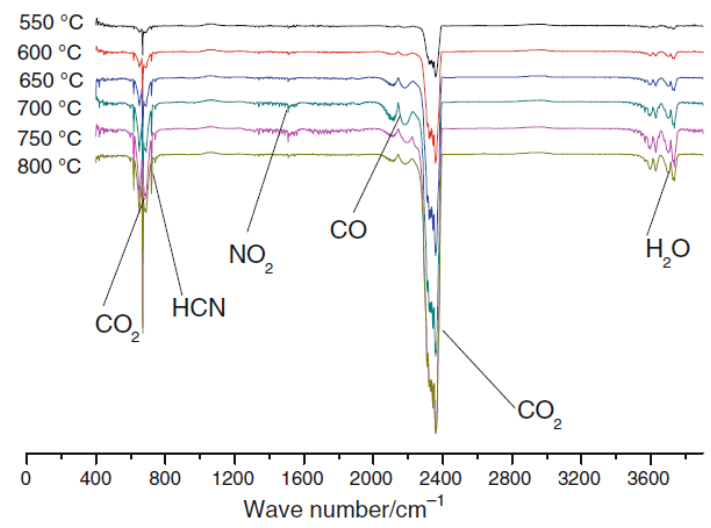

Figure 23. FTIR spectra of the degradation of PBO in air at different temperature[106]

FTIR is limited by its measurement nature. For instance, large degradation products such as monomer units of PBO cannot be accurately identified. Therefore, Py-GC/MS can be used to further analyze the degradation products of $\mathrm{PBO}$. $\mathrm{PBO}$ was pyrolyzed at $750{ }^{\circ} \mathrm{C}$ under inert atmosphere and the pyrolyzates were analyzed by GC/MS. A short pyrolysis time of $12 \mathrm{~s}$ was carried out. GC/MS only gives partial pyrolysates and do not take into consideration the possibility of the recombination of fragmented bonds during pyrolysis.

From the identified pyrolysis products of $\mathrm{PBO}$, it can be observed that carbon dioxide accounts for a major proportion of the thermal decomposition of PBO. However, PBO molecular chain was also recorded. In fact, it accounts for the highest peak area among the pyrolysates analyzed[108] (Table 18). This suggests that the main process occurring during its thermal decomposition is depolymerization reaction [106]. Another study regarding the pyrolysis products analysed by Py-GC/MS was also reported in 2008 [109]. The proportion of the monomer unit was higher ( $46 \%)$. This is coherent with the possibility that the degradation is ruled by depolymerization.

Table 18. Identified products from the pyrolysis and GC/MS of $P B O$ at $750^{\circ} \mathrm{C}$

\begin{tabular}{lll}
\hline Compound & Assigned Molecular Mass & Peak area (\%) \\
\hline $\mathrm{CO}_{2}$ & 44 & 23.8
\end{tabular}




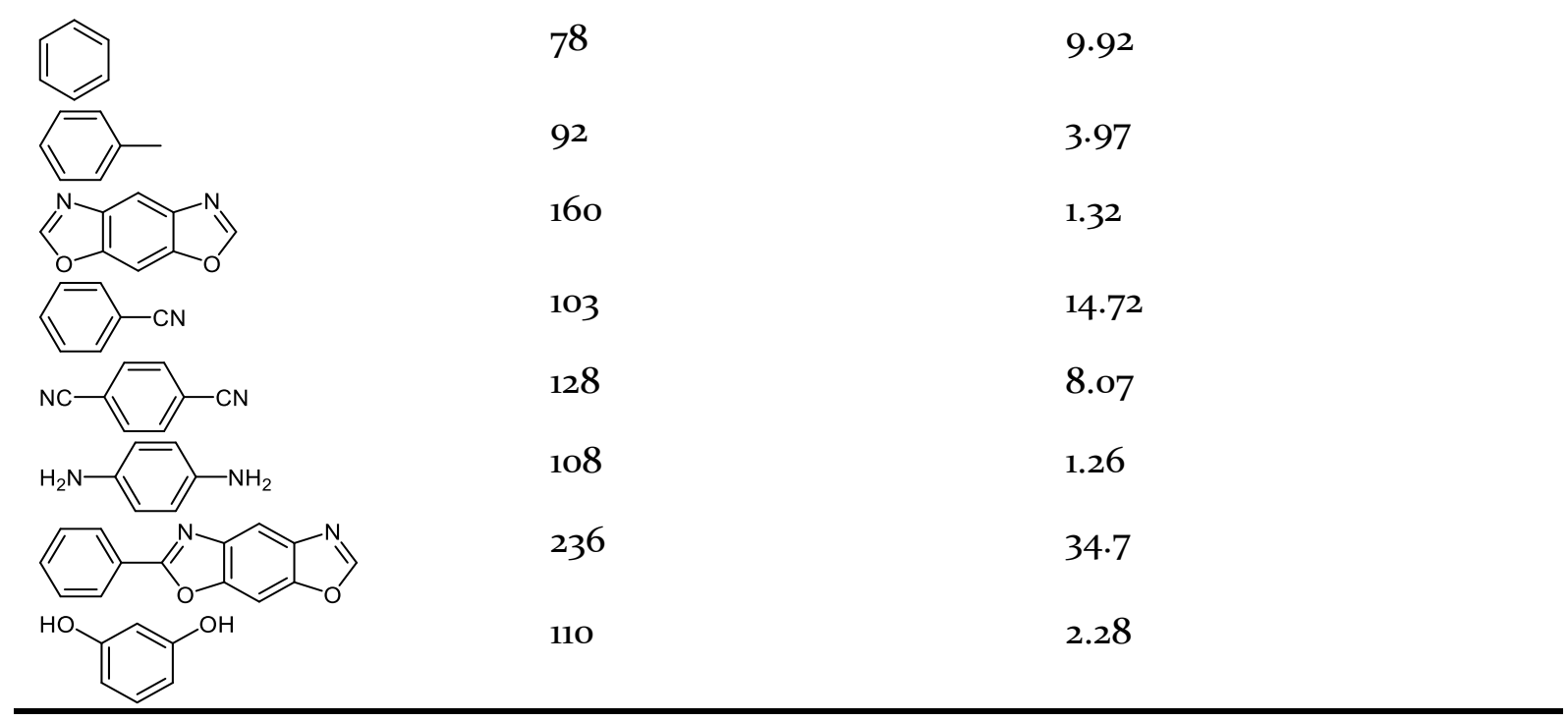

The thermal decomposition pathway has been further investigated by using model compounds. Fragments of thermal decomposition products of $\mathrm{PBO}$ were identified and the effect of endchain functional groups was studied[109]. These analyses, coupled with the use of ${ }^{13} \mathrm{C}$-enriched precursor for the synthesis of $\mathrm{PBO}$ to study its decomposition, a better understanding of the decomposition mechanism was achieved.

From the decomposition products identified using TG/MS and GC/MS, it was possible to suggest a tentative thermal degradation mechanism. Two modes of degradation were assumed.

The first mode consists of the homolytic scission of single bonds, which generate benzoxazole and phenyl radical (Scheme 15). The unstable benzoxazole radical is further fragmented. This produces aromatic nitrile and possibly $\mathrm{HCN}, \mathrm{CO}_{2}$ and $\mathrm{H}_{2} \mathrm{O}$ along with other hydrocarbons. The phenyl radical may graft onto another PBO molecule or abstract hydrogen to generate phenylbenzoxazole, producing benzonitrile and benzene.

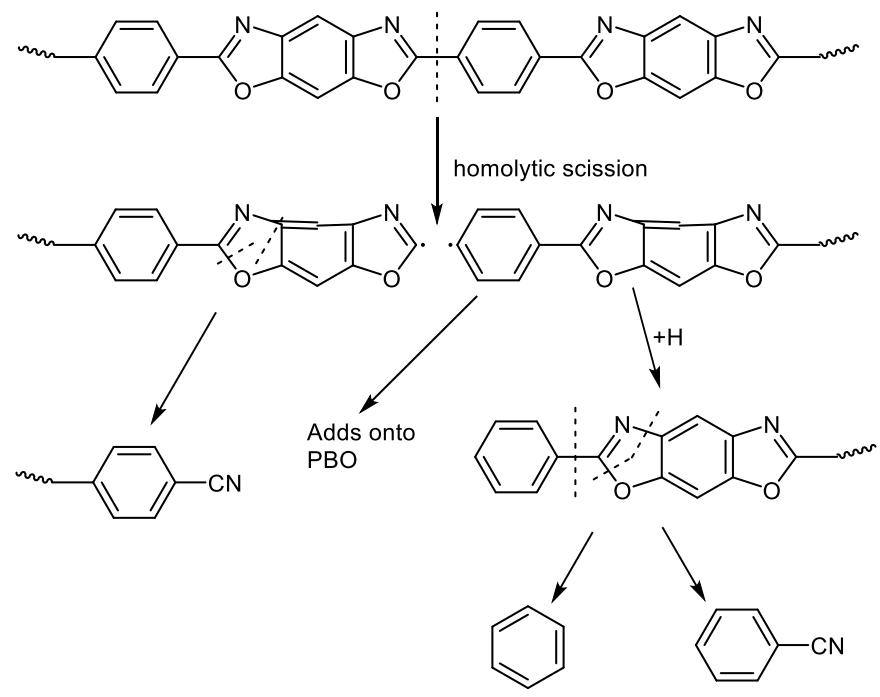

Scheme 15. Possible mode of thermal decomposition for PBO, initiated by the homolytic scission of C-C bond

The second mode of decomposition starts with the decomposition of the heterocyclic ring. This leads to the formation of a nitrile, which could generate benzonitrile, dicyanobenzene, and a diradical. The latter further fragments to form an aromatic nitrile and, possibly, $\mathrm{HCN}, \mathrm{CO}_{2}$, water and other small carbon compounds (Scheme 16). 


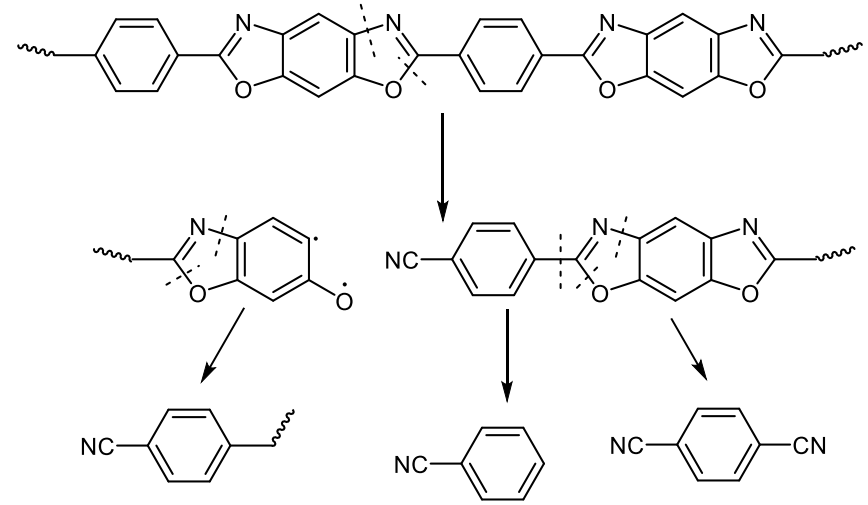

Scheme 16. Possible thermal degradation pathway for PBO with the decomposition of the heterocyclic ring [107]

Work on the study of the thermo-oxidative degradation of PBO was also reported. The first steps of the degradation reported was similar to the Scheme 15, consisting of the homolytic scission of single bonds. The study involved using Py-GC/MS to determine the decomposition products and coupling the results with TGA-DTA/MS to reach a plausible mechanism. The presence of oxygen caters for the oxidation of aromatics that are formed during the pyrolytic degradation of $\mathrm{PBO}$, leading to $\mathrm{CO}_{2}, \mathrm{H}_{2} \mathrm{O}$, and $\mathrm{NO}_{2}$.

\section{Fire behavior}

PBO has proved to have outstanding thermal stability as well as excellent oxidation tolerance.

Different studies have been carried out in order to evaluate the fire properties of PBO [91,110]. Cone calorimetry of knitted PBO fibers was compared with poly(p-phenylenediamineterephtalamide) fibers (PPTA). The experiment was carried out at two different heat flux (50 $\mathrm{kW} / \mathrm{m}^{2}$ and $75 \mathrm{~kW} / \mathrm{m}^{2}$ ). The cone calorimetry results showed that the peak of heat release rate of PBO under either heat flux is relatively low. In fact, it is one of the lowest heat release rates for a purely organic polymer.

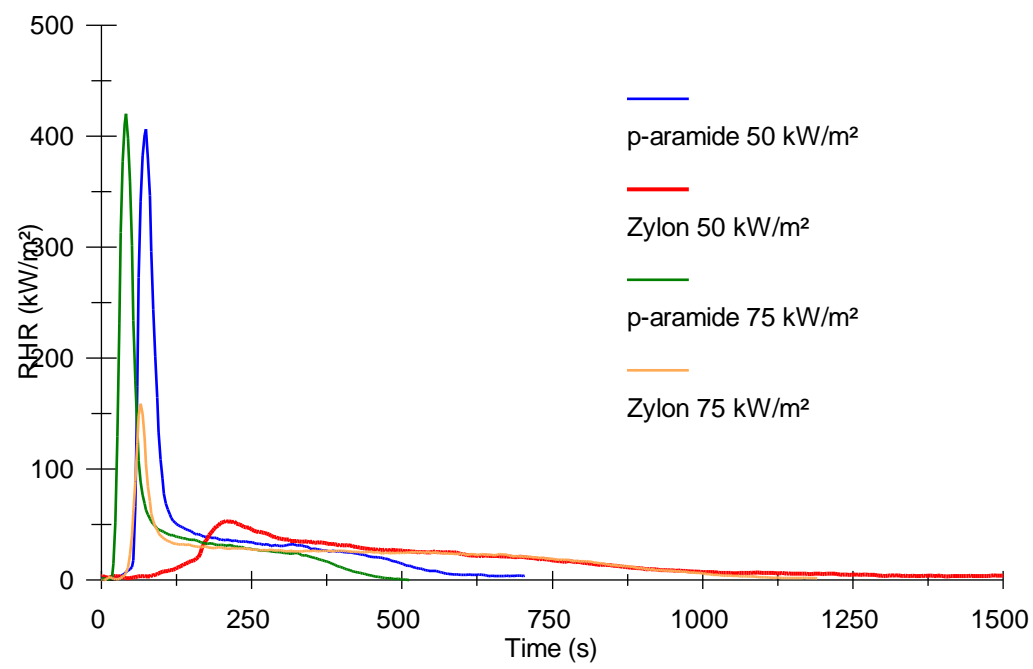

Figure 24. Rate of heat release curves of knitted PPTA and PBO fibers

The time to ignition of $\mathrm{PBO}$ with an external heat flux of $50 \mathrm{~kW} / \mathrm{m}^{2}$ is $56 \mathrm{~s}$ and the peak heat release rate is $60 \mathrm{~kW} / \mathrm{m}^{2}$ and $150 \mathrm{~kW} / \mathrm{m}^{2}$ [14]. This is extremely low for a polymer. For instance, the peak heat release rate of Kevlar, another high performance polymer reaches $400 \mathrm{~kW} / \mathrm{m}^{2}[111$. PBO burns with a small flame until the peak heat release rate is reached. After that, the fibers glow, leading to their degradation. The aspect of PBO before and after being subjected to an 
external heat flux is mostly unchanged. However, due to the degradation of the material, the mechanical properties are inexistent [91].

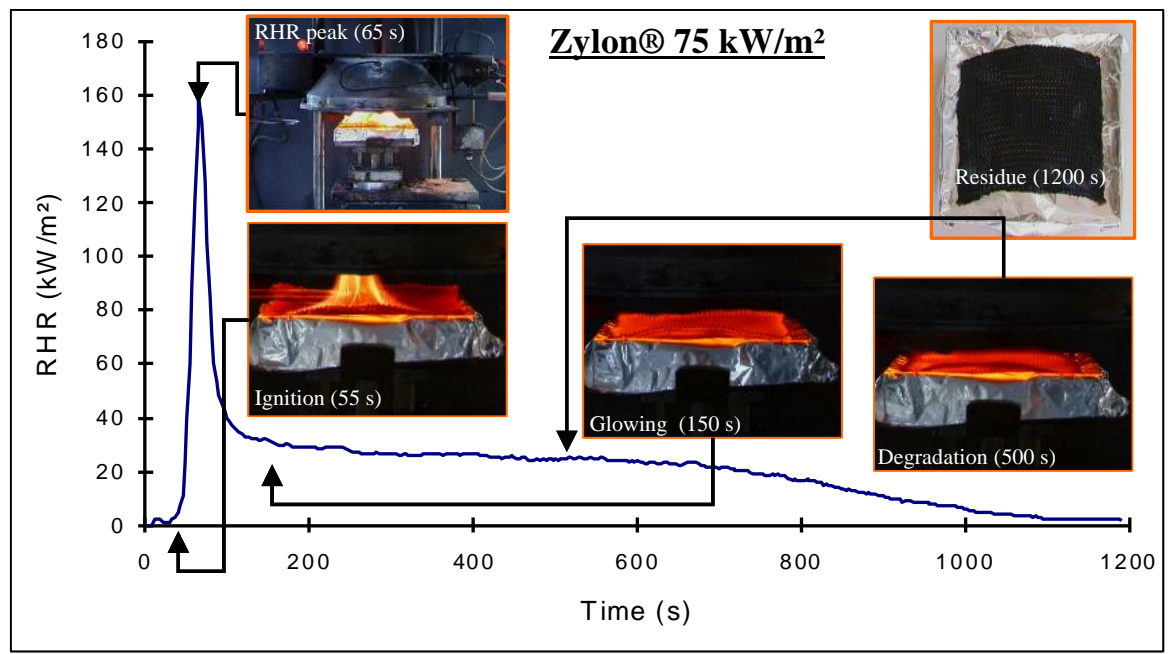

Figure 25. Reaction to fire of PBO fibers in cone calorimeter conditions with an external heat flux of $75 \mathrm{~kW} / \mathrm{m}^{2}[111]$.

However, when comparing the total heat released by $\mathrm{PBO}$ and p-aramid, it was reported that very close values were recorded. This may be due to the post-glowing phenomenon, which endured for the remaining duration of the test [111].

The fire growth rate (FIGRA) is a good indicator of the flame spread potential of a material. That of PBO is close to zero at $50 \mathrm{~kW} / \mathrm{m}^{2}$. With an external heat flux of $75 \mathrm{~kW} / \mathrm{m}^{2}$, the FIGRA of PBO peaks at $25 \mathrm{~W} / \mathrm{s}$. After this, the FIGRA decreases and remains close to zero [111].

Smoke density was also measured during the cone calorimetry test. The results showed that the smoke evolved during the combustion of PBO is low. This is evidenced in the volume of smoke production (VSP) curve, whereby the smoke obscuration of different polymers were tested during cone calorimetry tests with an incident heat flux of $75 \mathrm{~kW} / \mathrm{m}^{2}$ [111]. It can be observed that the VSP curve corresponding to PBO remains close to zero.

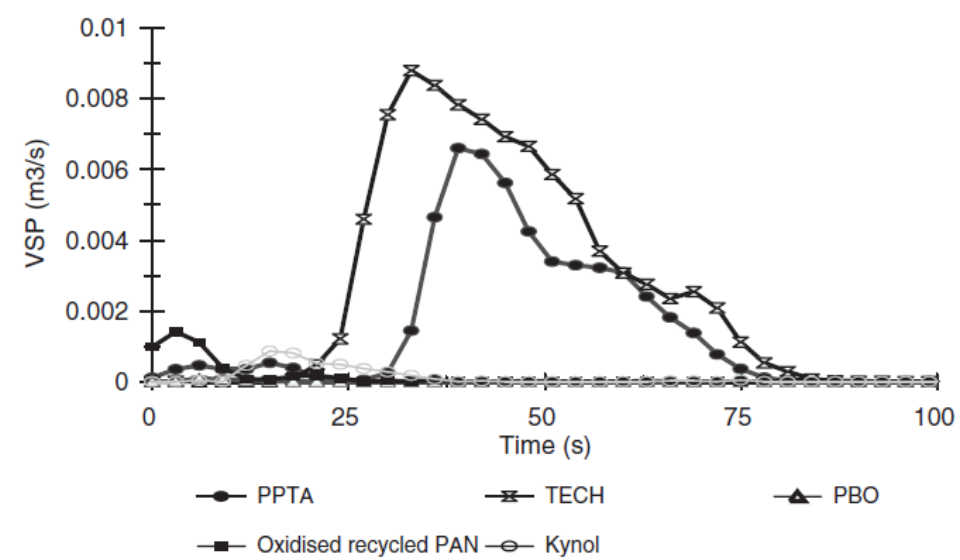

Figure 26. VSP curves (external heat flux $=75 \mathrm{~kW} / \mathrm{m}^{2}$ ) of some knitted fibers, including PBO [111] 


\section{Concluding remarks}

Polybenzoxazole fibers are rigid rod polymeric materials with very well-ordered structure. As with most rigid rod polymeric materials, this accounts for their excellent thermal properties.

The study of the decomposition mechanism of PBO has led to the conclusion that the major mechanism corresponds to depolymerization of the neat polymer. This implies that there are few volatile combustibles released when the polymer decomposes. This could explain why peak of heat release rate is relatively low when the material is tested with a cone calorimeter. Moreover, PBO has shown that it has a tendency to char when it degrades. This means that the depolymerization decomposition reaction is also accompanied with some crosslinking. This, coupled with a low release of combustibles might explain the excellent results from the cone calorimeter tests. Indeed, the formation of a char between the radiation source and the inner part of the material may protect the later from further decomposing.

However, the highly exothermic peak in the differential scanning calorimetry means that the presence of oxygen has a strong influence on the degradation of $\mathrm{PBO}$. This implies that in air, the high temperature resistance of PBO is greatly diminished.

The low heat release rate and almost inexistent smoke obscuration make PBO an excellent candidate for high performance fibers. 


\section{Polybenzimidazole (PBI)}

Polybenzimidazoles are a class of high performance heterocyclic polymers. Aliphatic polybenzimidazoles were first synthesized by Robinson and Brinker in the late 1950s[112]. However, it was not until 1961 that the first aromatic PBI was synthesized by Vogel and Marvel [113]. Hoechst Celanese commercialized a polybenzimidazole fiber for thermal protective clothing and fire blocking applications in 1983. The most commercially available polybenzimidazole on the market is poly(2,2'-(m-phenylene)-5,5'bibenzimidazole) (Figure 27, referred to as PBI) under the trade name Celazole. PBI is reported to have the highest compressive strength among all high performance, commercially available thermoplastics. Nowadays, PBI Performance Products Inc. is the major producer of high performance PBI materials.

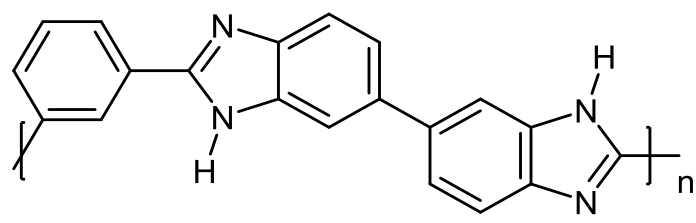

Figure 27. Structure of poly(2,2'-(m-phenylene)-5,5'bibenzimidazole) (PBI)

PBI is typically synthesized via a condensation reaction of aromatic bis-o-diamines and dicarboxylates. The benzimidazole moiety is the repeating unit of the molecular backbone of the polymer.

\section{Synthesis}

Poly[2,2'-( $m$-phenylene)-5,5'-bibenzimidazole] (PBI) is the most studied commercially available polybenzimidazole. It is prepared from tetraminobiphenyl, $\mathrm{TAB}$, with diphenylenephtalate, DPIP.

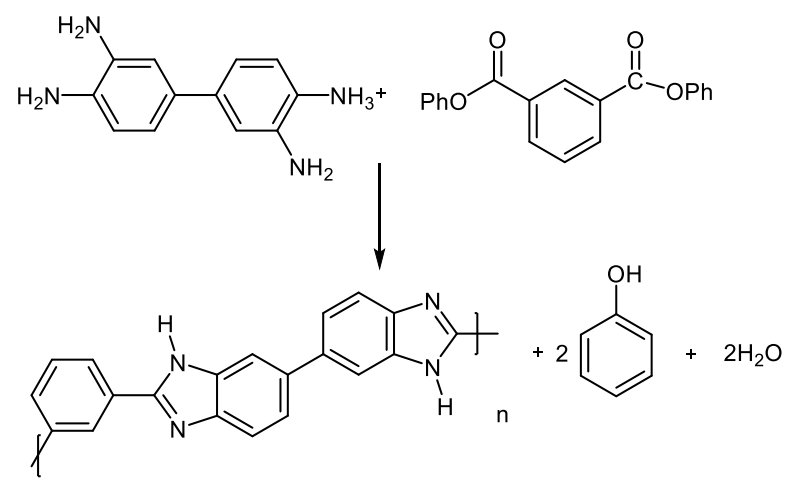

Scheme 17. Synthesis of PBI

The commercial production of PBI is a two-stage process; both required a controlled, inert atmosphere. The first stage involves the melting of DPIP which solubilizes TAB. Increase in temperature initiates the polymerization, generating phenol and water. This causes the formation of a foam brittle foam. The second stage consists of crushing the foam to obtain the powdered polymer.

\section{Thermal Properties}

PBI has excellent thermal properties and flame resistance. It has a glass transition temperature of $425{ }^{\circ} \mathrm{C}$. It is reported that the polymer decomposes before melting. PBI has the highest mechanical property retention over $205^{\circ} \mathrm{C}$ among all unfilled resins. 
When it comes to short-term use, PBI can be exposed to $450{ }^{\circ} \mathrm{C}$ (approximately 10 min exposure time). For long-term exposures in air ( $>200 \mathrm{~h}$ ) the maximum temperature capability is reported to be $320^{\circ} \mathrm{C}[13]$.

TG analyses in air at a heating rate of $10^{\circ} \mathrm{C} / \mathrm{min}$ has shown that the polymer does not decompose until $500{ }^{\circ} \mathrm{C}$. Under inert atmosphere, the thermal stability is increased to $600{ }^{\circ} \mathrm{C}$ (Figure 28 ).

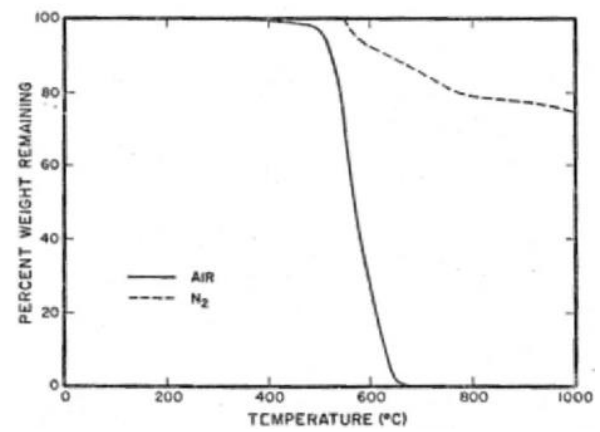

Figure 28. Thermogravimetric analyses on PBI at a heating rate of $10^{\circ} \mathrm{C} / \mathrm{min}$ in air (__ ) and under nitrogen (- - -) [114]

The TGA plots suggest that loosely bound water is not readily released from the polymer. The polymer keeps its initial weight until around $375{ }^{\circ} \mathrm{C}$, whereby a small mass loss is observed. In air, a slow decomposition starts at around that temperature, followed by a rapid degradation above $500{ }^{\circ} \mathrm{C}$. The sample was completely degraded at $700{ }^{\circ} \mathrm{C}$. However, under nitrogen, it kept its initial weight until $550^{\circ} \mathrm{C}$. A slow weight loss is observed at this temperature onwards.

This is further evidenced when the DTG curves are analyzed (Figure 29). Indeed, two peaks are observed on the DTG curve of PBI under nitrogen. The first peak is relatively narrow and has a maximum at $570{ }^{\circ} \mathrm{C}$ and the other is a broad peak, which starts at around $575{ }^{\circ} \mathrm{C}$ and continues until $825^{\circ} \mathrm{C}$.

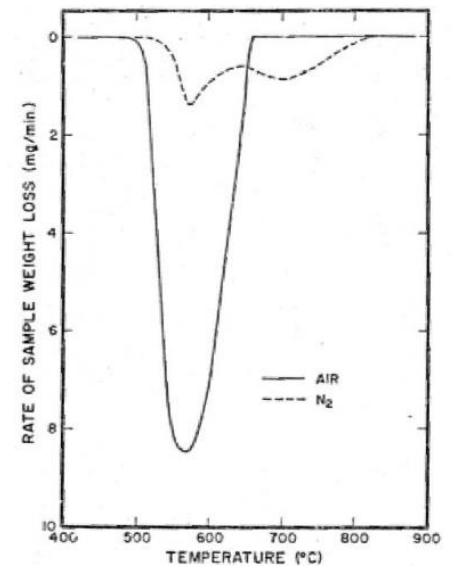

Figure 29. DTG plot of PBI in air (__ ) and under nitrogen (- - -)[114]

At $570^{\circ} \mathrm{C}$, the mass loss recorded on the TG curve is only $3 \%$. Papers suggest that this could be due to terminal or end group losses of light compounds such as hydrogen followed by further condensation of the polymer[115].

The second weight loss accounted for $23 \%$ of the total weight of the polymer. It is suggested that this degradation step corresponded to further condensation process resulting from extensive chemical rearrangement[69].

From the differential thermal analyses (Figure 30) and the derivative thermogravimetric (Figure 29) analysis of PBI in air and under nitrogen, it can be deduced that oxygen plays a significant 
role in the thermal degradation of PBI. Indeed, under nitrogen, the thermal decomposition of PBI is slightly endothermic. However, non-flaming oxidative degradation of PBI was exothermic, with a peak at $570{ }^{\circ} \mathrm{C}$. In addition, the DTG of PBI in air shows a mass loss rate at $570{ }^{\circ} \mathrm{C}$, which is approximately 6 times higher in air than under nitrogen with the same heating rate [114].

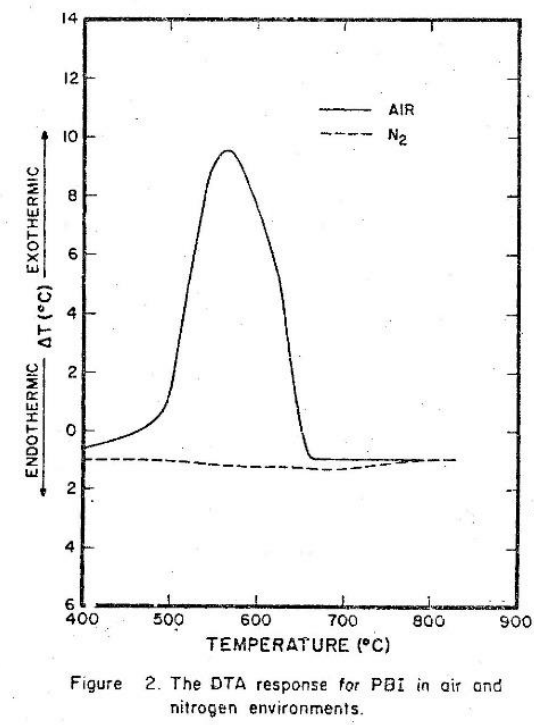

Figure 30. Differential thermal analysis (DTA) response of PBI in air (__ and under nitrogen (- - -) [116]

Isothermal thermogravimetric analyses in air and under nitrogen were also performed on PBI at temperatures from $200{ }^{\circ} \mathrm{C}$ to $350^{\circ} \mathrm{C}$ (Figure 31). The rate of weight loss at these temperatures are relatively low both in oxidative and inert atmospheres[117].
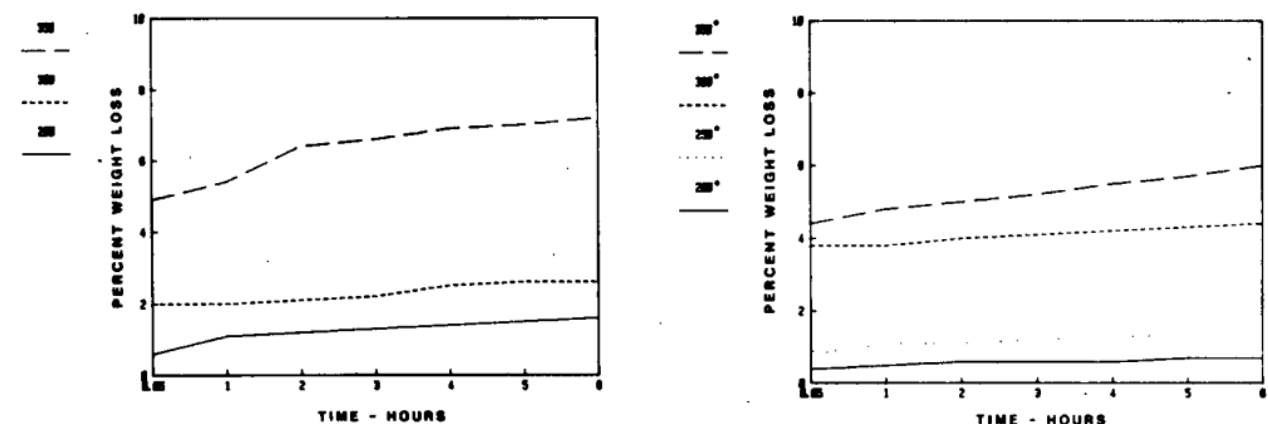

Figure 31. Isothermal TGA of PBI in air (left) and under nitrogen (right) [117].

A detailed study of the thermal degradation of PBI has been carried out by Chatfield et al[116]. Stepwise pyrolysis of PBI was carried out at 570,700 and $1000{ }^{\circ} \mathrm{C}$. The mass loss (of the original weight) during each step is summarized in Table 19. The total mass lost was $30.6 \%$. The additional $3.6 \%$ corresponds to the elimination of water occurring at $100{ }^{\circ} \mathrm{C}[116]$.

Table 19. Summary of weigh lost during stepwise degradation of PBI

\begin{tabular}{ll}
\hline $\begin{array}{l}\text { Temperature } \\
\text { range }\left({ }^{\circ} \mathrm{C}\right)\end{array}$ & Mass lost $(\%)$ \\
\hline $300-570$ & 2.3 \\
$570-700$ & 13.3 \\
$700-1000$ & 11.4 \\
\hline
\end{tabular}


There are other papers concerning the thermal behavior of PBI[116]. The study of the kinetics of the thermal decomposition of PBI was attempted by Wrasidlo et al. in 1964 [118] and by Schulman and Lochte in 1967 [119]. They used of isothermal kinetics, thermogravimetry, and mass-spectrometric thermal analysis (MTA) to determine the kinetic parameters of the thermal degradation of PBI. It was concluded that the decomposition of PBI occurred in two steps and a tentative degradation pathway was suggested (see mechanism of decomposition, Scheme 18).

Schulman and Lochte reported the difficulty in reaching accurate results of kinetic parameters due to the complex decomposition pattern of PBI. Firstly, being a highly temperature resistant polymer, PBI still exhibits significant residual weight at $1000{ }^{\circ} \mathrm{C}$. In addition, PBI has a hygroscopic and resistant to drying nature, making it complicated to be certain of its initial weight. Indeed, depending on the amount of water that is absorbed in the polymer, the weight loss due to water may greatly vary. This makes the identification of the different decomposition steps tricky. This is observable on the TG curve- PBI decomposes via many steps; therefore, the activation energy depends on the temperature.

The energy for the formation of individual degradation products were determined form Arrhenius plot and were used to find an average activation energy for the thermal decomposition of PBI. The average activation energy was somewhat temperature dependent.

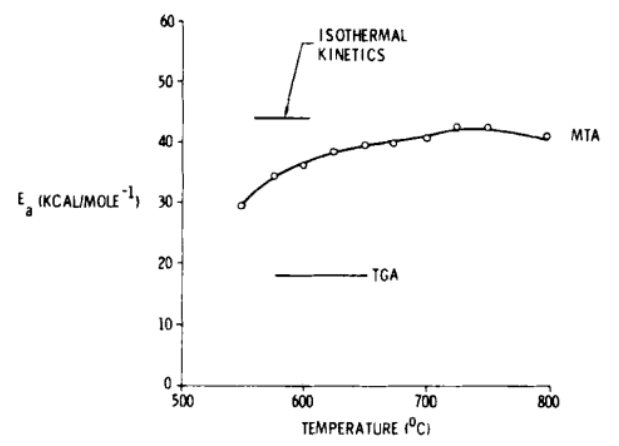

Figure 32. Temperature dependence of the activation energy for the thermal decomposition of PBI [119]

It was concluded that below $720{ }^{\circ} \mathrm{C}$, the activation energy of the thermal degradation of PBI is $75 \mathrm{~kJ} / \mathrm{mol}$. The rate constant of the degradation decreases above this temperature and was observed to be $142 \mathrm{~kJ} / \mathrm{mol}$. This is coherent with a two-stage reaction, whereby the second step corresponds to final dehydration step of the polymerization being the main low temperature reaction. This is accompanied by slow degradation, which is the principal reaction when polymerization is completed [119].

The degradation products were separated via a gas chromatography and were identified using mass spectrometry. A possible degradation pathway based on hydrolytic ring opening was suggested[119]. However, a more recent literature review simplified the originally proposed mechanism for the formation of HCN [120] (Scheme 18).

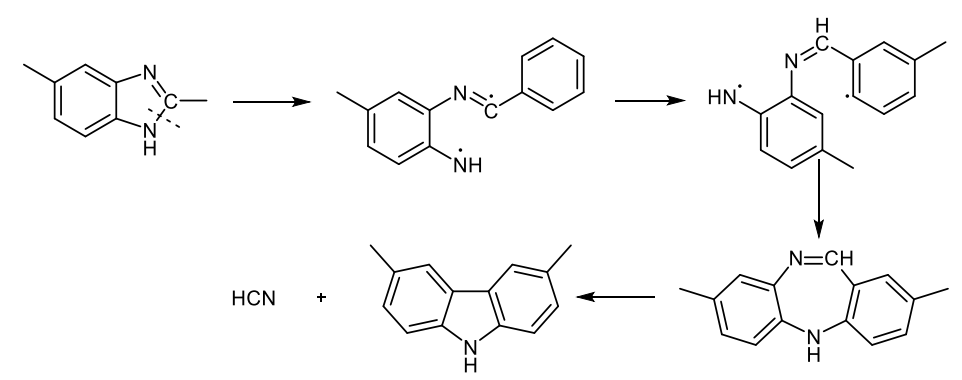


The mechanism suggests that the lower energy carbon-nitrogen bond undergoes homolytic scission, leading to a diradical. This highly unstable configuration would abstract a hydrogen on an adjacent phenyl group. Subsequently, a new ring unit can be formed, eliminating HCN in the process [119]. Further thermal decomposition of this relatively stable and would decompose at high temperatures, fracturing the phenyl group, yielding small fragments such as methane and amines.

\section{Fire properties}

PBI fiber does not sustain burning in air. This is evidenced by its limiting oxygen index of $41 \%$ [119]. Later studies on "newer" versions of the polymer have found a limiting oxygen index of 58 \% by $\mathrm{D}_{2863}$ ASTM test[122]. PBI was tested in a Flame Tunnel Test (ASTEM-84), there was no smoke developed, not any fuel contribution to the flame. The char length from the Vertical Burn Test (FSTM 191-5903) was 0.3 inches $(76.2 \mathrm{~mm})$.

Tests performed in a fire calorimeter has brought about some properties regarding the fire performances of PBI. The mass loss rate at the ignition is reported to be $1.5 \mathrm{~g} / \mathrm{m}^{2} \mathrm{~s}$ with and a heat release rate of $24 \mathrm{~kW} / \mathrm{m}^{2}$ at ignition. This value is relatively high, considering that it is a high performance polymer (HRR at ignition for PEEK $=15 \mathrm{~kW} / \mathrm{m}^{2}$ ). However, the effective heat of combustion of PBI is $16.2 \mathrm{~kJ} / \mathrm{g}$ which is less than half of that of neat polyethylene $(40 \mathrm{~kJ} / \mathrm{mol})$. PBI also has a UL-94 Vo rating [123]. The smoke extinction area of PBI is $100 \mathrm{~m}^{2} / \mathrm{kg}$, a relatively low value when compared to polyethylene $\left(325 \mathrm{~m}^{2} / \mathrm{kg}\right)$ or polystyrene $\left(1150 \mathrm{~m}^{2} / \mathrm{kg}\right)$ [58].

\section{Concluding remarks}

PBI has one of the highest glass transition temperatures among organic polymers. It has a rigid aromatic structure and neither burns nor sustains burning when removed from a flame. It has a high LOI and is classified as Vo under the UL-94 test.

Thanks to the char forming nature of the polymer, PBI maintains its integrity when exposed to an external heat flux. This char formation protects the polymer from further incident heat flux, making it highly flame resistant.

DSC analysis leads to believe that oxygen has a strong influence on the degradation of PBI. Indeed, the degradation of PBI under air releases much more energy than the amount of energy it absorbs when pyrolysis is performed on it.

The significant remaining mass after thermal tests show that PBI has strong thermal stability. This also makes the study of the degradation more complex because there are more than one degradation pathways that are competing with each other.

Therefore, a thorough mechanistic study is needed in order to clarify the degradation mechanism of PBI as well as extract the kinetic parameters of its thermal degradation. 


\section{Polypyridobisimidazole (PIPD or $\mathrm{M}_{5}$ )}

Polypyridobisimidazole (PIPD or M5), formally poly(2,6-diimidazo[4,5 b:4',5' e]pyridinylene-1,4(2,5dihydroxy)phenylene) is a relatively recent polymer in the rigid rod polymer family[124]. It was first developed by Akzo Nobel Central Research and is now developed by Magellan Systems. PIPD has a structure that is close to $\mathrm{PBO}$ with the exception of -OH functional groups present in PIPD (Figure 33). This allows for inter-chain hydrogen bonding, giving it extremely high compression strength. PIPD has a promising array of potential applications such as personnel protection, fire resistance, advanced composite materials and advanced fabrics.<smiles>CC(C)(C)c1nc2cc3[nH]c(-c4cc(O)c(C(C)(C)C)cc4O)nc3nc2[nH]1</smiles>

Figure 33. Repeat unit of Polypyridobisimidazole PIPD (M5)

\section{Synthesis}

The first synthesis of PIPD was carried out by researchers at Akzo Nobel and Co. in 1998. A schematic representation of the formation of PIPD is shown in the scheme below.

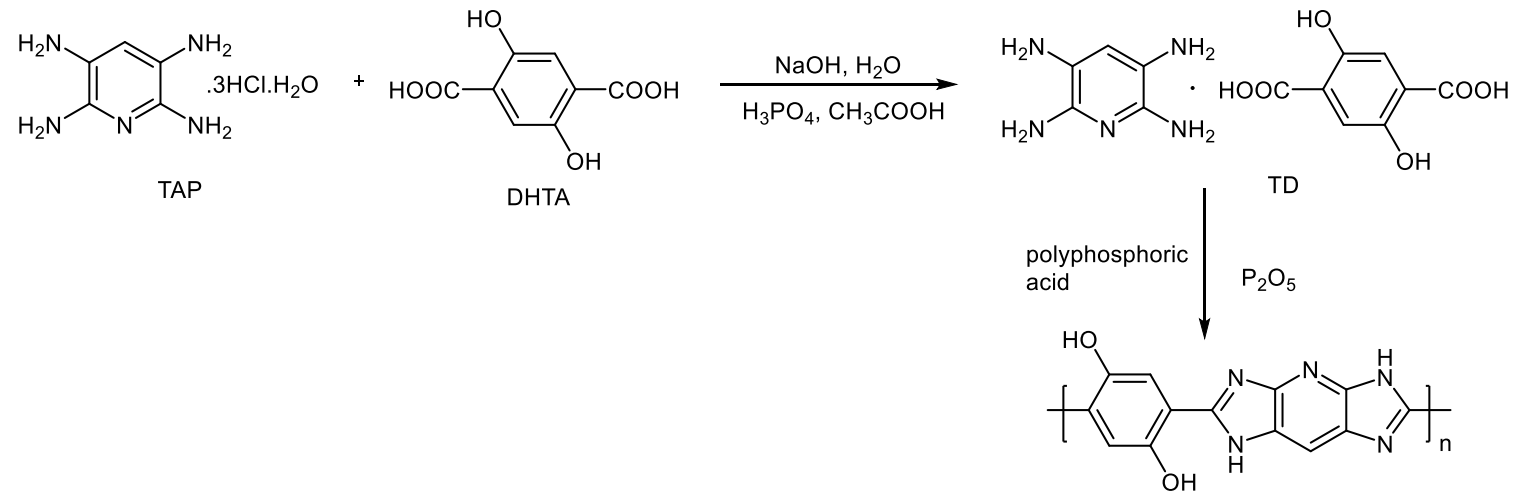

Scheme 19. Preparation of PIPD from TAP and DHTA

The polymerization reaction involves 2,3,5,6-tetraaminopyridine (TAP) and 2,5dihydroxyterephtalic acid (DHTA) to form 2,3,5,6-tetraaminopyridine 2,5dihydroxyterephtalate (TD salt) as a reaction intermediate (Scheme 19). The obtained dopes are spun into fibers, usually via dry jet wet-spinning process[5].

\section{Thermal properties}

PIPD is reported to have high thermal stability. This is due to its rigid chain molecular structures. The thermal decomposition of PIPD in air is reported to be around $530{ }^{\circ} \mathrm{C}$ [125]. Bourbigot et al. have studied the degradation of PIPD via thermogravimetric analysis in air and under inert atmosphere[126].

From thermogravimetric analysis, it was observed that PIPD was highly sensitive to oxygen. In thermos-oxidative conditions, PIPD decomposes between $450^{\circ} \mathrm{C}$ and $650{ }^{\circ} \mathrm{C}$, leaving a residue of about $4 \mathrm{wt} \%$. 


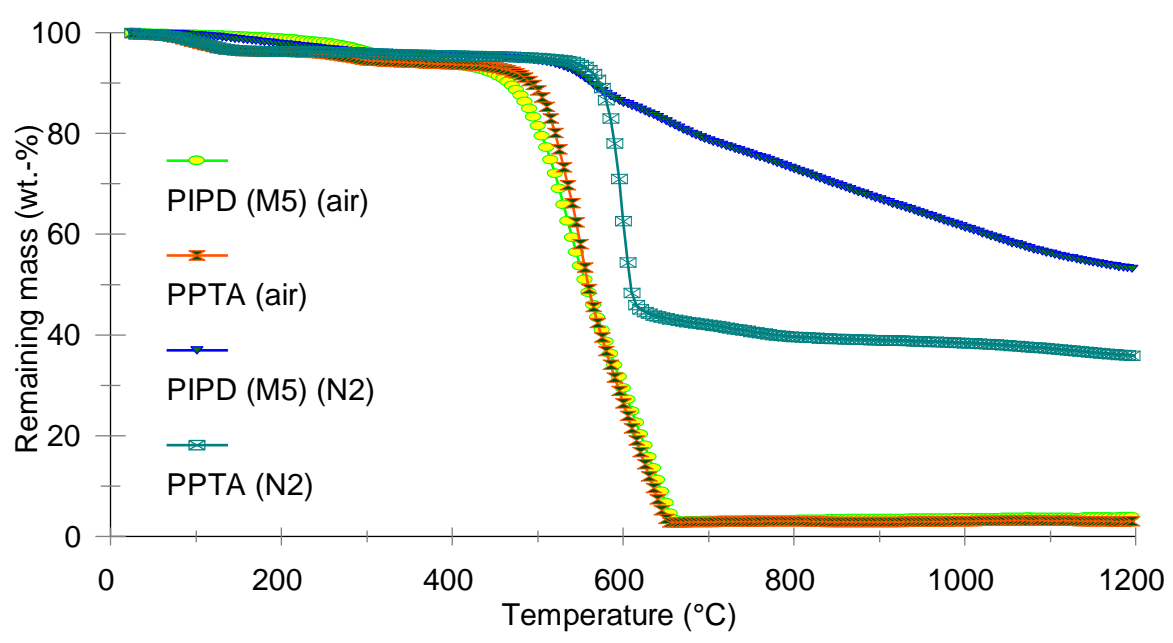

Figure 34. TG curves of PIPD (M5) and PPTA under air flow and nitrogen flow at a heating rate of $10{ }^{\circ} \mathrm{C} / \mathrm{min}[126]$

Under nitrogen, the thermal decomposition of PIPD starts at approximately the same temperature as it does in air. However, the rate of degradation is much slower. This can be observed on the TG curve (Figure 34). The residue formed at $1200{ }^{\circ} \mathrm{C}$ corresponds to $55 \mathrm{wt} \%$ of the original mass of PIPD.

Thermogravimetry coupled with differential scanning calorimetry (in air) was also performed on PIPD (Figure 35). The results showed that the degradation of PIPD fibers is highly exothermic and is due to thermo-oxidative degradation. The enthalpy of decomposition of PIPD is reported to be around $-17 \mathrm{~kJ} / \mathrm{g}$.

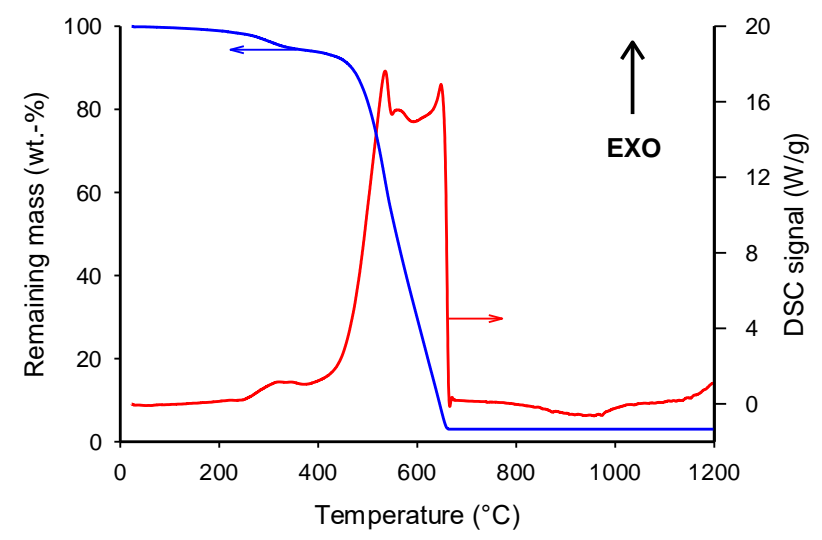

Figure 35. Simultaneous TG/DSC curves of PIPD fiber at a heating rate of $10{ }^{\circ} \mathrm{C} / \mathrm{min}$ in air [126]

\section{Fire behavior}

PIPD exhibits excellent fire performances due to its rigid rod structure, not unlike PBO. This is partly due to its non-existent melting point, its rigid chain, and the strength of its chain-to-chain interaction.

PIPD does not burn in air and is self-extinguishing. It has a documented LOI superior than 50 vol\%. Cone calorimeter test give outstanding results. With an external heat flux of $75 \mathrm{~kW} / \mathrm{m}^{2}$, the peak of heat release rate (pHRR) of PIPD is $50 \mathrm{~kW} / \mathrm{m}^{2}$ and the time to ignition (TTI) is $77 \mathrm{~s}$. For comparison purposes, it is interesting to note that the pHRR and TTI of PBO is $48 \mathrm{~kW} / \mathrm{m}^{2}$ and $56 \mathrm{~s}$, and in the case of p-aramid pHRR $=300 \mathrm{~kW} / \mathrm{m}^{2}$ and TTI $=20 \mathrm{~s}$. Upon burning, PIPD fibers form a char, which remains at the surface of the fiber[5]. This means that the fiber is partly protected from incident heat flux. One explanation of such excellent heat properties may be the fact that the crystal structure of PIPD contains around $21 \%$ water[124]. 
A thorough fire performance investigation comparing PIPD and PPTA has been carried out by Bourbigot et al.[127]. The HRR curve is given in Figure 36. The heat release rate when PIPD is subjected to $75 \mathrm{kw} / \mathrm{m}^{2}$ increases rapidly upon ignition (around $80 \mathrm{~s}$ ) and plateaus at around 50 $\mathrm{kW} / \mathrm{m}^{2}$. The heat release rate remains relatively constant for the remaining experiment time. This suggests that the char layer formed on top of the polymer protects its inner layer from further degradation, and thus prevents the release of combustibles, which could cause the ignition.

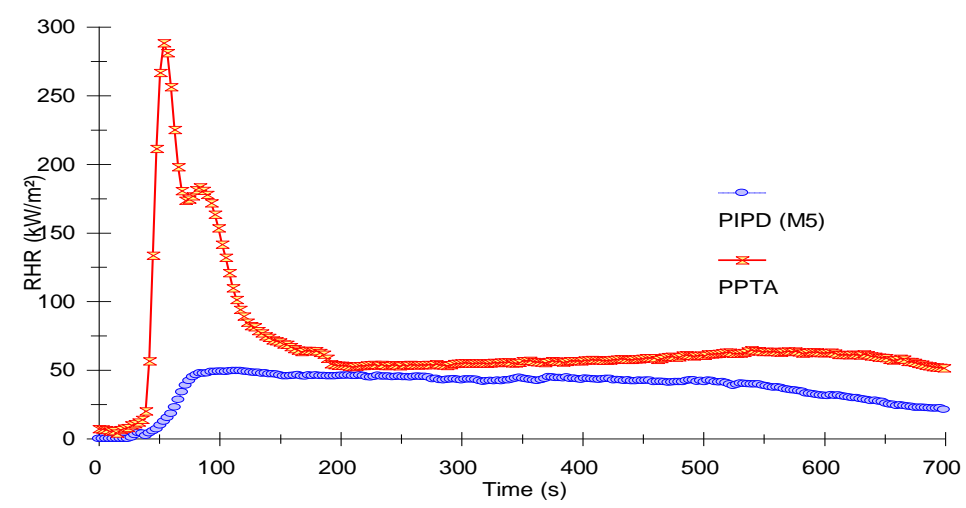

Figure 36. HRR curve of knitted PPTA and PIPD (M5) fibers with an external heat flux of $75 \mathrm{~kW} / \mathrm{m}^{2}$ [126].

Pictures of the polymers were taken during the test to evidence the the low flammability of PIPD. It can be observed that under $75 \mathrm{~kW} / \mathrm{m}^{2}$, there is hardly any visible flame on the PIPD sample.

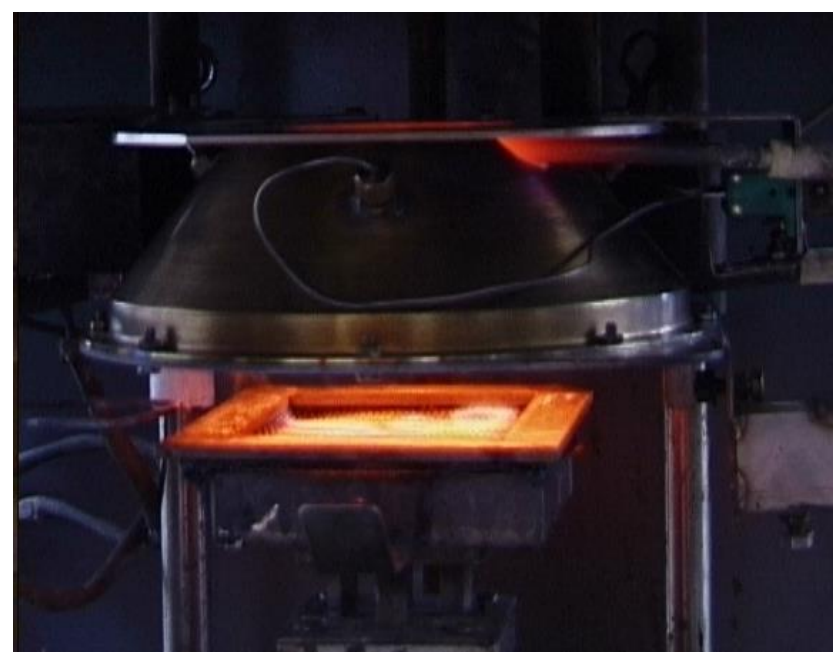

Figure 37. Fire behavior of $M_{5}$ when subjected to $75 \mathrm{~kW} / \mathrm{m}^{2}[126]$

The fire growth index (FIGRA) curve of PIPD shows a only one peak at $80 \mathrm{~s}$ (near the ignition time) and corresponds to FIGRA $=50 \mathrm{OW} / \mathrm{s}$. This confirms the low contribution to fire of PIPD [126].

The VSP curve of PIPD under the cone calorimeter conditions shows that there is a negligible amount of smoke produced when PIPD is subjected to $75 \mathrm{~kW} / \mathrm{m}^{2}$ [126].

\section{Concluding remarks}

The structure of PIPD gives it the ability to form hydrogen bonds between adjacent chains. This gives it extremely high fire resistance, not unlike other rigid rod polymeric fibers.

PIPD has extremely high thermal stability in nitrogen. Indeed, there is more than $50 \%$ of the weight is retained at $1200{ }^{\circ} \mathrm{C}$. This is exceptional for a wholly polymeric unfilled fiber. However, 
it is very sensitive to oxygen. This is evidenced by the TGA where we can see that the decomposition is abrupt and almost complete.

The DSC curve confirms the strong influence of oxygen in the decomposition process of PIPD. Indeed, a wide and high exothermic peak is observed, suggesting that the thermo-oxidative degradation of PIPD is favored under such conditions.

However, under external heat flux of $75 \mathrm{~kW} / \mathrm{m}^{2}$, a relatively low peak of heat release rate is observed $\left(44 \mathrm{~kW} / \mathrm{m}^{2}\right.$ as compared to around $400 \mathrm{~kW} / \mathrm{m}^{2}$ for Kevlar $\left.{ }^{\circledR}\right)$. This may be because PIPD forms a protective char layer at the surface of the fiber during the cone calorimeter test. This could account for the low pHRR reported.

Moreover, the fire behavior of PIPD is reminiscent of that of PBO. Indeed, PIPD exhibits a pHRR at $75 \mathrm{~kW} / \mathrm{m}^{2}$ of around $50 \mathrm{~kW} / \mathrm{m}^{2}$ and PBO has a pHRR of about $150 \mathrm{~kW} / \mathrm{m}^{2}$ at when exposed to the same heat flux. Despite the latter being higher than that of PIPD, it is a very low value as compared to other supposedly inherently fire retardant polymers such as $\mathrm{p}$-aramid ( $\mathrm{pHRR}=400$ $\mathrm{kW} / \mathrm{m}^{2}$ when exposed to $75 \mathrm{~kW} / \mathrm{m}^{2}$ ). We observe that rigid rod heterocyclic polymeric structures with strong interchain interactions may have a positive impact on the fire behavior of the material.

This interesting fire property is further evidenced with the low fire growth index of PIPD also contributes to making it an excellent fire retardant with outstanding mechanical properties. 


\section{Aramids}

Aromatic polyamides (aramids) form part of one of the first classes of high performance polymers. They present outstanding potential in terms of mechanical properties, thermal and electrical insulation. The first commercially introduced aramid was a meta-aramid fiber produced Dupont under the trade name Nomex ${ }^{\circledR}$ in the 1960 . A para-aramid, with much higher tenacity and modulus fiber was developed and commercialized by the same company under the trade name Kevlar ${ }^{\circledast}$ in 1971 (Figure 38). Twaron is another para-aramid that appeared on the market in the early 1980 s. It is similar to $\operatorname{Kevlar}^{\circledR}$ and shares some properties.<smiles>CNc1ccc(NC(=O)c2ccc(C(=O)CO)cc2)cc1</smiles>

Figure 38. Structure of Kevlar

Since this paper deals with high performance polymers, Kevlar and Twaron will be those primarily discussed in this section.

\section{Synthesis}

Para-aramid, formally poly( $p$-phenylenediamine-terephtalamide) (PPTA) was first developed by Stephanie Kwolek from DuPont.

The specific conditions for this synthesis have been reported by Kwolek[128] and Blades[129]

There are two major routes towards the preparation of aromatic polyamides:

Polycondensation using an aromatic dichloride and a corresponding diamine;

Direct polycondensation via a dicarboxylic acid and a diamine.

The first route is performed by the condensation 1,4-phenylenediamine (PPD) and terephtaloyl chloride (TCl) (Scheme 20) using N-methyl-2-pyrrolidone as solvent. The process is carried out at low temperatures.

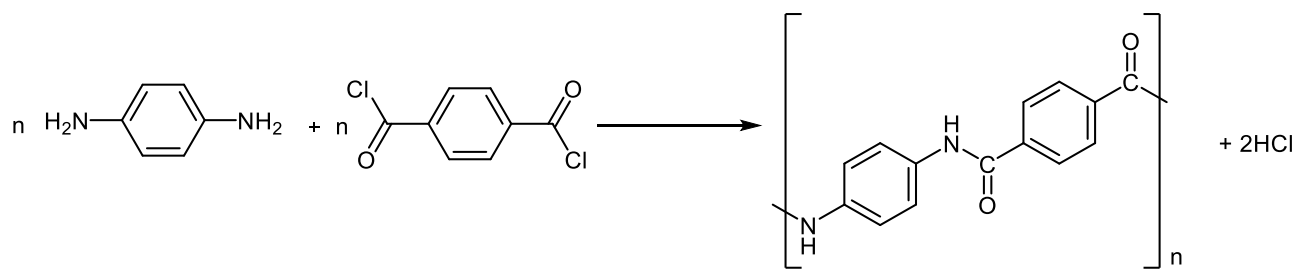

Scheme 20. PPTA synthesized via low condensation polymerization of PPD and TCl.

The direct polycondensation uses lower costs monomers. Indeed, $\mathrm{TCl}$ is costly and highly sensitive to air. However, the reaction between the diacid and the diamine does not proceed readily. A catalyst such as triphenyl phosphate is required for the reaction to occur readily. The reaction needs to be carried out at high temperatures in order to achieve high molecular weight yields. 


\section{Thermal Stability}

$\mathrm{P}$-aramid is one of the first polymers to display the combination of high temperature resistance and high mechanical properties in the same material. This is partly due to its highly ordered structure. Different classes of Kevlar ${ }^{\otimes}$ exist on the market, mostly commercialized by Dupont. However, the thermal properties of the different classes are relatively similar[104].

$\mathrm{P}$-aramid has a relatively high structural chain rigidity and a second order transition temperature of about $340{ }^{\circ} \mathrm{C}$ and a melting point of about $560{ }^{\circ} \mathrm{C}$ [129]. It is reported that p-aramid resist temperatures of up to $450^{\circ} \mathrm{C}$ for a few minutes and $250^{\circ} \mathrm{C}$ for at least 1 month.

Thermogravimetric analysis performed on p-aramid at a heating rate of $2{ }^{\circ} \mathrm{C} / \mathrm{min}$ under nitrogen led to the conclusion that there is a significant weight loss as from $460^{\circ} \mathrm{C}$. About $40 \mathrm{wt} \%$ of the material is lost from $480^{\circ} \mathrm{C}$ to $560^{\circ} \mathrm{C}$. There seems to be further slower degradation from $560^{\circ} \mathrm{C}$ onwards.

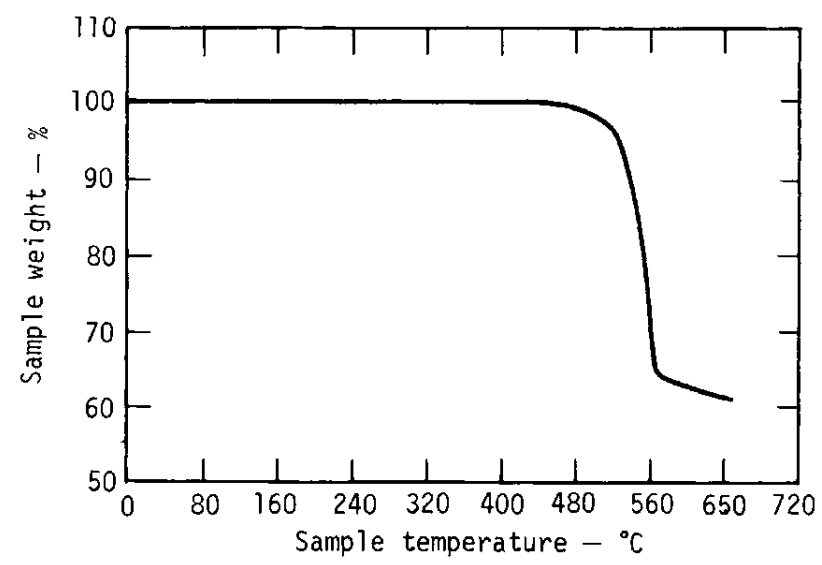

Figure 39. Thermogravimetric analysis of dry p-aramid at a heating rate of $2{ }^{\circ} \mathrm{C} /$ min under nitrogen[130]

TGA of p-aramid was also performed at $10^{\circ} \mathrm{C} / \mathrm{min}$ under nitrogen and in air (Figure 40)[131]. As expected, the onset of the thermal degradation is higher when the heating rate is higher.

The onset of the degradation under nitrogen was $562{ }^{\circ} \mathrm{C}$ and the maximum derivative weight loss occurred at $577^{\circ} \mathrm{C}$. $43 \%$ of residue remained at $700{ }^{\circ} \mathrm{C}$. According to the heat flow, which was measured simultaneously with the mass loss, the decomposition temperature of $\mathrm{p}$-aramid at the aforementioned conditions was $579{ }^{\circ} \mathrm{C}$.
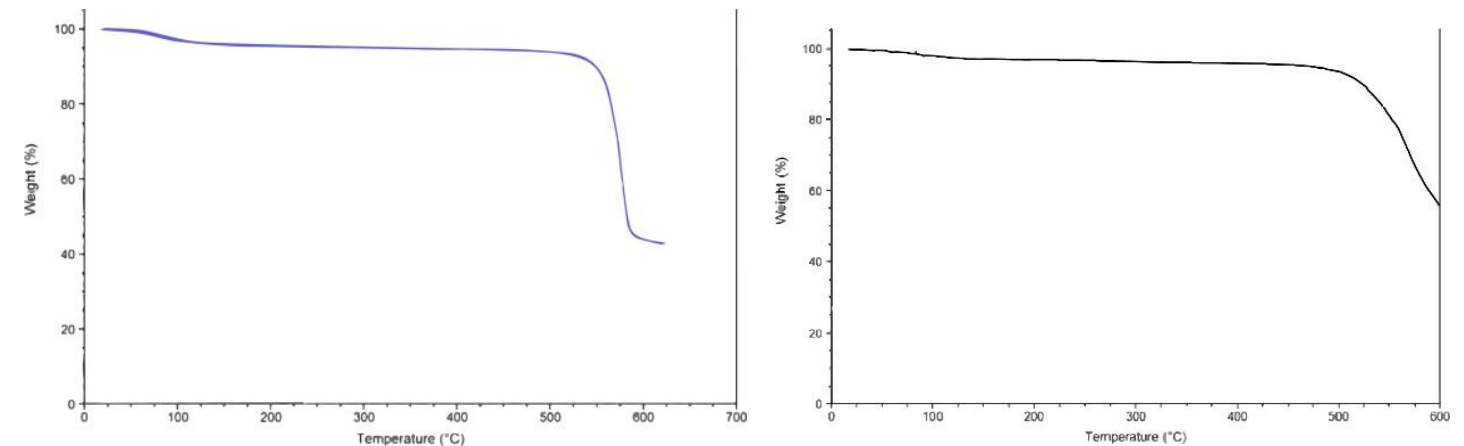

Figure 40. TGA plot of $\mathrm{p}$-aramid at a heating rate of $10^{\circ} \mathrm{C} / \mathrm{min}$ under nitrogen (left) [130] and in air (right) [132]

In air, at a heating rate of $10{ }^{\circ} \mathrm{C} / \mathrm{min}$, the onset of the decomposition occurred at $526{ }^{\circ} \mathrm{C}$ and the maximum derivative weight loss occurred at $569{ }^{\circ} \mathrm{C}$. At $600{ }^{\circ} \mathrm{C}, 56 \%$ of the initial weight of paramid was still present [130,133-135] 
The thermal degradation of p-aramid has also been studied by high-resolution thermal gravimetric techniques[136], Py-GC/MS [76].

The single-step, rapid thermal degradation of $p$-aramid was confirmed by high resolution TG. A slow weight loss was observed at around $300{ }^{\circ} \mathrm{C}$ under nitrogen but not in air. This was assigned to concurrent oxidation[134].

This technique was also used to determine the kinetic parameters of the thermal degradation of p-aramid[134]. Different other methods were also used to calculate the different kinetic parameters. Using these results, the average activation energy for the degradation of p-aramid in nitrogen atmosphere was reported to be $133 \mathrm{~kJ} / \mathrm{mol}$ and a pre-exponential factor of $\left(4.810^{8}\right)$ $\mathrm{min}^{-1}$. In air, the activation energy was determined to be $154 \mathrm{~kJ} / \mathrm{mol}$ and the pre-exponential factor $\left(8.610^{6}\right) \mathrm{min}^{-1}$. The order of the degradation reaction was found to be 0.7 in air and 1.1 in nitrogen. The degradation process in this reported study was for a temperature range $\left(470{ }^{\circ} \mathrm{C}-\right.$ $\left.540^{\circ} \mathrm{C}\right)[132]$.

The invariant kinetic parameter (IKP) method has also been applied on p-aramid[111]. The invariant method found an invariant activation energy of $378 \mathrm{~kJ} / \mathrm{mol}$ and an invariant preexponential factor of $\left(8.210^{19}\right) \mathrm{s}^{-1}$ in nitrogen and $103 \mathrm{~kJ} / \mathrm{mol}$ and $3232 \mathrm{~s}^{-1}$ in air. The degradation process in this study ranged from $500-650^{\circ} \mathrm{C}[111]$.

Pyrolysis-gas-chromatography-mass-spectrometry was performed on p-aramid at $600{ }^{\circ} \mathrm{C}$ in order to identify its different decomposition products. Evolved gas analysis at a heating rate of $20^{\circ} \mathrm{C} / \mathrm{min}$ was also reported. The pyrogram (at $20^{\circ} \mathrm{C} / \mathrm{min}$ heating rate) of p-aramid shows that most of the degradation products are released from $550^{\circ} \mathrm{C}-650^{\circ} \mathrm{C}[76]$.

The identified products of the pyrolytic decomposition of p-aramid are reported in Table 20.

Table 20. Major products identified by $P y$-GC/MS on p-aramid at $600{ }^{\circ} \mathrm{C}$ in inert atmosphere $[76,137]$

aniline +
cyanobenzene

Electron paramagnetic resonance (EPR) analysis on p-aramid 49[138] coupled with PyGC/MS[139] led to a tentative degradation pathway accounting for the formation of radicals in the polymer. The initial process is suggested to be homolytic scission of aromatic $\mathrm{NH}$ and amide $\mathrm{NH}-\mathrm{CO}$ linkages. This could be followed by a cyclization reaction initiated by the previous 
scission. Phenoxyl radical produced may lead to extensively delocalized and polycyclic free radical systems[134,140] (Scheme 21).

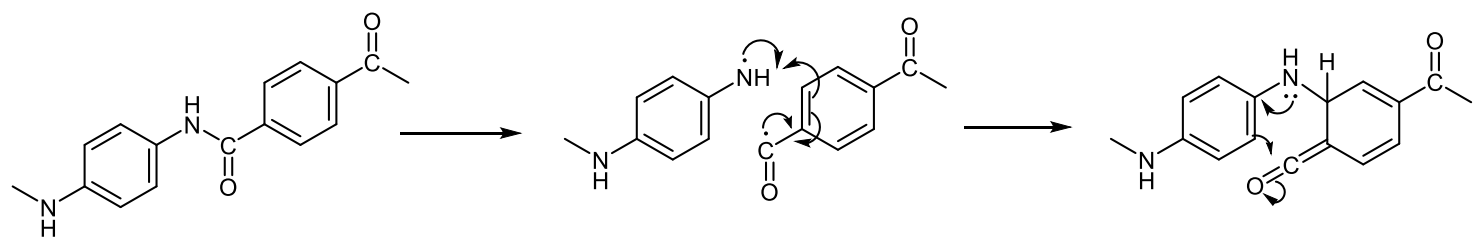<smiles>CCNc1ccc2nc3cc(C(C)=O)ccc3c(=O)c-2cc1NC[I-]C</smiles>

Scheme 21. Tentative thermal degradation pathway for the thermal decomposition of p-aramid 49[134]

Moreover, studies on the thermal degradation mechanism of $\mathrm{p}$-aramid led to some pioneering conclusions. It was reported that the scission of $\mathrm{NH}$ in the thermal degradation of $\mathrm{p}$-aramid is both thermodynamically and kinetically favorable[140]. An early report on the thermal degradation of different kinds of aromatic polyamides led to the conclusion that it occurred via the hydrolysis of amide bonds whereby water was generated with acid end groups and generated during the dehydration of other groups[141]. Another study suggested the possibility of bond cleavages and free radical intermediates as being the major degradation reaction. It was concluded that the main route was that of the cleavage of aromatic $\mathrm{C}-\mathrm{CO}$ of the amide linkages, which led to the formation of carbodiimide bonds[142]. Temperature dependent mechanisms involving iminol tautomerization, condensation of iminols, hydrolysis and decarboxylation was also reported[143].

A paper concerning the formation of nitrogen oxides during the thermal decomposition of $\mathrm{p}$ aramid was also reported[111,138].

Moreover, the study on the degradation of a model monomer unit led to useful insights regarding the decomposition pathway of p-aramid. It is suggested that the degradation occurs via two competing mechanism: Homolysis and hydrolysis. Indeed, there is always some water remaining in the polymer during its formation and this could initiate a hydrolysis reaction in the polymer.

\section{Fire behavior}

The fire performances of p-aramid were studied using different testing methods. One of the most widespread methods concerning the flammability rating of a polymer is the limiting oxygen index (LOI). The LOI of p-aramid is between 28 and 30 vol\% [144], which may seem to be low for an inherently fire retardant polymeric system. However, $\mathrm{p}$-aramid also has a high char yield when it degrades under inert atmosphere, as it is revealed by the TGA plots under nitrogen. It also has a high degradation temperature, which makes gives it an enhanced resistance to high heat $[130,145]$.

Pyrolysis combustion flow calorimetry (PCFC) was also performed on p-aramid. This was performed at a heating rate of $4.3^{\circ} \mathrm{C} / \mathrm{s}$ up to a temperature of $930{ }^{\circ} \mathrm{C}$. The heat release capacity of p-aramid was found to be $292 \mathrm{~J} / \mathrm{g}-\mathrm{K}$ and the total heat released was reported to be $15 \mathrm{~kJ} / \mathrm{g}$. It is generally accepted that in order to be considered flame resistant, a material should have a heat release capacity less than $100 \mathrm{~kJ} / \mathrm{g}-\mathrm{K}[11]$. These results suggest that $p$-aramid is not inherently flame retardant. 
P-aramid was also subjected to cone calorimeter tests under different incident heat flux (50 $\mathrm{kW} / \mathrm{m}^{2}$ and $75 \mathrm{~kW} / \mathrm{m}^{2}$ ) [91].

At $75 \mathrm{~kW} / \mathrm{m}^{2}$, the time to ignition (TTI) of p-aramid is $26 \mathrm{~s}$ and peak heat release rate of around $400 \mathrm{~kW} / \mathrm{m}^{2}$, occurring at $55 \mathrm{~s}$. It burns with a relatively high flame (Figure 41) and leaves little char residue[146].

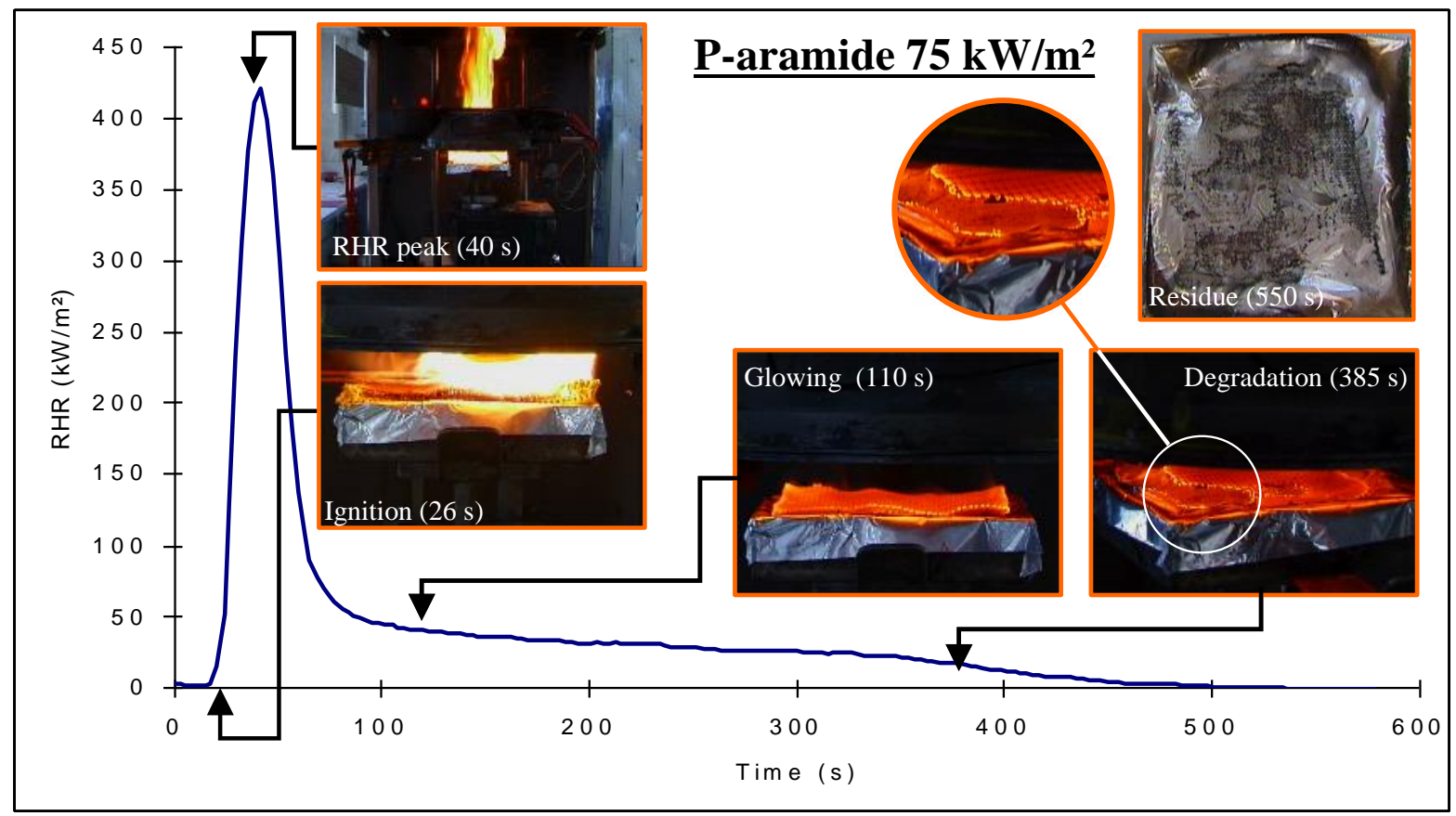

Figure 41. Burning behavior of p-aramid when subjected to $75 \mathrm{~kW} / \mathrm{m}^{2}$ heat incident heat flux [91]

$P$-aramid has a similar total heat release curve to $\mathrm{PBO}$ when submitted to $50 \mathrm{~kW} / \mathrm{m}^{2}$. It has a maximum fire index of growth rate of around $60 \mathrm{~W} / \mathrm{s}$ under $50 \mathrm{~kW} / \mathrm{m}^{2}$ and $110 \mathrm{~W} / \mathrm{s}$ under 75 $\mathrm{kW} / \mathrm{m}^{2}[91]$.

In terms of smoke obscuration, $p$-aramid evolves smoke with a peak at $0.012 \mathrm{~m}^{3} / \mathrm{s}$ [91]. This is much higher than PBO, which has a peak smoke obscuration at less than $0.001 \mathrm{~m}^{3 /} \mathrm{s}$.

\section{Concluding remarks}

$\mathrm{P}$-aramid is one of the first high performance polymers that was commercially available. It has a relatively high thermal stability both in air and under inert atmosphere. This high thermal stability may be attributed to its rigid like structure, as it is the case for PBO and PIPD. Interchain hydrogen bonds, made possible thanks to the para orientation of the monomers, enhance the stiffness of the polymer.

P-aramid is stable until $400{ }^{\circ} \mathrm{C}$ but at temperatures over $450{ }^{\circ} \mathrm{C}$, there is a drastic weight loss, meaning that the polymer completely degrades. Indeed, the thermo-oxidative degradation of $\mathrm{p}$ aramid is similar to that of PIPD.

However, when subjected to external heat flux, p-aramid does not melt under the flame. However, a glowing phenomenon is observed. This means that it can more or less retain some of its properties. Its relatively high LOI ( $28 \%)$ makes it a good candidate as a flame retardant material. When compared to PIPD ( $\mathrm{LOI}=50 \%$ ), p-aramid does not seem to be as good a fire retardant. However, additives can be used to increase the flame retardant capabilities of $\mathrm{p}$ aramid [147,148]. 


\section{Discussion}

The high performance polymeric materials have all proved to stand up to their criteria as defined in the introduction. They exhibit a very high thermal stability (decomposition temperature > $450^{\circ} \mathrm{C}$ ) and a good flame retardancy (high LOI, low HRR and relatively low smoke obscuration) as compared with usual engineering polymers (such as nylon or polyesters).

It was observed that a high aromatic content in the backbone of a polymeric material has a positive impact on its thermal stability and fire behavior. Moreover, a highly ordered polymeric backbone can also contribute to having these properties.

Among fully amorphous polymeric materials, PEI has great thermal stability and fire resistance. This may be partly explained by its highly aromatic backbone. Moreover, when looking at its decomposition behavior under nitrogen, it is observed that it leaves a high weight residue. This suggests that the polymer is somewhat heat resistant and does not readily degrade. This behavior is characteristic of fire retardant materials. The highly charring nature of PEI also plays a role in its fire retardant property. Charring creates a carbonaceous layer that may protect the bulk of the material when it is exposed to a heat. This is evidenced by a relatively low HRR measured by cone calorimetry. However, despite a low HRR, the presence of a flame is also recorded. This means that some combustibles are released when the polymer decomposes and there is sufficient heat released to sustain a fire. This can be explained by the decomposition mechanism of PEI. It suggests that the random scission of the polymer backbone may lead to volatile, combustible products. These products, which were identified by Py-GC/MS undergo thermooxidation in the presence of oxygen. Therefore, in a fire scenario, these decomposition products of PEI will feed an eventual flame.

Among amorphous polymers, PAI has also proved to have high thermal stability. Despite decomposing at a temperature slightly lower than PEI (temperature at onset of decomposition for PAI $=450^{\circ} \mathrm{C}$ and for $\mathrm{PEI}=500{ }^{\circ} \mathrm{C}$ ), the rate of decomposition of PAI is lower than PEI when tested by TGA under inert atmosphere. Moreover, one of the major products of the thermal decomposition of PAI at $600{ }^{\circ} \mathrm{C}$ under inert atmosphere arises from a depolymerisation reaction. This may explain the high yield of char residue. This high char residue may also explain its low flammability (LOI of 45 vol\%). However, there is still work to be done in order to obtain more information concerning the thermal decomposition and fire behavior of PAI. Indeed, in order to understand fully the fire behavior, a more complete thermal decomposition behavior is required. Therefore, a mechanism of the decomposition needs to be established. This would provide a better insight on the combustibles that are susceptible to form during a fire scenario. A proper understanding of the thermal decomposition behavior may also explain the high charring, thus the high fire properties of PAI.

PEEK, being a semi crystalline polymer, behaves somewhat differently as compared to wholly amorphous polymers. When it comes to thermal behavior under nitrogen, PEEK has shown outstanding stability, with an onset of degradation at around $575^{\circ} \mathrm{C}$. This is exceptional even for a wholly aromatic polymer. Indeed, other aromatic polymers such as aromatic polyamides usually decompose at temperatures around $450{ }^{\circ} \mathrm{C}$ (as is it the case for Kevlar). Moreover, the residue yield at high temperatures is above $45 \%$ at $900{ }^{\circ} \mathrm{C}$. This high a residue suggests that during the thermal degradation of the material, only a small fraction of the material releases combustibles. In addition, the studies of the thermal degradation mechanism of PEEK, the high 
char residue seems to be due to crosslinking reactions that take place at high temperature. This crosslinking may also explain the high flame retardancy of PEEK. Indeed, as with PEI, a highly charred material implies a lower release of fuel for a fire. This may occur due to the carbonization of a fraction of the polymer when it is subjected to thermal stress. Moreover, if charring occurs at the surface of the polymer, it can act as a barrier, preventing heat from reaching the bulk of the polymer, but also prevents fuel from reaching the flame. All these factors play some role to the inherent fire retardancy of PEEK. However, further decomposition and flame behavior studies need to be performed in order to understand fully the role of each individual factors that contribute to the fire retardant behavior of PEEK.

Another type of polymeric structure that has stood out among the high performance polymers are those with a heterocyclic backbone. It is explained by the inherent high stability of these polymers. Indeed, heterocyclic polymers such as PI, PBO and PIPD have highly ordered structures with strong interactions between polymer chains making them thermally stable.

Polymers with a heterocyclic polymer backbone have shown the best thermal stabilities and fire behavior. PI, PBI, PBO, and PIPD are among the best candidates in terms of flame retardancy. Indeed, when subjected to a cone calorimeter test, all these materials had an HRR that was below $60 \mathrm{~kW} / \mathrm{m}^{2}$ when irradiated with a heat flux of $50 \mathrm{~kW} / \mathrm{m}^{2}$. These are significantly low values considering the high incident heat flux on the material.

These high performances can be explained by their decomposition behavior. Indeed, when it comes to fire, it is the release of combustibles from the bulk of a material that contributes to a sustained fire.

For instance, PI analyses of the decomposition products have shown that a large fraction of the polymer contributes to char formation. However, the decomposition mechanism has revealed that there some small molecules are evolved when the material is under thermal stress. These small molecules are combustibles (such as phenol and aminophenol) that can contribute to the propagation of a fire. This explains that PI presents a flame when it is exposed to a high heat flux $\left(75 \mathrm{~kW} / \mathrm{m}^{2}\right)$. However, considering the high heat flux that was used, the heat release rate remains relatively low $\left(53 \mathrm{~kW} / \mathrm{m}^{2}\right)$.

PBI on the other hand is somewhat different from PI. The thermal behavior of PBI seems to be dependent on its thermal history. Indeed, PBI possesses a hygroscopic nature, meaning that it will take up water if left in a humid environment. This affects the thermal properties of PBI because depending on the amount of water present in the material, the first decomposition process that is observed is usually that of the elimination of water. This usually occurs over a range of temperatures, making it difficult to predict the decomposition behavior. However, a tentative decomposition mechanism has been reported. A ring opening reaction within the polymer backbone is suggested to occur. This means that the first reaction is a bond scission that does not directly lead to the breaking of the polymer chain, implying that there the release of combustibles does not occur readily when the material stars to degrade. It suggests that the bond scission occurring leads to the formation of a protective char. Nevertheless, methane and amines are also reported as decomposition products, which can fuel a flame upon burning. This means that in a fire scenario, its decomposition behavior may cause an increase in flame spread, thus endangering lives.

In the case of $\mathrm{PBO}$, the decomposition mechanism suggest that a large fraction of the material is converted to char. Moreover, the mechanism also suggests that the main reaction occurring during the thermal decomposition is a depolymerisation. This means that the decomposition products may remain as somewhat large molecules. These molecules contribute less to a fire as 
compared to small combustibles. Another possibility is that the result of depolymerisation contributes to charring of the polymer. The decreased released of combustibles and the high char residue in $\mathrm{PBO}$ may explain its low heat release rate when subjected to fire tests. Indeed, when PBO is subjected to fire calorimetry, there was no visible flame. The polymer degraded due to the high heat flux and a brittle charred structure remained. However, the thermal decomposition of PBO under thermo-oxidative conditions are not great. Indeed, despite still having a high temperature for the onset of the degradation, the decomposition is abrupt and complete. This means that under thermo-oxidative conditions, the totality of the polymer is oxidized.

Similarly, PIPD has a highly charring nature. TGA of PIPD also shows a high char residue when tested under nitrogen. Under thermo-oxidative atmospheres, the residual mass of PIPD at high temperature is significantly lower than under nitrogen. However, this does not seem to affect its high fire performance. Indeed, when exposed to a high heat flux of $75 \mathrm{~kW} / \mathrm{m}^{2}$, only a small peak of heat release rate is observed $\left(44 \mathrm{~kW} / \mathrm{m}^{2}\right)$. This could be explained by the formation of a protective carbonaceous layer that forms on the surface of the polymer. This protective layer prevents the bulk of the polymer from being exposed to the high temperature of the incident heat flux. It also limits the release of combustibles from the bulk to the flame by creating a physical barrier for mass transport from bulk to surface (where the flame lies). However, few studies deal with the thermal decomposition and decomposition mechanism of PIPD. Therefore, a proper understanding of how the thermal degradation products of PIPD may contribute or not to a flame is not achieved. It may be of interest to emphasize some effort on the comprehension of the decomposition behavior of PIPD both in thermo-oxidative and inert atmospheres in order to extract the structural and physico-chemical factors that contribute to the highly interesting thermal and fire properties of PIPD.

PIPD, PBO, and PBI fall in the category of rigid rod polymers. It evidences that such a structural property would imply excellent thermal stability. However, this is only partially true. P-aramid, also possesses a rigid rod structure. However, despite having relatively good thermal and fire behavior, the performances are not as good as the heterocyclic polymers mentioned before. This could be explained by the fact that the thermal decomposition of $\mathrm{p}$-aramid yields a smaller char fraction. Indeed, when examining the thermal decomposition products that are released during its thermal decomposition, many small aromatic compounds are identified. These may fuel an eventual flame in a fire scenario. This is further evidenced in the cone calorimeter test that was performed on p-aramid. High flames were observed ( $\mathrm{pHRR}$ of around $400 \mathrm{~kW} / \mathrm{m}^{2}$ ), suggesting that despite the apparently high char yield observed on TGA, the nature of the degradation products also play a significant role in fueling a flame. Another explanation might be that the char that forms with p-aramid is not dense enough to protect the underlying bulk of the material. This could be due to a lower amount of crosslinking occurring at high temperature, causing the heat to reach the bulk of the material and the degradation of the polymer. It might be of interest to study the density and the structure of the char to see if the amount of crosslinking. Finally, another possible explanation for the high heat release rate could be that the scission of the amide bonds occurs throughout the material, breaking the chains cleanly, thus leading to a higher proportion of small combustible molecules to feed the flame.

\section{Conclusion}

In this work, we have seen that there are many aspects of a polymeric material that may have a more or less significant role in the thermal stability and fire behavior of a polymeric material. However, it is clear that the two properties are somewhat correlated. Highly ordered structures in the polymeric structure of a material often leads to a high thermal stability and a high fire 
performance. This was observed in PEEK, PIPD, PI as well as PBO. However, it is important to note that this does not always suffice. This was observed with $\mathrm{p}$-aramid which, despite being highly ordered (to the point of behaving like a rigid rod polymer), the fire performances do not match what the thermal stability promises. Moreover, a high degree of aromaticity may cause and enhancement in the fire and thermal properties of a material. This was observed in most polymers that were reviewed in this paper. In terms of structural properties, it was observed that highly aromatic, heterocyclic polymers with high inter-chain interactions have highly desirable thermal and fire performances. We have also observed that the reaction to fire of a material can have a strong dependence on its thermal decomposition pattern. Indeed, polymers that release a high amount of combustibles often behave poorly in fire scenarios. On the other hand, polymers that favor a cross-linking reaction seems to behave positively in a fire scenario. However, this does not suffice, the structure and density of the char is important when it comes to a fire scenario. A fragile char would not bring much fire protection, as it can be seen with Kevlar. 


$\begin{array}{ll}\text { Glossary } & \\ \text { BMI } & \text { Bismaleimide } \\ \text { DPMS } & \text { Direct Pyrolysis Mass spectrometry } \\ \text { DSC } & \text { Differential Scanning Calorimetry } \\ \text { DTG } & \text { Derivative Thermogravimetric Analysis } \\ \text { EPR } & \text { Electron Paramagnetic Resonance } \\ \text { FIGRA } & \text { Fire Growth Rate } \\ \text { FTIR } & \text { Fourier Transform Infrared } \\ \text { HRR } & \text { Heat Release Rate } \\ \text { IKP } & \text { Invariant Kinetic Parameter } \\ \text { LOI } & \text { Limiting Oxygen Index } \\ \text { MCC } & \text { Microscale Combustion Calorimetry } \\ \text { MS } & \text { Mass Spectrometry } \\ \text { OFW } & \text { Ozawa Flynn Wall } \\ \text { PAEK } & \text { Polyaryletherketone } \\ \text { PAI } & \text { Polyamide imide } \\ \text { PBI } & \text { Polybenzimidazole } \\ \text { PBO } & \text { Polybenzoxazole } \\ \text { PCFC } & \text { Pyrolysis Combustion Flow Calorimetery } \\ \text { PEEK } & \text { Poly(ether etherketone) } \\ \text { PEI } & \text { Polyether imide } \\ \text { PEK } & \text { Polyetherketone } \\ \text { pHRR } & \text { Peak of Heat Release Rate } \\ \text { PIPD } & \text { Polypyridobisimidazole } \\ \text { PPSU } & \text { Poly (phenymene sulfone) } \\ \text { PPTA } & \text { Poly(p-phenylene terephthalate) } \\ \text { Py-GC/MS } & \text { Pyrolysis-Gas Chromatography/Mass Spectrometry } \\ \text { TGA } & \text { Thermogravimetric Analysis } \\ \text { THR } & \text { Total Heat Released } \\ \text { TONSET } & \text { Temperature at degradation onset } \\ \text { TTI } & \text { Time to Ignition } \\ \text { VSP } & \text { Volume of Smoke Produced } \\ & \end{array}$


[1] Mittal, V. High Performance Polymers: An Overview. High Perform. Polym. Eng. Plast. 2011, No. September, 1-20.

[2] Parker, D.; Bussink, J.; van de Grampel, H. T.; Wheatley, G. W.; Dorf, E.-U.; Ostlinning, E.; Reinking, K.; Schubert, F.; Jünger, O.; Wagener, R.; et al. Polymers, High-Temperature. In Ullmann's Encyclopedia of Industrial Chemistry; Wiley-VCH Verlag GmbH \& Co. KGaA: Weinheim, Germany, 2012.

[3] Elias, H.-G. Macromolecules, Volume 3: Physical Structures and Properties; 2008.

[4] Hergenrother, P. M. The Use, Design, Synthesis, and Properties of High Performance/High Temperature Polymers: An Overview. High Perform. Polym. 2003, 15 (1), 3-45.

[5] Sikkema, D. J. Design, Synthesis and Properties of a Novel Rigid Rod Polymer, PIPD or 'M5': High Modulus and Tenacity Fibres with Substantial Compressive Strength. Polymer (Guildf). 1998, 39 (24), 5981-5986.

[6] Ozawa, T. A New Method of Analyzing Thermogravimetric Data. Bull. Chem. Soc. Jpn. 1965, 38 (11), 1881-1886.

[7] Flynn, J. H.; Wall, L. A. A Quick, Direct Method for the Determination of Activation Energy from Thermogravimetric Data. J. Polym. Sci. Part B Polym. Lett. 1966, 4 (5), 323328.

[8] Friedman, H. L. Kinetics of Thermal Degradation of Char-Forming Plastics from Thermogravimetry . Application to a Phenolic Plastic. No. 6, 183-195.

[9] High Performance Polymers: Their Origin and Development; Seymour, R. B., Kirshenbaum, G. S., Eds.; Springer Netherlands: Dordrecht, 1987.

[10] Nelson, G. Fire and Polymers: An Overview. In Fire and Polymers II; 1995; Vol. 29, pp 126.

[11] Afshari, M.; Kotek, R.; Chen, P.; Hickory, O. High Performance Fibers - 1. High Perform. Polym. Eng. Plast. 2011, 269-340.

[12] Mittal, V. High Performance Polymers: An Overview. In High Performance Polymers and Engineering Plastics; John Wiley \& Sons, Inc.: Hoboken, NJ, USA, 2011; pp 1-20.

[13] Chung, T.; Chung, T. A Critical Review of Polybenzimidazoles A Critical Review of Polybenzimidazoles : Historical Development and Future R \& D. 2006, 1797.

[14] Bourbigot, S.; Flambard, X. Heat Resistance and Flammability of High Performance Fibres: A Review. Fire Mater. 2002, 26 (4-5), 155-168.

[15] Bloomfield, R.; Crossman, D.; Raeissi, A. Using Polyetherimide Thermoplastic for Forward Lighting Complex Reflectors. 2016, No. 724.

[16] Galluci, R. R. Thermoplastic Polyetherimides (PEI). In Engineering Plastics Handbook; Margoli, J., Ed.; 2006; pp 155-180.

[17] Foreman, J.; Lundgren, C.; Gill, P. Measurement of the Physical Properties of Engineering Thermoplastics Using Thermal Analysis. Tech. Pap. ... 1993.

[18] Tant, M. R.; McManus, H. L. N.; Rogers, M. E. High-Temperature Properties and Applications of Polymeric Materials - An Overview. ACS Symp. Ser. 1995, 603, 1-20.

[19] Kenny, J. M.; Torre, L. Degradation Kinetics of High-Performance Polymers and Their Composites; 1995; Vol. 9, pp 140-154. 
[20] Farong, H.; Xueqiu, W.; Shijin, L. The Thermal Stability of Polyetherimide. Polym. Degrad. Stab. 1987, 18 (3), 247-259.

[21] Halawani, N.; Augé, J. L.; Morel, H.; Gain, O.; Pruvost, S. Electrical, Thermal and Mechanical Properties of Poly-Etherimide Epoxy-Diamine Blend. Compos. Part B Eng. 2017, 110, 530-541.

[22] Lee, J.; Takekoshi, T.; Giannelis, E. P.; Giannelis, E. P. Fire Retardant Polyetherimide Nanocomposites. MRS Proc. 1996, 457 (1), 513.

[23] Lisa, G.; Hamciuc, C.; Hamciuc, E.; Tudorachi, N. Journal of Analytical and Applied Pyrolysis Thermal and Thermo-Oxidative Stability and Probable Degradation Mechanism of Some Polyetherimides. J. Anal. Appl. Pyrolysis 2016, 118, 144-154.

[24] Zaragoza, S.; Álvarez, A.; Álvarez, B.; Lõpez-Beceiro, J.; Naya, S.; Forcén, P.; Artiaga, R.; Zaragoza, S.; Alvarez, A.; Álvarez, A.; et al. Thermogravimetric Study of Thermal Degradation of Polyetherimide. J. Appl. Polym. Sci. 2015, 132 (31), 1-8.

[25] Zhu, H.; Jie, X.; Wang, L.; Kang, G.; Liu, D.; Cao, Y. Effect of MIL-53 on Phase Inversion and Gas Separation Performance of Mixed Matrix Hollow Fiber Membranes. RSC Adv. 2016, 6 (73), 69124-69134.

[26] Perng, L.-H. Thermal Decomposition Characteristics of Poly(Ether Imide) by TG/MS. Polym. Res. 2000, $7, n_{3}^{\circ}$ (3), 185-193.

[27] Batista, N. L.; Costa, M. L.; Iha, K.; Botelho, E. C. Thermal Degradation and Lifetime Estimation of Poly(Ether Imide)/Carbon Fiber Composites. J. Thermoplast. Compos. Mater. 2015, 28 (2), 265-274.

[28] Li, J.; Stoliarov, S. I. Measurement of Kinetics and Thermodynamics of the Thermal Degradation for Charring Polymers. Polym. Degrad. Stab. 2014, 106, 2-15.

[29] Perng, L. H. Thermal Degradation Mechanism of Poly(Ether Imide) by Stepwise PyGC/MS. J. Appl. Polym. Sci. 2001, 79 (7), 1151-1161.

[30] Carroccio, S.; Puglisi, C.; Montaudo, G.; Doria, V. A.; Chimiche, S.; Doria, V. A. Thermal Degradation Mechanisms of Polyetherimide Investigated by Direct Pyrolysis Mass Spectrometry. Am. Chem. Soc. Polym. Prepr. Div. Polym. Chem. 200o, 41 (1), 684-685.

[31] Khanna, Y. P.; Pearce, E. M. Aromatic Polyamides . 11 . Thermal Degradation of Some Aromatic Polyamides and Their Model Diamides. 1981, 19, 2817-2834.

[32] Żurakowska-Orszàgh, J.; Chreptowicz, T. Thermal Degradation of Polyimides-II. Eur. Polym. J. 1981, 17 (8), 877-88o.

[33] Hirsch, D. B.; Williams, J. H.; Harper, S. A.; Beeson, H.; Pedley, M. D. Oxygen Concentration Flammability Thresholds of Selected Aerospace Materials Considered for the Constellation Program; 2007.

[34] Bashford, D. Thermoplastics.

[35] Koo, J. H.; Venumbaka, S.; Cassidy, P. E.; Fitch, J. W.; Grand, A. F.; Bundick, J. Flammability Studies of Thermally Resistant Polymers Using Cone Calorimetry. Fire Mater. 2000, 24 (5), 209-218.

[36] Marks, B. M. Boron Trifluoride - Hydrogen Fluoride Catalyzed Sunthesis of Poly(Aromatic Ketone) and Poly(Aromatic Sulfone) Polymers, 1969.

[37] Rose, J. B.; Staniland, P. A. Thermoplastic Aromatic Poly(Ether Ketones) and Their Application as Electrical Insulants. Eur. Pat. Appl. Google Patents 1979, p 31 pp. 
[38] Bonner, W. H. Aromatic Polyketones and Preparation Thereof, 1962.

[39] Iwakura, Y.; Uno, K.; Takiguchi, T. Syntheses of Aromatic Polyketones and Aromatic Polyamide. J. Polym. Sci. Part A-1 Polym. Chem. 1968, 6 (12), 3345-3355.

[40] Attwood, T. E.; Dawson, P. C.; Freeman, J. L.; Hoy, L. R. J.; Rose, J. B.; Staniland, P. A. Synthesis and Properties of Polyaryletherketones. Polymer (Guildf). 1981, 22 (8), 1096-1103.

[41] Shukla, D.; Negi, Y. S.; Uppadhyaya, J. Sen; Kumar, V. Synthesis and Modification of Poly(Ether Ether Ketone) and Their Properties: A Review. Polym. Rev. 2012, 52 (2), 189228.

[42] Colquhoun, H. M.; Lewis, D. F. Synthesis of Aromatic Polyetherketoneswith Trifluoromethanesulphonic Acid. Polyhedron 1988, 29 (10), 1902-1908.

[43] Johnson, R. N.; Farnham, A. G.; Clendinning, R. A.; Hale, W. F.; Merriam, C. N. Poly (Aryl Ethers) by Nucleophilic Aromatic Substitution. I. Synthesis and Properties. J. Polym. Sci. Part A-1 Polym. Chem. 1967, 5 (9), 2375-2398.

[44] Ueda, M.; Ichikawa, F. Synthesis of Aromatic Poly(Ether Ketone)s by Nickel-Catalyzed Coupling Polymerization of Aromatic Dichlorides. Macromolecules 1990, 23 (4), 926-930.

[45] Mohanty, D. K.; Lowery, R. C.; Lyle, G. D.; McGrath, J. E. Ketimine Modifications as a Route to Novel Amorphous and Derived Semicrystalline Poly(Arylene Ether Keytone) Homo and Copolymers. In Int. SAMPE Symp; 1987; Vol. 32, pp 408-419.

[46] Roovers, J.; Cooney, J. D.; Toporowski, P. M. Synthesis and Characterization of Narrow Molecular Weight Distribution Fractions of Poly(Aryl Ether Ether Ketone). Macromolecules 1990, 23, 1611-1618.

[47] Chen, M.; Gibson, H. W. Large-Sized Macrocyclic Monomeric Precursors of Poly(Ether Ether Ketone): Synthesis and Polymerization. Macromolecules 1996, 29 (16), 5502-5504.

[48] Conceição, T. F.; Bertolino, J. R.; Barra, G. M. O.; Mireski, S. L.; Joussef, A. C.; Pires, A. T. N. Preparation and Characterization of Poly(Ether Ether Ketone) Derivatives. Artic. J. Braz. Chem. Soc 2008, 19 (1), 111-116.

[49] Kuo, M. C.; Tsai, C. M.; Huang, J. C.; Chen, M. PEEK Composites Reinforced by NanoSized $\mathrm{SiO}_{2}$ and $\mathrm{A}_{1} 2 \mathrm{O}_{3}^{\wedge}$ Os Particulates. Mater. Chem. Phys. 2005, 90 (1), 185-195.

[5o] Patel, P.; Hull, T. R.; McCabe, R. W.; Flath, D.; Grasmeder, J.; Percy, M. Mechanism of Thermal Decomposition of Poly(Ether Ether Ketone) (PEEK) from a Review of Decomposition Studies. Polym. Degrad. Stab. 2010, 95 (5), 709-718.

[51] Perng, L. .; Tsai, C. .; Ling, Y. . Mechanism and Kinetic Modelling of PEEK Pyrolysis by TG/MS. Polymer (Guildf). 1999, 40 (26), 7321-7329.

[52] Hay, J. N.; Kemmisht, D. J.; Kemmish, D. J. Thermal Decomposition of Poly(Aryl Ether Ketones). Polymer (Guildf). 1987, 28 (12), 2047-2051.

[53] Patel, P.; Hull, T. R.; Lyon, R. E.; Stoliarov, S. I.; Walters, R. N.; Crowley, S.; Safronava, N. Investigation of the Thermal Decomposition and Flammability of PEEK and Its Carbon and Glass-Fibre Composites. Polym. Degrad. Stab. 2011, 96 (1), 12-22.

[54] Patel, P.; Hull, T. R.; Mccabe, R. W.; Flath, D.; Grasmeder, J.; Percy, M. Mechanism of Thermal Decomposition of Poly ( Ether Ether Ketone ) ( PEEK ) from a Review of Decomposition Studies. Polym. Degrad. Stab. 2010, 95 (5), 709-718.

[55] Vasconcelos, G. da C.; Mazur, R. L.; Ribeiro, B.; Botelho, E. C.; Costa, M. L. Evaluation of Decomposition Kinetics of Poly (Ether-Ether-Ketone) by Thermogravimetric Analysis. 
Mater. Res. 2014, 17 (1), 227-235.

[56] Tsai, C. J.; Perng, L. H.; Ling, Y. C. A Study of Thermal Degradation of Poly ( Aryl-EtherEther-Ketone ) Using Stepwise Pyrolysis / Gas Chromatography / Mass Spectrometry. 1997, 11, 1987-1995.

[57] Lyon, R. E.; Walters, R. N. Pyrolysis Combustion Flow Calorimetry. J. Anal. Appl. Pyrolysis 2004, 71 (1), 27-46.

[58] Lyon, R. E.; Janssens, M. L. Polymer Flammability; 2015.

[59] F.J.MARTIN, C. P. F. and. Flammability of Polymers; 1965; Vol. 1.

[6o] Margolis, J. Engineering Plastics Handbook; McGraw-Hill Professional, 2005.

[61] Colon, I.; Maresca, L. M.; Kwiatkowski, G. T. U.S Patent 4,263,466, 1981.

[62] Colon, I.; Matzner, M.; Products, A. P.; Corporation, U. C.; Brook, B. Aromatic Biphenylene Polymers Synthesis via Nickel Coupling of Aryl Dichlorides. 1992, 224 (1 992), 199-224.

[63] Sheet, T. D. Radel ${ }^{\circledR}$ R-500o. 2016, 1-5.

[64] Youjie, Z.; Yi; X.; Yong, W. Thermal Degradation Kinetics of Polyphenylene Sulfone Resins Under Nitrogen and Oxygen Atmosphere.

[65] Srithong, S.; Jiraratananon, R.; Hansupalak, N. A Simple Postsulfonation of Poly(Arylene Ether Sulfone) Radel ${ }^{\circledR}$ R. J. Appl. Polym. Sci. 2011, 119 (2), 973-976.

[66] Ajinjeru, C.; Kishore, V.; Chen, X.; Lindahl, J.; Sudbury, Z.; Hassen, A. A.; Kunc, V.; Post, B.; Love, L.; Duty, C. The Influence of Rheology on Melt Processing Conditions of Amorphous Thermoplastics for Big Area Additive Manufacturing (BAAM). Solid Free. Fabr. 2016 2016, 754-761.

[67] Ellison, S. T.; Gies, A. P.; Hercules, D. M.; Morgan, S. L. Py-GC / MS and MALDI-TOF / TOF CID Study of Poly ( Phenyl Sulfone ) Fragmentation Reactions. 2oog, 5526-5533.

[68] Safronava, N.; Lyon, R. E.; Crowley, S.; Stoliarov, S. I. Effect of Moisture on Ignition Time of Polymers. Fire Technol. 2015, 51 (5), 1093-1112.

[69] Harper, C. A. Thermoplastics; McGraw Hill Professional, Access Engineering, 2000.

[7o] Ha, C.-S.; Mathews, A. S. Polyimides and High Performance Organic Polymers. Adv. Funct. Mater. 2011, 1-36.

[71] Anthony, K. J. Preparation of Aromatic Polyiminolactones. Google Patents 1966.

[72] Hondred, P. R.; Yoon, S.; Bowler, N.; Moukhina, E.; Kessler, M. R. Degradation Kinetics of Polyimide Film. High Perform. Polym. 2011, 23 (4), 335-342.

[73] Sroog, C. Polyimides. J. Polym. Sci. Macromol. Rev. 1976, 11 (1), 161-2o8.

[74] Ozawa, T.; Arii, T.; Kishi, A. Thermogravimetry and Evolved Gas Analysis of Polyimide. Thermochim. Acta 2000, 352 (353), 177-180.

[75] Lua, A. C.; Su, J. Isothermal and Non-Isothermal Pyrolysis Kinetics of Kapton?? Polyimide. Polym. Degrad. Stab. 2006, 91 (1), 144-153.

[76] Shin, T.; Hajima, O.; Chuichi, W.; Tsuge, S.; Ohtani, H.; Watanabe, C. Pyrograms and Thermograms of 163 High Polymers, and MS Data of the Major Pyrolyzates; 2011.

[77] Hatori, H.; Yamada, Y.; Shiraishi, M.; Yoshihara, M.; Kimura, T. The Mechanism of 
Polyimide Pyrolysis in the Early Stage. Carbon N. Y. 1996, 34 (2), 201-208.

[78] Li, L.; Guan, C.; Zhang, A.; Chen, D.; Qing, Z. Thermal Stabilities and the Thermal Degradation Kinetics of Polyimides. Polym. Degrad. Stab. 2004, 84 (3), 369-373.

[79] Zhang, X.; Yan, X.; Shi, M. The Flame Retardancy and Pyrolysis Mechanism of Polyimide Fibers Investigated by Cone Calorimeter and Pyrolysis-gas Chromatography-mass Spectrometry. J. Ind. Text. 2017, No. 28, 152808371773207.

[8o] Hshieh, F. Y.; Hirsch, D. B.; Beeson, H. D. Ignition and Combustion of Low-Density Polyimide Foam. Fire Mater. 2003, 27 (3), 119-130.

[81] Satheesh Chandran, M.; Reghunadhan Nair, C. P. Maleimide-Based Alder-Enes. In Handbook of Thermoset Plastics; Elsevier, 2014; pp 459-510.

[82] Zahir, A.-C.; Renner, A. Process for the Manufacture of Crosslinked Polymers Which Contain Imide Groups. US4100140A, 1998.

[83] Regnier, N.; Mortaigne, B. Thermal Behavior of Bismaleimide Resin. Polym. Adv. Technol. 1994, 5 (9), 513-520.

[84] Iredale, R. J.; Ward, C.; Hamerton, I. Modern Advances in Bismaleimide Resin Technology: A 21st Century Perspective on the Chemistry of Addition Polyimides. Prog. Polym. Sci. 2017, 69, 1-21.

[85] Meador, M. A. B.; Christopher Johnston, J.; Frimer, A. A.; Gilinsky-Sharon, P. On the Oxidative Degradation of Nadic End-Capped Polyimides. 3. Synthesis and Characterization of Model Compounds for End-Cap Degradation Products. Macromolecules 1999, 32 (17), 5532-5538.

[86] Ueda, M.; Aoyama, S.; Konno, M.; Imai, Y. A Facile Synthesis of Polyamides by a Direct Polycondensation with Thionyl Chloride. 1978, 2091, 2089-2091.

[87] Barikani, M.; Mehdipour-ataei, S. Aromatic / Cycloaliphatic Polyimides and PolyamideImide from Trans-1 , 4-Cyclohexane Diisocyanate : Polymer (Guildf). 1999, 1102-1107.

[88] Mallakpour, S.; Rafiemanzelat, F. Diisocyanate Route as a Convenient Method for the Preparation of Novel Optically Active Poly(Amide-Imide)s Based on N-TrimellitylimidoS-Valine. Eur. Polym. J. 2005, 41 (12), 2945-2955.

[89] Abbasi, H.; Antunes, M.; Velasco, J. I. Influence of Polyamide-Imide Concentration on the Cellular Structure and Thermo-Mechanical Properties of Polyetherimide/PolyamideImide Blend Foams. Eur. Polym. J. 2015, 69, 273-283.

[9o] Ma, X.; Lee, N. H.; Oh, H. J.; Hwang, J. S.; Kim, S. J. Preparation and Characterization of Silica/Polyamide-Imide Nanocomposite Thin Films. Nanoscale Res. Lett. 2010, 5 (11), 1846-1851.

[91] Bourbigot, S.; Flambard, X.; Duquesne, S. Thermal Degradation of Poly (pPhenylenebenzobisoxazole ) and Poly ( $\mathrm{p}$-Phenylenediamine Terephthalamide ) Fibres. Polym. Int. 2001, 50 (August 2000), 157-164.

[92] Hu, X.; Jenkins, S. E.; Min, B. G.; Polk, M. B.; Kumar, S. Rigid-Rod Polymers: Synthesis, Processing, Simulation, Structure, and Properties. Macromol. Mater. Eng. 2003, 288 (11), 823-843.

[93] Martin, D. C.; Thomas, E. L. Ultrastructure of Poly(p-Phenylenebenzobisoxazole) Fibers. Macromolecules 1991, 24 (9), 2450-2460.

[94] Wolfe, J. . Polybenzothiazoles and Polybenzoxazoles. Encyclopedia of Polymer Science and 
Engineering; John Wiley \& Sons, Inc., 1988; pp 601-635.

[95] Chae, H. G.; Kumar, S. Rigid-Rod Polymeric Fibers. 2005, No. July.

[96] Itoya, K.; Sawada, H.; Kakimoto, M.; Imai, Y. Facile Synthesis of Aromatic Polybenzoxazoles from Monomers Having O- Aminophenol and Nitrile Functions. 1999, 683-686.

[97] Chang, J.-H.; Park, K. M.; Lee, S.-M.; Oh, J. B. Two-Step Thermal Conversion from Poly(Amic Acid) to Polybenzoxazole via Polyimide: Their Thermal and Mechanical Properties. J. Polym. Sci. Part B Polym. Phys. 200o, 38 (19), 2537-2545.

[98] Calle, M.; Lozano, A. E.; Lee, Y. M. Formation of Thermally Rearranged (TR) Polybenzoxazoles: Effect of Synthesis Routes and Polymer Form. Eur. Polym. J. 2012, 48 (7), 1313-1322.

[99] Li, G. High-Performance Rigid-Rod Polymer Fibers. Struct. Prop. High-Performance Fibers 2016, 141-166.

[10o] Nielsen, C. A.; Pierini, P. Thermal and Thermo-Oxidative Degradation of PBO: Determination of Kinetics and Reaction Products. 1993, 11 (April), 156-171.

[101] Liu, X.; Yu, W. Degradation of PBO Fiber by Heat and Light. Res. J. Text. Appar. 20o6, 10 (1), 26-32.

[102] Tamargo-Martínez, K.; Villar-Rodil, S.; Paredes, J. I.; Montes-Morán, M. A.; MartínezAlonso, A.; Tascón, J. M. D. Thermal Decomposition of Poly(p-Phenylene Benzobisoxazole) Fibres: Monitoring the Chemical and Nanostructural Changes by Raman Spectroscopy and Scanning Probe Microscopy. Polym. Degrad. Stab. 2004, 86 (2), 263-268.

[103] Huang, Y. Thermal Stability of Poly(p-Phenylenebenzobisoxazole) Fibres Hong. 2008, 17 (11), 853-859.

[104] Liu, X.; Yu, W. Evaluating the Thermal Stability of High Performance Fibers by TGA. J. Appl. Polym. Sci. 2006, 99 (3), 937-944.

[105] Denny, L. R.; Goldfarb, I. J.; Soloski, E. J. Thermal Stability Of Rigid-Rod Polymers. 1989, 134, 395-406.

[106] Cai, G. M.; Yu, W. D.; Ming, G.; Wei, C.; Yu, D. Study on the Thermal Degradation of High Performance Fibers by TG/FTIR and Py-GC/MS. J. Therm. Anal. Calorim. 2011, 104 (2), 757-763.

[107] So, Y.; Froelicher, S. W.; Kaliszewski, B.; Decaire, R. Reactions at Elevated Temperatures. 1999, 6565-6569.

[108] So, Y.-H.; Froelicher, S. W.; Kaliszewski, B.; DeCaire, R. A Study of Poly(Benzo[1,2- $d$ :5,4$d$ ']Bisoxazole-2,6-Diyl-1,4-Phenylene) Reactions at Elevated Temperatures. Macromolecules 1999, 32 (20), 6565-6569.

[109] Bo, P. Thermal Degradation Process of PBO Fiber. J. East China Univ. y Sci. Technol. 2008.

[110] Kim, P. K.; Pierini, P.; Wessling, R. Thermal and Flammability Properties of Poly(pPhenylene- Benzobisoxazole). J. Fire Sci. 1993, 11 (4), 296-307.

[111] Bourbigot, S.; Flambard, X.; Poutch, F. Study of the Thermal Degradation of High Performance Fibres - Application to Polybenzazole and p -Aramid Fibres. 20o1, 74, 283290.

[112] Brinker, C. B.; I.M, R. Polybenzimidazoles. US 2895948 A, 1959. 
[113] Vogel, H.; Marvel, C. S. Polybenzimidazoles, New Thermally Stable Polymers. J. Polym. Sci. 1961, 50 (154), 511-539.

[114] Einhorn, I. N.; Chatfield, D. A.; Wendel, D. J. Thermochemistry of Polybenzimidazole Foams; 1976.

[115] Chung, T.-S. A Critical Review of Polybenzimidazoles. Polym. Rev. 1997, 37 (2), 277-301.

[116] Chatfield, D. A.; State, D.; Diego, S.; Einhorn, I. N. Stepwise Thermal Degradation of a Polybenzimidazole Foam. J. Polym. Sci. Polym. Chem. Ed. 1981, 19 (3), 601-618.

[117] Coffin, D. R.; Serad, G. A.; Hicks, H. L.; Montgomery, R. T. Properties and Applications of Celanese PBI-Polybenzimidazole Fiber. Text. Res. J. 1982, 52 (7), 466-472.

[118] Wrasidlo, W.; Levine, H. H. Polybenzimidazoles. I. Reaction Mechanism and Kinetics. 1964, 2 (September 1963), 4795-4808.

[119] Shulman, G. P.; Lochte, W. Thermal Degradation of Polymers. IV. Poly-2,2'-( m Phenylene)-5,5'-Bibenzimidazole. J. Macromol. Sci. Part A - Chem. 1967, 1 (3), 413-428.

[120] Musto, P.; Karasz, F. E.; MacKnight, W. J. Fourier Transform Infra-Red Spectroscopy on the Thermo-Oxidative Degradation of Polybenzimidazole and of a Polybenzimidazole/Polyetherimide Blend. Polymer (Guildf). 1993, 34 (14), 2934-2945.

[121] Guenthner, A.; Lamison, K. R.; Reams, J. T.; Vij, V.; Yandek, G. R.; Davis, M. C.; Wright, M. E.; Cambrea, L. R.; Mabry, J. M. HIGH-TEMPERATURE COMPOSITE RI : SINS : REWRITING THE RULES FOR. 2011, 22 (o704).

[122] N., B.; J.D., S. Thermal Decomposition of High-Temperature Resistant Polymers; 1970.

[123] HORROCKS, A. R.; EICHHORN, H.; SCHWAENKE, H.; Saville, N.; THOMAS, C. Thermally Resistant Fibres; Woodhead Publishing Ltd, 2001.

[124] Northolt, M. G. G.; Sikkema, D. J. J.; Zegers, H. C. C.; Klop, E. A. A. PIPD, a New HighModulus and High-Strength Polymer Fibre with Exceptional Fire Protection Properties. Fire Mater. 2002, 26 (4-5), 169-172.

[125] Huges, W. J.; Report, F.; Huges, W. J. Polymer Flammability. Natl. Tech. Inf. 2005, No. May, $\mathbf{1 - 8 2 .}$

[126] Bourbigot, S.; Flambard, X.; Ferreira, M.; Devaux, E.; Poutch, F.; G, L. De. Characterisation and Reaction to Fire of "M5" Rigid Rod Polymer Fibres. J. Mater. Sci. 2oo3, 38 (10), 21872194 .

[127] Zhang, T.; Jin, J. H.; Yang, S. L.; Li, G.; Jiang, J. M.; Tao, Z.; Junhong, J. I. N.; Shenglin, Y.; Guang, L. I.; Jianming, J. Preparation and Properties of Novel PIPD Fibers. Chinese Sci. Bull. 2010, 55 (36), 4203-4207.

[128] S, K. Wholly Aromatic Carbocyclic Polycarbonamide Fiber Having Orientation Angle of Less than about 45\{20. Google Patents June 25, 1974.

[129] Blades, H. High Strength Polyamide Fibers and Films. US Patent 3869 429. 3,869,429, March 4, 1975.

[130] Penn, L.; Larsen, F. Physicochemical Properties of Kevlar 49 Fiber. J. Appl. Polym. Sci. 1979, $23(1), 59^{-73}$.

[131] Yip, P. W. Analysis of Two Methods for Characterization of Flame Resistant Military Fabrics and Commercial Textile Fibers: Simultaneous DSC-TGA and Pyrolysis GCMS. 2014, No. April. 
[132] Perepelkin, K. E.; Andreeva, I. V.; Pakshver, E. A.; Morgoeva, I. Y. Thermal Characteristics of Para-Aramid Fibres. Fibre Chem. 2003, 35 (4), 265-269.

[133] Brown, J. R.; Ennis, B. C. Thermal Analysis of Nomex ${ }^{\circledR}$ and Kevlar ${ }^{\circledR}$ Fibers. Text. Res. J. 1977, $47(1), 62-66$.

[134] Li, X.-G.; Huang, M.-R. Thermal Degradation of Kevlar Fiber by High-Resolution Thermogravimetry. J. Appl. Polym. Sci. 1999, 71 (4), 565-571.

[135] Akato, K.; Bhat, G. High Performance Fibers from Aramid Polymers; Elsevier Ltd, 2016.

[136] Mosquera, M. E. G.; Jamond, M.; Martinez-Alonso, A.; Tascon, J. M. D. Thermal Transformations of Kevlar Aramid Fibers During Pyrolysis: Infrared and Thermal Analysis Studies. Chem. Mater. 1994, 6 (11), 1918-1924.

[137] Brown, J. R.; Power, A. J. Thermal Degradation of Aramids: Part I-Pyrolysis/Gas Chromatography/Mass Spectrometry of Poly(1,3-Phenylene Isophthalamide) and Poly(1,4-Phenylene Terephthalamide). Polym. Degrad. Stab. 1982, 4 (5), 379-392.

[138] Wang, X. W.; Hu, Z. M.; Liu, Z. F. Thermal Degradation of Meta- and Para-Aramid Fibers in Different Atmospheres. Int. Polym. Process. 2008, 23 (1), 81-87.

[139] Brown, J. R.; Hodgeman, D. K. C. An e.s.r. Study of the Thermal Degradation of Kevlar 49 Aramid. Polymer (Guildf). 1982, 23 (3), 365-368.

[140] Kalashnik, A. T.; Pakikarova, N. P.; Dovbii, Y. V.; Kozhina, G. V.; Kakmykova, V. D.; Papkov, S. P. Comparative Analysis of the Thermal Degradation of Poly-p-Bemzamide and Poly-p-Phenylene Terephthalamide. Polym. Sci. U.S.S.R. 1977, 19 (12), 3173-3181.

[141] Bhuiyan, A. L. Some Thermodynamic Aspects of the Thermal Degradation of Wholly Aromatic Polyamides. Eur. Polym. J. 1983, 19 (3), 195-198.

[142] Krasnov, Y. P.; Logunova, V. I.; Sokolov, L. B. Hydrolytic Processes of the Thermal Degradation of Isomeric Aromatic Polyamides. Polym. Sci. U.S.S.R. 1966, 8 (11), 2176-2183.

[143] Ehlers, G. F. L.; Fisch, K. R.; Powell, W. R. The Thermal Breakdown Mechanism of Polybenzoxazoles and Polybenzothiazoles. J. Polym. Sci. Polym. Symp. 1973, 43 (1), 55-75.

[144] Blyumenfel'd, A. B.; Puzeyev, A. I.; Kovarskaya, B. M.; Akutin, M. S. The Degradation of Methoxy-Substituted Aromatic Polyamide. Polym. Sci. U.S.S.R. 1973, 15 (10), 2651-2661.

[145] Hurley, M. J.; Gottuk, D.; Hall, J. R.; Harada, K.; Kuligowski, E.; Puchovsky, M.; Torero, J.; Watts, Jj. M.; Wieczorek, C. SFPE Handbook of Fire Protection Engineering, Fifth Edition; 2016.

[146] Bourbigot, S.; Flambard, X.; Poutch, F.; Duquesne, S. Cone Calorimeter Study of High Performance Fibres - Application to Polybenzazole and P-Aramid Fibres. 20o1, 74, 481486.

[147] Zhang, H. Fire-Safe Polymers and Polymer Composites. 2004, DOT/FAA/AR (September), 1-209.

[148] Vitruvius. Building Materials; 1999. 